\title{
THE CULTURE OF
}

\section{GPENHOUSE}

ORCYIDS

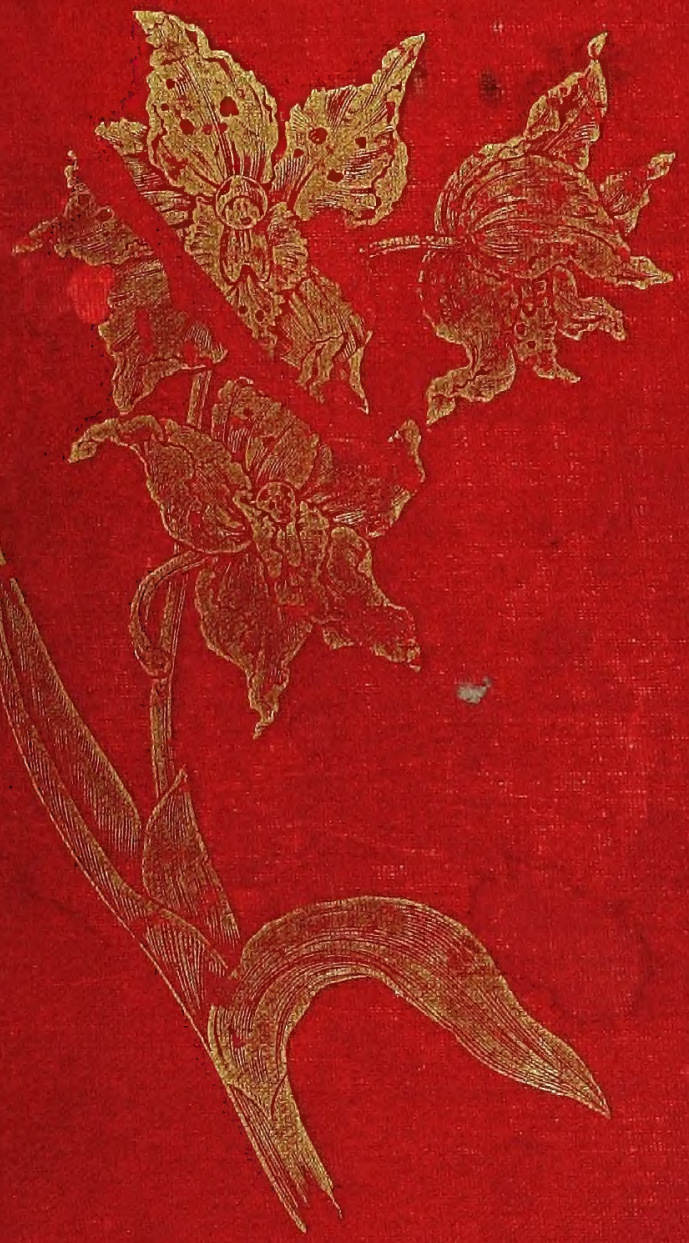




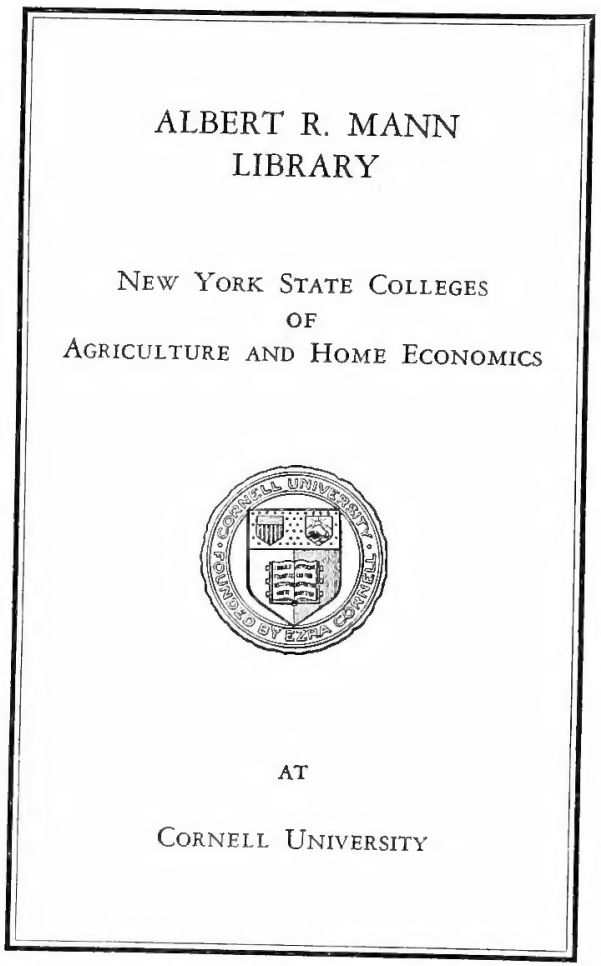




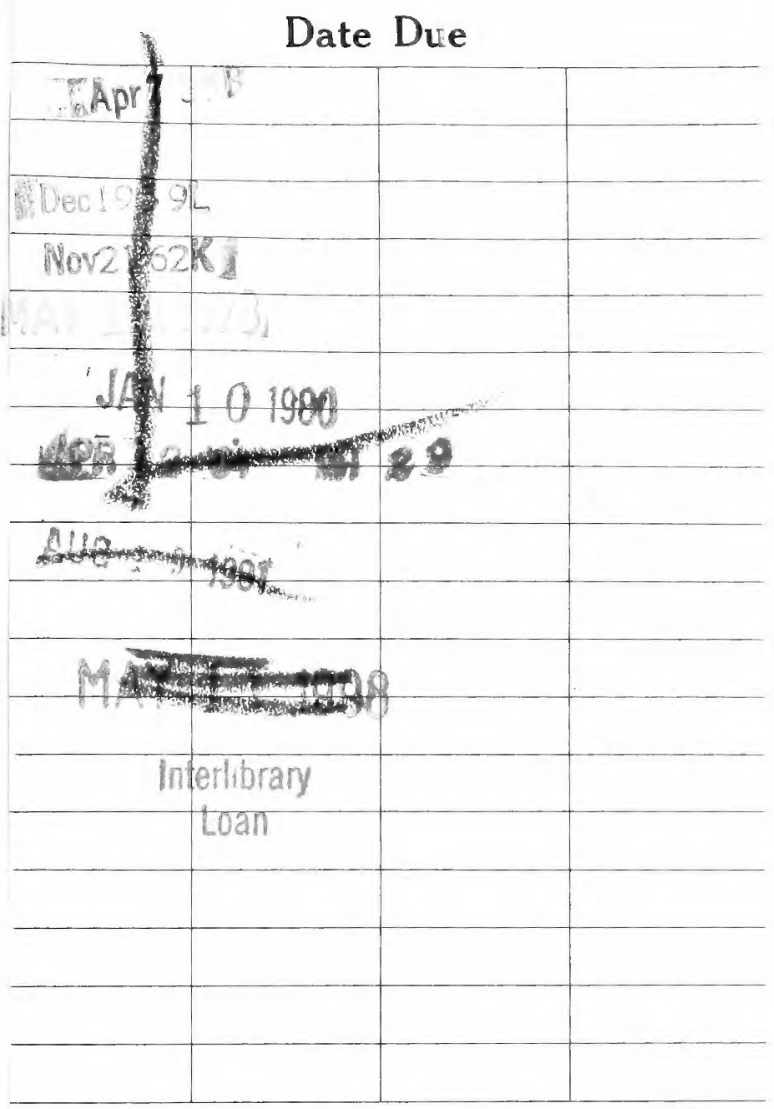

Library Bureau Cat. No. 1137

\section{Cornell University Library}

The culture of greenhouse orchids, old sy

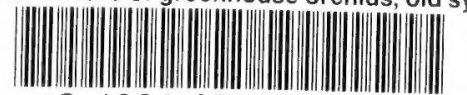

31924003417908 
L 




\section{THE CULTURE OF GREENHOUSE ORCHIDS}




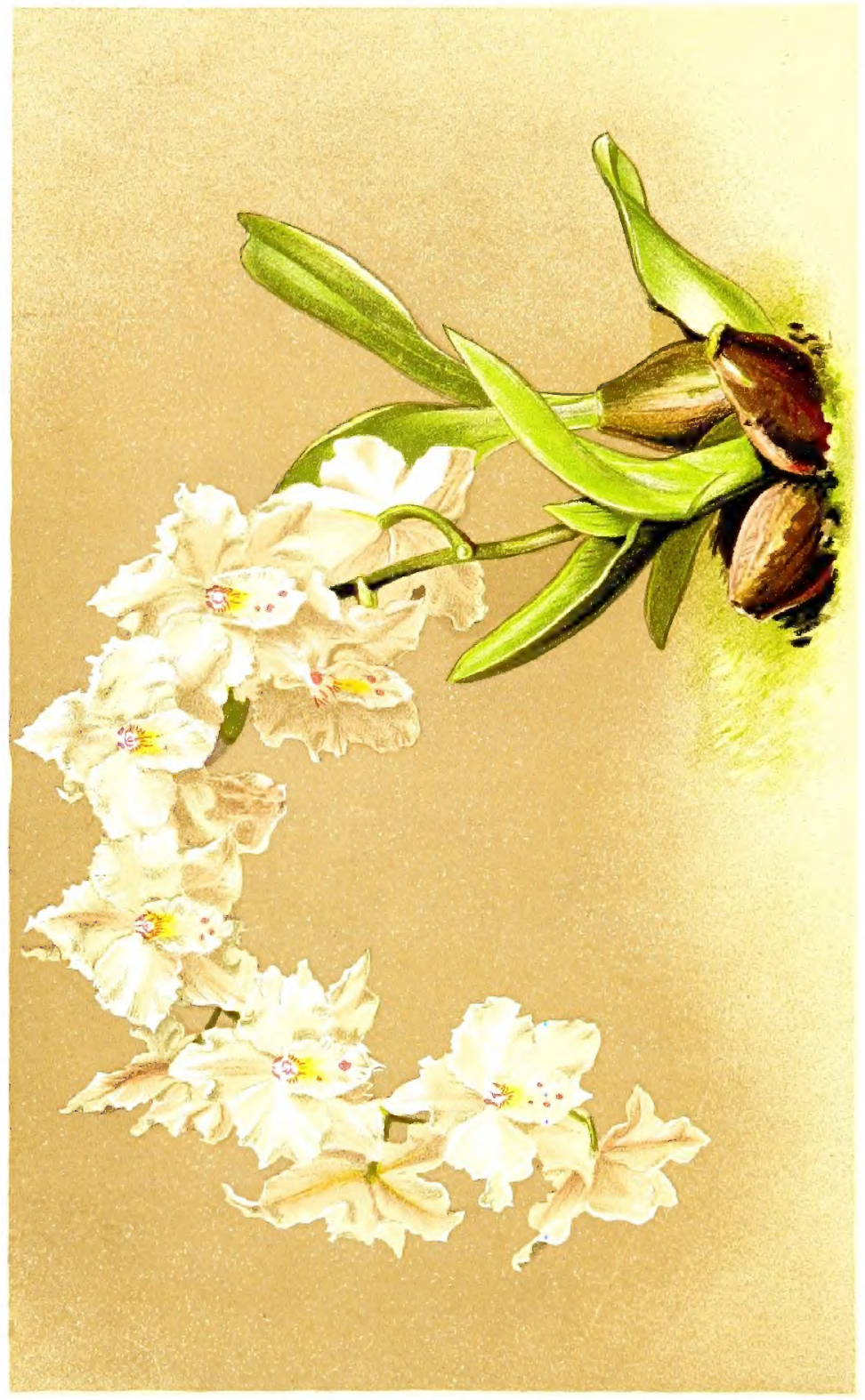




\section{-}





\title{
THE CULTURE OF ,
}

\section{GREENHOUSE ORCHIDS}

\author{
OLD SYSTEM AND NEW
}

I) Y

FREDERICK BOYLE

AUTHOR OF "ABOUT ORCHIDS-A CHAT," ETC.

SUPERVISED BY JOSEPH GODSEFF

WITH THREE PLATES IN COLOUR AND FIFTY ILLUSTRATIONS FROM PHOTOGRAPHS BY COL. F. C. TAILOR

LONDON: CHAPMAN \& HALL, LD, 1902 



\section{P R E F A C E}

The literature of orchidology is voluminous in these days. But the book written "by an amateur for amateurs" is still needed. I have at least the advantage of knowing what manner of work it should be, for I have suffered from the want of it. The various manuals current are not fitted, though designed, for the class I would address - that large number of persons whose gardener, competent in other branches of his profession, must "turn up the volume" for guidance in dealing with orchids, and, often eno oh, appeals to his master's judgment thereon. How many they are niy correspondence proves. Such persons demand plain words from the author, not general expressions; having no capacity to read between the lines, they must needs mark every gap where all is smooth for the trained orchid-grower. From that class I myself have struggled upwards until I, too, consult the expert without observing deficiencies. But I do not forget the time when wicked words arose as I turned from one authority to another, seeking in vain the 


\section{Preface}

simple fact, the clear downright statement "yea" or "nay," the bit of elementary instruction which ignorance requires. Remembering that era, I feel able to write such a book as would have cheered and belped me then. It is said that poets "learn in suffering what they teach in song." I venture to apply the aphorism.

This is no disparagem nt on the valuable works existing. What they lack may be expressed in one word-precision. General terms are used, and they suffice for the experienced. But the beginner knows not how to interpret them. He does too much or too little, and always he is irritated by uncertainty. Upon these points it is unnecessary to say more; the reader will judge.

But the issue of a new book on the Culture of Orchids may be tified on other grounds. For several years past the shrewd horticulteurs of Belgium have favoured a system utterly different to ours, even opposed in some respects to the principles which we are used to think essential. At the present time it is universally accepted in Belgium, and generally throughout the Continent; but in England few orehid-growers could be found who have given it a trial-the great majority, perhaps, have not yet heard of it. And they laugh, not altogether without reason, if told of practices by the foreigner which defy all their established rules; but they would cease to laugh at sight of vi 


\section{Preface}

a Belgian collection grown on the new system. It may be all wrong in theory, but in practice somehow it works wonders.

Evidently, it is desirable that English amateurs should be acquainted with every detail of a discovery so important, which, among other advantages claimed, certainly m-as a perceptible reduction in the expense anci' ne ouble of culture. 'They may adopt it or no. It would be a grave responsibility to recommend such a drastic change. Circumstances vary. There are excellent gardeners who, having worked all their lives on the orthodox methods with credit, would not willingly give the new a fair trial. And, in truth, the orthodox methods have served us well for more than half a century. Therefore I shall say only this: the Belgians raise finer plants than we, and, on $\mathrm{n}$ average, finer flowers. After opposing the herwoy with scorn for years, Mr. Grodseff is now enthusiastic in its facour; and it is adopted at St. Albaus.

I deal with cool orchids alone in this volumethe class most interesting to the public. Even thus limited, however, to keep it of a handy sizefor the era of big bouks has passed-I have omitted botanical details which have no reference to the bloom. Very, very few of those for whom I write need scientific memoranda for identifying a plant by the character of its leaves and psendo-bulbs, or even by the analysis, in Greek and Latin terms, of vii 


\section{Preface}

its flower. They trust the dealer to supply that species or variety which they ask of him, and in a lifetime they will not find themselves mistaken.

I have ventured on a great innovation, however, suggested by my own experience. I give the minimum price of all orehids mentioned, where a price can be fixed at this time of writing. The convenience of this information is evident, but it was not so easy to decide how the system should be worked in practice. I have explained my method in an article.

Finally, some may ask what are my credentials for offering advice upon the culture of orchids? They need not be cited, for Mr. Joseph Godseff has examined every page of the work, and he allows me to affix his imprimatur.

\section{FREDERICK BOYLE.}

Norith LuDGE,

ADDISCOMBE. 


\section{CONTENTS}

The Nature of Orchids The Orchid-IIOUse . . . . . . . . 16 ORchid Names . . . . . . . . . . 35 Potting Orchids . . . . . . . . . 41 Orchto Prices . . . . . . . . . 52 Species, Vlrietres and Cultete . . . . . 67 



\section{LIST OF ILLUSTRATIONS}

\section{COLOURED PLATES}

Odontoglossum chisuda Alcxandre . . Erontispiece Latia anceps. . . . . . . To face p. 114 UNCidicm maclianthum . . . . . . . 200

\section{ILLUSTRATIONS IN TEXT}

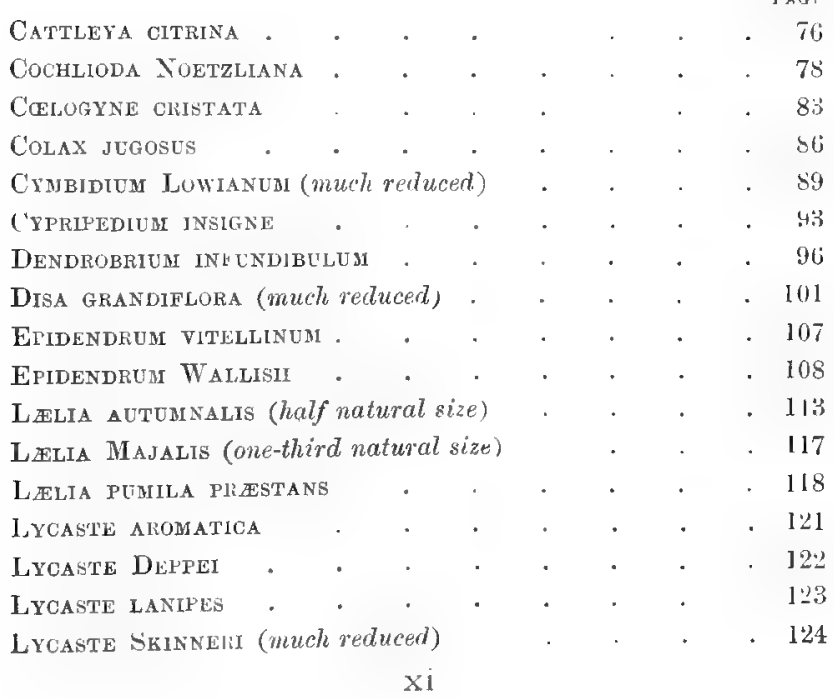




\section{List of Illustrations}

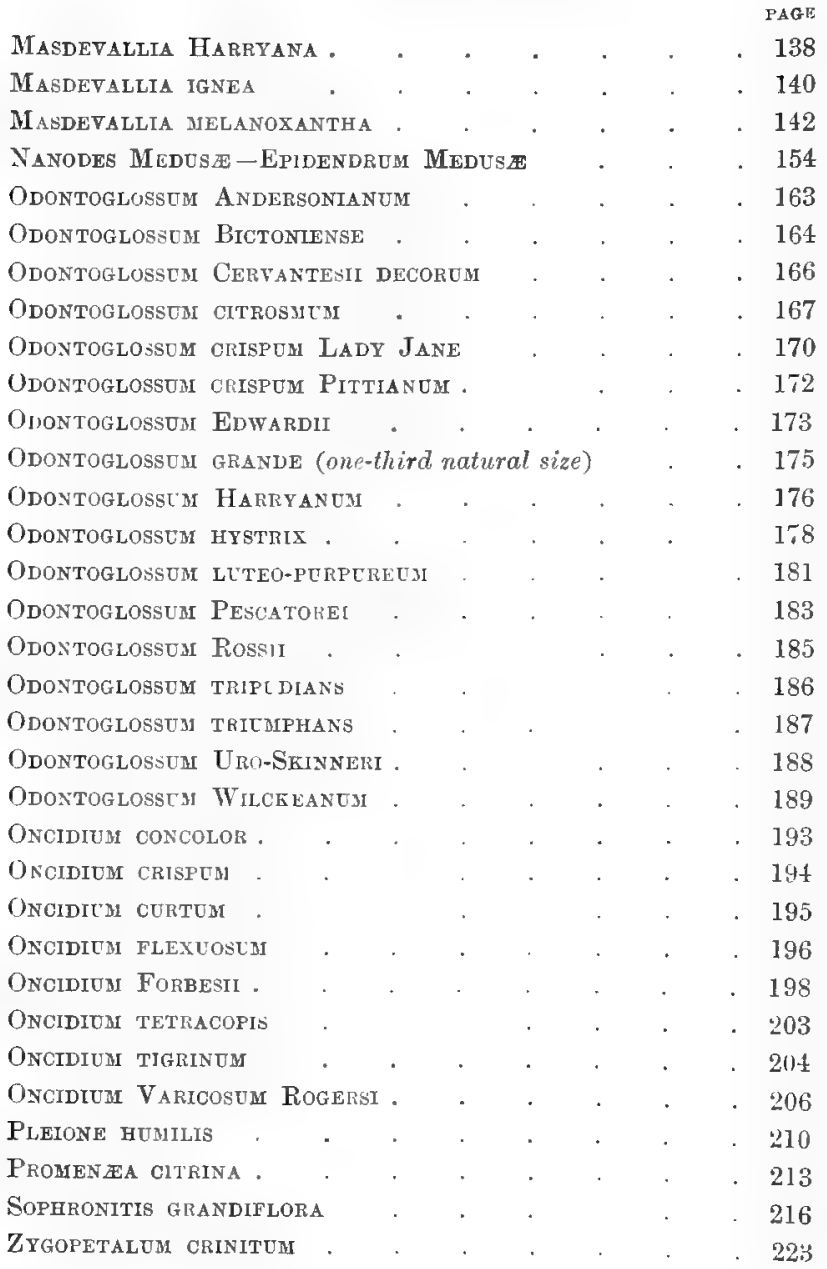




\section{THE CULTURE OF \\ GREENHOUSE ORCHIDS}

\section{THE NATURE OF ORCHIDS}

IT is not the scientific view of this question which concerns us. We are going to cultivate orchids, and our study of them need not be carried beyond the point necessary for that purpose. But he who would succeed should know, in a general way, the conditions under which these plants thrive at home, so that he may be able to refer to First Principles when perplexed. Let him be aware, nevertheless, of unskilled advisers who have dwelt in lands where orchids flourish, and therefore, as they say, "ought to know something about them." Too often the amateur listens to such well-meaning friends, and suffers. I shall explain why they mislead him presently.

Strong, healthy roots, and many of them, are 


\section{The Culture of Greenhouse Orchids}

essential to the vigour of all plants, but especially to epiphytal orchids-that is, such as grow on trees, the great majority. They are protected only by leaves and boughs against the wind, which rises to prodigious force upon occasion, and the rain, which falls as from a sluice. Many species grow to an enormous bulk; Mr. Burbidge found a Grammatophyllum "as big as a Pickford's van," he says. To reach that size it must have got through many a hurricane; but the clasp of the roots preserved it. Orchids are broken off by the wind continually. The branch to which they cling is severed, or the tree itself overthrown; but scarcely one is ever blown away.

It follows that an orchid must feel itself safe, firmly planted or solidly attached to its support, or it will not thrive. The inexperienced are apt to disregard this point. Observing how quickly and vigorously the roots of a healthy plant catch hold, they often leave it insecure- "wobbly," in fact - when the shape is awkward, trusting that it will anchor itself. This is injudicious. However lightly the compost be laid around it, the plant should be firmly fixed. My own practice is to tie it down with copper wire, which is removed when the roots have attached themselves. But only copper can be used for the purpose. Iron is fatal. 


\section{The Nature of Orchids}

It used to be held that epiphytal orchids take no sustenance from the material in which they are placed, whatever it be. Closer experience does not support this extreme view, and Belgian growers reject it with emphasis, asserting that the terre de bruyere (oak-leaf mould), which they prefer, is actually food for the plants. I deal with the new treatment of orchids, discovered by Belgian ingenuity a very few years ago, in its place; assuredly it is not to be overlooked. But if plants grow more strongly in terre de bruyere, that does not prove that they draw nourishment from it, beyond the gases and exhalations which they draw likewise from peat, though in less quantity. The fact may be due to other rules of the new system. Species which have large roots will do equally well, not to say better, without any kind of potting stuff, if they be kept sufficiently damp. I grow Oncidium crispun, for instance, One. Forbesi, and others, on bare tiles; but this is a practice to be followed only by one who can feel sure that the watering will never be overlooked. Odontoglots so treated would perish gradually, but not because they would miss the sustenance of peat or terre de brunere. The reason they would perish is that their roots, so much more slender and delicate, could not be kept moist-that is to say, it would be possible, no doubt. but by an 


\section{The Culture of Greenhouse Orchids}

expenditure of time and trouble which would daunt the most enthusiastic.

We may still believe, then, as did our forefathers, that orchids live mostly on "air," if that be understood to mean gases and moisture. At the same time the air must be fresh and brisk, for cool genera especially. So important is this, that there are country places, far from the smoke and pollution of a town, where no great attention is paid to the orchids, yet they thrive so well that experts recognize plants forwarded from thence to the salerooms by their appearance. The ideal situation for an orchid-house is a breezy mountain-top. In fact, I understand that more than one enterprising cultivator among our foreign rivals is about to remove his "growing establishment" to the highest ground within reach, at a great expense.

But if orchids love fresh air, it follows that they cannot have too much of it. We were told formerly that they dislike a draught. I am not sure that I understand what was meant, but if it be a current of fresh air from end to end of the house, those counsellors are wrong. Day and night air should be admitted through the bottom ventilators, unless there be danger that frost will reach the plants. From spring till late autumn both doors of my cool house stand open all day, and they would stand 


\section{The Nature of Orchids}

open all night too, but for fear of cats and slugs. The top ventilators also should never be closed during these months, day or night; but they must not be so far open as to let the damp escape freely. Less than an inch suffices. On a hot summer day a thoughtless gardener will open the top ventilators wide, forgetting that the air will dry up in a few minutes, and the plants will suffer. More frequently, however, it is his thoughtless employer who does the mischief.

For constant damp-with ventilation-is most important of all. But it must not be obtained by watering the plants; that, I think, is the commonest cause of failure. Those Oncidiums mentioned, clinging to naked tiles, are watered only thrice in the twenty-four hours, as a rule, at midsummer. This great question is treated at length in its place. But I do not believe that it is possible to have too much moisture in the atmosphere of the cool house. The plants there come from mountains in the tropic or sub-tropic zones, where rain and mist and sunshine succeed one another all the year round. And on bright days the air is scarcely less damp, for sunshine draws out the moisture of the sodden earth.

Another essential condition is - light. Cool species, happily, are not so exacting as some in this 


\section{The Culture of Greenhouse Orchids}

respect. Odontoglots dwell at home upon branches thirty feet above the ground-never less than twenty feet, and never more than forty, as the great Roezl observed; and the trees, of course, are living. Thus they are always shaded by foliage. But it does not follow-most emphatically not-that they do best in shade here. I shall presently show that light in those countries is so vastly more brilliant than ours, that shady places with us must seem dark to a New Granadan orchid. They are grateful for all the light we can give, though they put up with less. But sunshine they dread far more even than others.

The reader must distinguish most carefully between light and sunshine. Travellers will assure him that they have seen orchids flourishing in the blaze of noon when the thermometer marked some awful degree of heat. Countless are the amateurs who have acted on this true report-and paid the penalty. It is not to be said that all have suffered --unfortunately, for the exceptions encourage an error which is commonly fatal. There is record of some most successful growers - Dr. Paterson, for example-who never shaded their Cattleyas and Dendrobes at all. I am not prepared to suggest a reason why the usual consequences did not follow, for I never had an opportunity to investigate; but 


\section{The Nature of Orchids}

some reason there was assuredly in the local conditions. I myself saw a report of Dr. Paterson's system in the days of inexperience. It agreed with my own observations in either hemisphere. Orchids are quite comfortable in tropic glare-how absurd to protect them against our feeble sunshine! Forthwith I discarded blinds in the stove and intermediate house. It was midsummer. In three days the leaves showed a brown patch, which spread and spread, though I lowered the blinds in haste. That will certainly be the experience of ninety-nine per cent. who follow the same course. The hundredth escapes, owing to some peculiarity of circumstances.

Those who denounce shading forget that the Dendrobe on a tree-top has no glass above its head. There lies the fatal difference. But there is another point. Its roots do actually burn up, and its pseudo-bulbs wither, in the hot season. But that does not signify - in fact, it is a process necessary for the health of the plant. For in the wild state orchids rest in summer; with us they grow, and rest in winter.

As a general rule, the amateur will do wisely to disregard the reports of travellers. Even though they be well acquainted with orchids in the natural state, unless they understand the conditions to which we must necessarily subject them, their 


\section{The Culture of Greenhouse Orchids}

advice will probably be unsound. I once heard a great horticulturist mutter, when a distinguished but unpractical personage was holding forth, "I never want to hear what orchids do at home-it only puts me out!" He referred, of course, to the impressions which an unskilled traveller brings home.

Such observers, however intelligent, do not bear in memory that the wild orchid has to make the struggle for existence as best it can. The seed grows where it chances to fall, unless, of course, the situation be so unfavourable that it cannot live. No mortal watches it; no one cares whether it thrive or perish. It may worry along for years, never flowering, perhaps, just keeping life enough to grow at the appointed time. We see daily evidence of this. I once bought a mass of Loclia purpuratu, in which not a pseudo-bulb for ten years, or perhaps twenty, had reached the height of four inches. Then suddenly the conditions changed. Seasons favourable to its peculiar situation occurred, or it crept out of those unsuitable surroundings; forthwith the pseudo-bulbs lengthened, swelled, and flowered. But generally, no doubt, in such cases the orchid drags on a wretched existence, contending with adverse circumstances. Nevertheless, the uninitiated traveller who sees it blooming, makes 


\section{The Nature of Orchids .}

no comparisons. Returning to Europe, he will "put us out" by telling how he saw such and such an orchid flourishing under conditions which we had thought impossible. And then, perhaps, some of his hearers try the experiment, at their cost. It follows that the amateur should not be hasty to accept the report of eyewitnesses in this matter. Professionals need no warning at the present day.

In the natural state, as has been said, orchids grow during the rainy season, which may be called the winter of those lands-in the sense that the air is less hot-though human beings find it more oppressive-sunshine is very much less frequent and less powerful, and light duller; but it must always be remembered that a dull light in the tropics is more luminous than our summer maximum. Mr. H. J. Veitch offered some striking figures on this point in his paper on "The Hybridization of Orchids," at the Conference of 1885. Sunlight at the Equator falls nearly perpendicular the year round, and throughout the tropics its utmost inclination is slight; but in our latitude, at midsummer, the angle is as low as $28^{\circ}$, and at midwinter it falls to $15^{\circ}$. And this is not all. "Light," says Mr. Veitch, " in passing through the atmosphere, even under the most favourable circumstances, is subject to absorption, and is intercepted by it; but 


\section{The Culture of Greenhouse Orchids}

the amount varies with the angle. Thus it has been shown that of a given quantity of light falling perpendicularly upon a given point, one-fifth is absorbed or intercepted by the atmosphere; if it fall at an angle of $50^{\circ}$, more than one-fourth is absorbed; and at an angle of $75^{\circ}$, fully one-half. Hence in the winter months, even when the days are clear and bright, we can get no more than fiveeighths of the solar light these New Granadan Cattleyas receive in their native country, on the assumption that other circumstances remain the same." But they are far from the same. The tropic sun breaks through continually during the rainy months. And what proportion of our winter days are clear and bright?

It follows that every effort should be made to secure such light as we may command, especially in winter.

The natural habit of orchids to grow during the dull season and rest during the heat of summer could not possibly be permitted in this latitude. We must needs call upon them to reverse the process, and they consent without the smallest difficulty; in fact, if their wants be properly supplied, the most of them will grow more strongly than at home. Our light is deficient, but then our day is far longer. They gain not less than two 


\section{The Nature of Orchids}

hours in the morning at midsummer, and as much in the evening, which evidently compensates the disadvantage. In winter certainly there is an equal loss, but then the plants are resting, and they do not mind much.

Those who picture orchids exposed to the blaze of a tropic sun month after month may wonder how they can keep any life within them, though resting. But it must be noticed that at sunset, after each broiling day, such damp rushes up from the soil that in a few moments every branch is dripping. The rising of the mist on Bornean rivers impressed my imagination curiously. Before the short twilight ends, thin spirals curl upwards on every side. Swiftly they unite. Presently the surface is covered as by a sheet. Every orchid drinks its fill all night to sustain it against the burning hours of day. M. Forget tells me that in parched districts of South America-where indeed it seems strange that plants living on moisture can exist through the heats-fogs, such as may be cut with a knife, roll in from seaward when the sun goes down. They answer the same purpose. It follows that the atmosphere should be saturated by night-especially, perhaps, while orchids are resting. This is not done commonly.

I have wandered somewhat from my proper 


\section{The Culture of Greenhouse Orchids}

sphere. No reasoning mortal has ever urged that cool species will flourish, or even exist, without protection from the sun. And Odontoglots rest so lightly that too many amateurs searcely let them rest at all. Even under those circumstances they live and flower, but they do not increase in size from year to year as they should. And such misguided amateurs, as I observe, are apt to treat their Oncidiums in the same way, which is disastrous. Oncidiums take a decided rest if they be allowed; and if they be not allowed they dwindle and perish in two or three years. However, these practical matters are dealt with elsewhere.

The use of manure for orchids is an interesting question, debated from time to time with small result. That they love the fumes or gases of ammonia is indisputable, but I refer to the application of manure in solid or liquid form. It is understood that some growers, who take no part in the discussion, improve the look of their plants wonderfully by this means-at the expense of their vitality say others. Opponents of the system ask how things which live upon a naked bough, high up in air, could make acquaintance with the unsavoury compounds recommended? I do not adrocate manure, for the one thing certain is that it must be used with great discretion, or disaster will be the 


\section{The Nature of Orchids}

consequence. But the objection cited is worthless. Those who rely upon it overlook the parrots, not to mention other birds, that feed and perch and roost in flocks. A glorious spectacle is the sudden rising of a body of macaws when startled; and in Central or South America one can enjoy it many times in the course of an early walk for the trouble of firing off a gun. The tree-top breaks into a scarlet flame, which explodes, as it were, like a rocket, and fire-balls whiz off from the centre. The droppings of those great birds day after day must be enormous, and the orchids get a share. Parrots and parroquets, if smaller individually, congregate in hundreds on one tree. I mention these only, but there are flocks of little birds which perhaps contribute more excreta in the bulk. And these roost among the orchids; macaws and parrots do not commonly, preferring the denser foliage of lianas. Monkeys must not be forgotten, nor, especially, fruit-eating bats. Evidently there is no lack of manure upon the branches, and of the strongest sort.

I take it, therefore, that orchids are benefited by the direct application of a stimulant, but the difference of conditions must always be borne in mind. Droppings melt off a round bough in an instant during the rains, when plants are feeding, and dry 


\section{The Culture of Greenhouse Orchids}

up promptly in the heat when they are at rest; but if we give them manure, it remains for an indefinite time in the potting material. Thus abnormal growths may be produced which suddenly collapse, for we see just the same result in the case of pelargoniums and such flowers grown for the London market. They are "fed" to the uttermost, and despatched in haste at the moment of perfection. When that is past they dwindle away. Many readers, doubtless, have bought a lovely plant in Covent Garden, of some variety which they desired and expected to propagate; but its life seemed to fade with its bloom, and, what is even more distressing, cuttings from it would not root.

Upon the other hand, Belgian growers, taking them all round, are more successful than most of us in raising fine plants, though the flowerspike, be it noted, is not proportionately big. English collections might easily be named which equal their best in growth, and excel them in bloom; but, on the average, I think they are superior. Something may be allowed for the new system of culture to which I have alluded, something to climate. But the quality of the water must not be overlooked. Nursery gardens always lie within reach of a canal, from which they pump the water into tanks. I know nothing of the 


\section{The Nature of Orchids}

sanitary rules in Belgium, but these canals serve, in fact, as sewers, whether lawfully or no. The pollution is not serious in such a volume of water -it does no harm, perhaps, to human beings_but that fractional quantity of manure may be just the amount which benefits an orchid withont evil consequences. So it appears to me. But I make the observation; I give no advice.

Stimulants in the atmosphere are another thing. All gardeners of experience would like to drench the floor of the orchid-house with the drainings of the stable-yard-the farm-yard for choice-once a week, if not twice. They are not always allowed their way, however. It would seem easy to give the plants what they desire in a form less objectionable, for it is only ammonia. Neat little machines are advertised for the purpose, and often used. But they do not appear to be very effectual, somehow. 


\section{THE ORCHID-HOUSE}

IN laying down rules for the construction and fitting of an orchid-house, it has seemed best to include all the three classes-cool, intermediate, and hot-though this book deals with the first only. They may all be grown under one roof, with glass partitions between-indeed, that system has many advantages. Persons who develop an enthusiasm for the culture-and few there are who do not, if they care for flowers at all-commonly long to try their skill with Cattleyas and Dendrobes, after gaining confidence by success among Odontoglots and Lycastes. Nothing is easier, if their cool house be built after the model I advise, provided they have space-and money. Open a doorway at the far end, build another compartment beyund, and another still for Dendrobes and Vandas, if ambition go so far; arrange them as directed, multiply pipes, increase the heating power, and-that is all.

But there is a point to be seriously noted. If I6 


\section{The Orchid-house}

the amateur be determined to grow cool species alone, never under any circumstances to take up those others, he should choose a site where his house can be built north and south, but facing east, or, if that be unattainable, east and west, facing north. New Granadan Odontoglots are not quite comfortable under a southern aspect, which suits the lowland genera, for heary shading is required to protect them from the sun, and that excludes also the light. But I would not discourage the amateur who has only one spot, with a southern aspect, in which to place his Odontoglossum house. More attention is needed to keep it moist, but the plants bloom very freely, if they do not make such rotund bulbs as an expert would wish.

Upon the other hand, some Mexican species, as Oncidium tigrinum, Cattleya citrina, Latia $M a-$ jalis, love the sun so well that in a lean-to running north and south they should have a place apart; if that can be given them towards the north end, they want only a slight shading in the hottest season. A rule which I have noted is very useful to guide inexperience in this matter. Hard and shiny pseudo-bulbs warn us that the species is sunny-nature protects it thus; a soft pseudo-bulb means that the species is shady, and needs defence against the sun in proportion to its softness. There 


\section{The Culture of Greenhouse Orchids}

are cases which appear to be exceptions at a glance. Among Mexican epiphytes, for example, we have Cattleyce citrina, which craves sunshine, and yet its pseudo-bulbs are comparatively soft. But observe the integument, like thin white paper, which clothes them; that is another device to serve the same purpose. Dendrobiums, I think, are all sunny; but those most exacting can be distinguished by their greater hardness and polish. Some Odontoglots have pseudo-bulbs less soft than others, and such, like O. Rossii, should hang close to the glass; but none can be termed hard by comparison with Cattleyas. Thus they tell us to keep them shady. But 0 . grande, from Guatemala, and its relative, $O$. Insleayi, are exceptions to the rule-though their pseud(v-bulbs are rough and soft, they like the sun. Nature does not refuse us a warning in this case, however; the leaves are broad, harsh and thick, unlike those of any other species, and they protect the bulbs.

I am not to give architectural suggestions for the orchid-house; it is principles which signify. Nevertheless they are displayed most effectually by illustration, and therefore I will sketch a building which seems, to Mr. Godseff's mature experience, the ideal form to accommodate all three classes.

This is called a "hip-span" house. It rises on 


\section{The Orchid-house}

one side from a brick wall 8 feet 9 inches high. The advantage of the wall is proved by experience. All orchids like the moisture which it gires off by evaporation, but those which have no pseudo-bulbs, as Vandas, Erides, Sobralias, are specially benefited. And they are tall mostly. Ranged on that side of

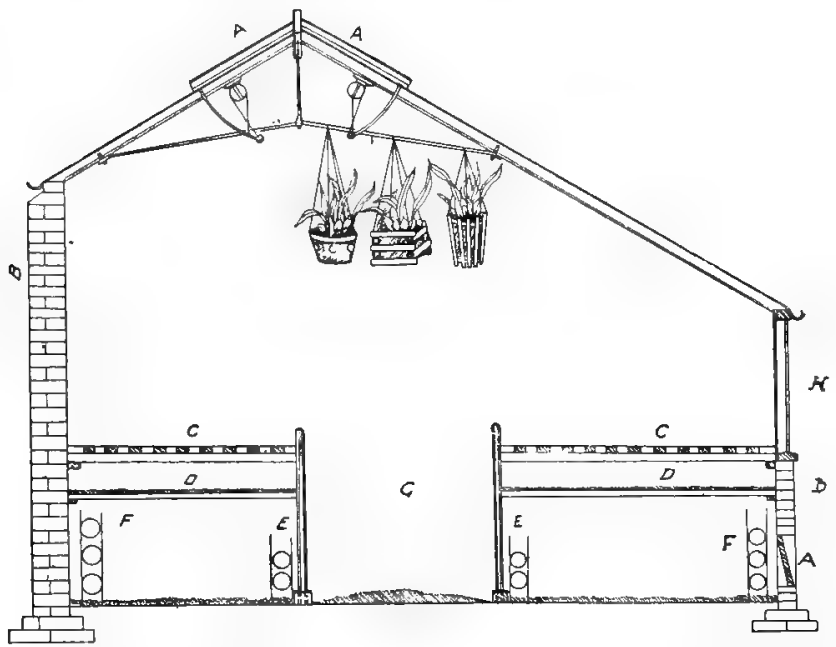

$A, A, A$, ventilators in roof and front wall; B, B, brickwork; C, C, upper staging; D, D, lower staging: E, E, flow pipes; F, F, return pipes; G, pathway; $H$, front sash.

N.B.-Six inches should be left clear between the wall and the stage to allow a free current of air and heat.

the house, they grow more strongly, and they look their best.

If only cool and shade-loving species be cultivated, the house should face north or east, as has 


\section{The Culture of Greenhouse Orchids}

been said; if warm and sunny, the aspect should be south or west. There is an alternative, however. Such a house may be built on each side of a wall running north and south. In that case, shady species would be grown in the one facing eastwards ; sunny species in the one facing westward.

A convenient length is 30 feet; but if it be desired to have cool, warm, and hot species under one roof, the building may be any length, divided into spaces, 25 or 30 feet each, by glass partitions.

It should have only one door, opening into the cool department. Thus the hottest, occupied by Dendrobes, etc., which would be furthest from the entrance, would have the advantage of a closed end, which proves to be very valuable.

The height should be 12 feet from the floor to the under side of the ridge; width 15 feet, inside measurement. The back rafters then would be 6 feet 6 inches long; front ditto, 12 feet 6 inches long.

The front sash, 2 feet 9 inches in height, should not open.

Ventilators should be provided on each side the roof, all along, about 16 inches in depth, so that one set may be opened whatever the direction of the wind. The bottom ventilators, on the front only, 9 inches high by 18 inches long, should be beneath the stage. I find it useful to cover these 


\section{The Orchid-house}

with perforated zinc, which does not obstruct the air, but excludes slugs.

The pathway should be 4 feet wide, with a stage on either hand 5 feet in breadth towards the wall, 6 feet towards the front.

The height of the house, and the width of the pathway, allow plants to be hung from the roof neatly and conveniently. This is an immense advantage. Very many species must be suspended near the light, with the air freely circulating round them, to thrive as they should.

This is the best position also for seedling orchids. The seed should be strewn over the surface of pans thus suspended.

The staging should be double, as shown in the plan, to secure an equable temperature and constant humidity.

A tank for rain-water, 6 feet by 16 feet, should be provided at the far end of the house. This is so important, that one tank represents the minimum desirable.

It is a great mistake to grudge piping; superfluous heat can always be turned off, but a deficiency cannot be supplied. Have the boiler rather too strong than too weak. Such a house as we have sketched, devoted to Cattleyas and Lælias, should be fitted with ten 4 -inch pipes, flow and return; 


\section{The Culture of Greenhouse Orchids}

Dendrobes and E'ast Indian species proportionately more, and cool orchids less, of course.

But the majority of those whom I address are not prepared to build for the purpose. They must do with such houses, or such house, as they have. And the result will satisfy them, probably. No class of plants is so easy to grow as orchids-none so long-suffering. The public is wondrous slow to learn this truth. It clings resolutely to traditions which have long been out of date. Orchids were costly when those who gathered and shipped them understood nothing of their requirements, and so probably the consignment was doomed at starting; when they travelled by sailing vessels, and lay becalmed for weeks in the neighbourhood of the Equator; when no one knew exactly what to do with them on arrival. If buyers were few, they were enough to compete heavily for the small remnant which sometimes survived the voyage. And the culture was both troublesome and expensive, with glass at "famine price," hot-air flues instead of water-piping, and general ignorance about the treatment. Marvellous it seems now that gardeners should have been skilful and careful enough to make them thrive under such conditions, at any cost. But all that is ancient history. I have heard a humorous authority declare that any 


\section{The Orchid-house}

one who can grow mustard and cress, can grow cool orchids at present. It is no monstrous exaggeration. But still the public repeats and credits the legends of that early time.

If the amateur will keep before him the principles which I have laid down in the first chapter, he will not regret "going in for orchids," whatever the situation or the architecture of his house may be, provided that it have sufficient light. All other defects can be remedied more or less.

I should mention, however, a very common difficulty. Builders love encaustic tiling for the paths, and concrete for the floor of a conservatory, and householders generally have the same taste. It is neat, but it will not do. I myself fought with this disadvantage for years, trying various methods to overcome it; for concrete will never hold the damp. At length I bordered the paths with garden tiles, and filled the area beyond them with sea-sand. It lies four inches deep, and this, watered with the hose once, twice, or three times a day, according to the season, gives ample moisture. The paths themselves I have covered to an equal depth with shell-gravel, coarse white sand, and crushed gypsum from Derbyshire over all. The effect is good; no water can be seen though the whole floor be soaking; and my orchids are happy at last. 


\section{The Culture of Greenhouse Orchids}

If it be possible, a stand-pipe from the main should be set in the house, and a hose attachednot for watering plants, of course, but for " damping down." It will spare the gardener much trouble, not to speak of time; and the wise always seek to relieve him of dull mechanical labour. For, in the first place, he is tempted to scamp such work; in the second, he can be better employed.

Ventilators at the bottom, beneath the staging, are most desirable, and easily contrived. One cannot have too many of them for use in hot weather, or indeed in cold, if the heating power be sufficient, and if their position be such that the air will lose its chill before reaching the plants. Top ventilation also is necessary, but only just enough to keep the air in motion. In my own cool house, a leanto, the uppermost pane does not reach the wall. An iuch space remains open all along, throughout the summer months; in November I block it up easily enough, and reopen it in March or April. N.B.-This space must not be forgotten when using XL or any fumigant.

Syringing is not to be recommended for the sake of the plants, unless after a very hot day. And then it sbould be used softly. Tender young growths are apt to decay when water stands at their heart. Also an inexperienced and careless 


\section{The Orchid-house}

gardener may think a plant is soaking when in fact its roots are dry. But then, again, if mischief follow sometimes, there is a permanent advantage. Insects hate the syringe. It is to be observed that all professional growers with whom I am acquainted use it freely. But they would rather not; they advise everybody to abstain, for the practice can only be justified by necessity. So I leave the matter. Do not syringe if you can keep your orchids clean and moist without it.

Insects play the part of Nemesis in our schemes of enjoyment. Every plague that haunts the greenhouse attacks orchids, but if the gardener be quick of eye and watchful, they are easily kept under in the cool house, provided he have time and means to battle with them; to grudge him either is imbecility, though not unusual. It must be remembered, however, that Thrips of both species and Red Spider are native pests. Flourishing in the garden outside, they cannot long be excluded from the house, though Red Spider, which dislikes damp, will not take up its abode there unless, by bad management, the atmosphere be kept far too dry. There is an exception, however. It will attack Disa grandiflora under all circumstances. But of this I speak in another place.

Insects are combated by smoking, steaming, 


\section{The Culture of Greenhouse Orchids}

dipping, or spraying. Tobacco is hazardous among Odontoglots and Miltonias; so much depends upon the quality used, besides the question of strength. Experiments may cost one very dear. Some growers burn Macfarlane's "sheets" in the cool house without the least anxiety. I have never found the courage to do that, remembering ton bitterly how I lost every Odontoglot I possessed by smoking once on a time - it was not Macfarlane's preparation, certainly. I have used his sheets for years in the warm houses, and it is true that they do not affect the Miltonias or Odontoglots there. But it is always best to leave well alone.

Incidentally, however, it is worth while to observe that the smoke of pure tobacco is as harmless for Miltonias and Odontoglots as for any other orchid. Public gardens, such as Kew, are privileged to receive smuggled or confiscated tobacco, and they burn it with impunity everywhere. It is not to be hoped, of course, that private individuals will ever enjoy this favour; nor is it to be wished seriously, for if the revenue from tobacco fell off, taxes far more burdensome must be imposed. But it would certainly be easy to mix some chemical with the stuff which would make it effective for this legitimate object, in small quantities, whilst spoiling it for the pipe. Such 


\section{The Orchid-house}

proposals have been laid before Government, I believe, but the gardening interest is not yet strong enough to command a hearing. It grows, however.

There is another system which might be introduced without damage to the revenue. In the United States, and also in France and Belgium, they put down the leaf-stalk and other refuse of tobacco factories in the neighbourhood of the pipes, where it gives off a vapour when heated and moistened, imperceptible to our nostrils but deadly to insects. Happy mortals thus escape all trouble whatsoever. Here again chemists would certainly be able to devise an adulteration which would check illegitimate use of the rubbish. The British market-gardener is heavily penalized in competition with foreigners, by climate, by the cost of labour, and by disproportionate expenses all round. Every year he finds it more difficult to hold his own. But his is a great industry, of national importance, which would grow at a prodigious rate if it were not checked by the enormous importation. Government might relieve us, at least, of pedantic restrictions.

This is somewhat of a digression, for the orchidgrower has not nearly so much interest in the grievance as the struggling tradesman who cultivates 


\section{The Culture of Greenhouse Orchids}

cucumbers and pelargoniums for the market. He can keep his small house clean with no serious trouble or expense; if it be a large one, he has wealth proportionate. But a reference is not out of place here, for orchidists, though few comparatively, form a powerful body, who can make themselves heard if they will, whilst those others belong to the dumb millions.

Putting tobacco aside, we have "XL," a preparation comparatively new which fulfils the boast of its name; it is "XL-ent." As has been said, we ought not to be troubled with red spider in the cool house, and the horrid little scale which infests Cattleyas does not trouble us at all. $\mathrm{XL}$ is powerless against these, nor will it exterminate the big variety of scale which settles on the underside of the leaves; but to mealy-bug and thrips it is deadly.

There are various instruments for steaming tobacco-juice. One I have tried, the Thanatophore, sold by Messrs. Williams of Holloway. It answered perfectly; my houses were absolutely clear for an indefinite time. Any reader to whom expense is no grave consideration may turn the page-the Thanatophore is what he wants.

Naphthaline is not used in this country to my knowledge, but Belgian growers "swear by it." 


\section{The Orchid-house}

The stuff can be obtained of any chemist. A man walks backward through the house holding a redhot shovel before him, on which a man following sprinkles naphthaline. So they pass out at the other door, or escape as quickly as they may, for the fumes are deadly. Nothing remains alive, they say, after this operation. I cannot speak by experience, however, for my plant-houses are attached to the divelling, and, from all accounts, the doctor, if not the coroner, would be summoned shortly afterwards.

Postscriptum.-I have just been told by a Belgian grower that he has ceased to use naphthaline because open flowers are so frequently injured by it.

Dipping is safe and effectual. To dip a large collection may be rather a serious undertaking, but I write for the modest amateur. He will find it a day's work at most, and for several weeks afterwards, even in the height of summer, he need not concern himself with insects. A good prescription is this:-

To 2 gallons of soft water add-

4 lbs. of Appleby's tobacco-paper,

212 ozs. of Gishurst's compound,

$2, "$ soft soap.

Heat the mixture till near boiling. When cool 


\section{The Culture of Greenhouse Orchids}

enough, squeeze all the solution out of the paper, and strain. Use it as hot as is safe. After dipping, assure yourself that the mixture lies in the axils of the leaves; then lay the plant upon its side for ten minutes. Afterwards wash it in soft water.

Note.-It must be used stronger to kill "scale."

When the house is clear of insects, it may be kept in that blessed state by means of Richard's XL insecticide.

Our worst plague, after all, is slugs, if they be allowed to get the upper hand, and cockroaches are terrible. Both attack the flower-spikes by preference, as, indeed, do all the rest; but these horrid creatures devour the fruit of twelve months' anxious culture in a single night. There is no remedy but care and vigilance when once they get established. To prevent that should be your aim.

Slugs are introduced as a rule in the sphagnum moss, as are tiny flat snails, mischierous beyond belief in proportion to their size. A legend current among gardeners cheers us with the assurance that they will not live in a house where rain-water alone is used. I have heard this notion bitterly derided by sufferers, and it is indisputable that if these small snails cannot live under the rain-water treatment, they take a long while in dying. But 


\section{The Orchid-house}

If they do not multiply, and I think they do not, the fact is intelligible. Snail-shells are made of lime. Hard water contains a supply, but there is none in rain-water. Thus, it may be, they gradually become extinct.

As for slugs, it will be observed that they do not like orchids. If there be any other food within reach they will make for it. Accordingly, they may be trapped with bits of cabbage-leaf or potato. Especially they are fond of bran; if a little heap be put in their way they will be found hidden in it. But, for all we can do, if slugs be fairly estallished, to get rid of them is a desperate task. I think of a neighbour who has been fighting the enemy for years. He encircles a flower-spike with cotton wool, which neither slug nor cockroach can creep over. And still the percentage of loss is awful.

It is very easy to exclude cockroaches if one be building a new house. They cannot live nor breed unless in darkness. Take care there are no holes to shelter them, and you will never be troubled. In an old house another rule applies. Their eggs will not hatch unless in a dry place; so keep all suspicious corners well watered. They are easily poisoned, but never exterminated by that means. Finally, as has been said, a little bunch of cotton 


\section{The Culture of Greenhouse Orchids}

wool tied round the flower-spike and frayed out protects it.

It is hardly necessary to say, in this year of grace, that orchids must have rain-water. Hard water coats the leaves of any plant with a grey sediment, which is chalk or lime. This stops the respiration, more or less. But in the case of orchids, it is not the respiration of leaves only which is checked. Other plants take their sustenance from the earth, and they suffer comparatively little. But an orchid feeds upon the atmosphere, through its roots especially, and when these are coated with chalk it starves, for they cannot do their duty.

A good supply of rain-water, therefore, is in the last degree desirable, and the quantity in daily use must be stored within the house to keep it at an equal temperature. Intercept all the rain you can; whatever the amount, your tanks will probably run dry at midsummer. But if water can be pumped from a standing pool, it is at least as good; of course it must not be used at once, with the chill in it.

I do not mean that orchids perish, or even deteriorate quickly, if the hard water be kept in the house for some days. They will bear even that unnatural affliction patiently, but it is not to be hoped that they will thrive as under more kindly circumstances. Rain-water is actively beneficial to 


\section{The Orchid-house}

them, as hard water is actively mischievous, for it contains gases which they love.

The tanks should be sunk in the floor, but if they stand upon it they may be made ornamental. I have faced mine with the deep-red brick termed "terra cotta," which is very porous. The brickwork is not close, as in a wall, but chequer-wise, leaving interstices or pockets. In these I set Adiantum. A pipe runs from the main-along the ground, invisible-and climbs the facing. At the top it divides, passing all round. The encircling portion is stabbed with little holes. Whenever the hose is not in use, I hitch on the connection of this pipe, and make it just dribble over the brickwork. All day, saving a few minutes, and all night the water trickles imperceptibly. In that constant drip the Adiantums grow and multiply que c'est une merveille! Long since they have clothed every inch of the surface with a mantle of tenderest green.

Another great advantage of this arrangement is that the bricks, always soaked through, give off more and more moisture as the heat rises.

To keep up the temperature in the cool house is a very easy and inexpensive matter; our trouble is to keep it down. Experiments by Mr. Smee and others show that most Odontoglots-the cool varieties, naturally-will bear several degrees of frost 


\section{The Culture of Greenhouse Orchids}

for a night or two uninjured. O. crispum succumbs at $13^{\circ}$. But this is only a scientific fact, pleasant to recall, when by some mischance the glass shows $32^{\circ}$ on a winter morning. Assuredly no orchid we cultivate is indifferent to frost.

During November, December, January, February, and March the night temperature should be $50^{\circ}$ to $45^{\circ}$; during April, May, June, July, August, September, and October, $55^{\circ}$; and always the day temperature should be five degrees higher $-55^{\circ}$ and $60^{\circ}$. Of course, this ideal cannot be maintained in summer. Even in a lean-to facing the north, heavily shaded, freely watered and ventilated, the heat will rise to $70^{\circ}$ or more daily, nor will it fall much below $60^{\circ}$ at night. But under the conditions named - of shade and water and ventilation-not the least harm is done; neglect of the conditions would be disastrous, however. That must always be remembered. Upon the whole, too great heat in winter is a much more frequent cause of mischief than summer sun. I repeat that during those most important months-November to April-when the bulk of the plants are setting and maturing their flowers, $55^{\circ}$ by day, $50^{\circ}$ by night, are the maximum permissible; and if the glass begin to fall lower in the small hours, so as to touch $45^{\circ}$ at daylight, so much the better. 


\section{ORCHID NAMES}

ThIs is a hateful theme. Assuredly I have no prejudice against things Greek; quite the reverse. I offer myself a victim to all the gods of Philistia by confessing that the story of mankind lost its highest interest for me when Philopomen perished -if he might truly be called ultimus Grecorum. But that is not the point of view which concerns us.

Orchids have been damned by their names. I recollect the words of a friendly editor, credited, above all, with judgment in appreciating the public taste. I had proposed to write some narratives of adventure, since published, based on the discovery of certain species. Said he, "Couldn't you hang your stories on some other peg? The British public hates orchids!" I had already cause to suspect that it was so, and I asked of this sagacious expert what the reason might be? "Oh, it's the names, I suppose!" he answered. Also, traditions not yet dispelled have their influence, no doubt. Orchids are still regarded as 


\section{The Culture of Greenhouse Orchids}

things uncanny, outside the interest of work-a-day mortals.

It is infinitely deplorable. We see now that the error might have been avoided partly, and with benefit also. I do not recollect who were the tasteful personages that devised such pretty names as "Lælia" and "Vanda;" "Ada" is Dr. Lindley's -would he had pursued that excellent track! "Cattleya" from Mr. Cattley of Barnet, "Miltonia" from Lord Milton, may pass. But how few are these! I have nearly exhausted the list, for "Rodriguesia," "Pescatorea," though personal names, are not commendable, sounding as unnatural as the worst to English ears. Nineteen in twenty among genera, and most species, bear a Greek or Latin title, qualified only by bad grammar. It would not signify if they were short, pleasing, easily remembered. "Lælia" is Latin; "Vanda" Sanscrit. But we can adopt them cheerfully, whilst only long habit demoralizes us to the point of familiarity with "Odontoglossum " and "Zygopetalum,"

The Botanists are directly responsible, of course. It must not be said that they have no imagination -was not Rousseau a botanist, and Darwin?-but they are haunted by a futile fancy for giving what they call descriptive names, in a dead language, 


\section{Orchid Names}

so that all nations may understand. As a matter of fact no nation understands, and very few individuals. Under that grotesque assumption, however, we are burdened with a genus called "Teeth-tongue" (Odontoglossum), "A tumour" (Oncidium), "Insects' jaws" (Maxillaria). And what do these terms describe? One must have an anatonical report, minutely detailed too, to see where the point comes in. But the early orchidgrowers are not blameless-those noblemen and wealthy persons who might have given a new genus which reached their hands an easy, pleasant name, before consigning it to the savants.

At the present time the evil is arrested in some measure. Owners who pay respect to the injunctions of the Orchid Committee name hybrids or new varieties after a person or place, or some character in ancient history or mythology. But for the mischief done there is no remedy.

Once on a time I was looking at a fine plant of Oncidium uniflorum, in company with an official, at Kew. Not a spike there but had two flowers! "If you called that plant uniflorum," I said, "by some mischance, surely you might have corrected the error before this. It is not only absurd, but misleading."

"My dear fellow," the pundit replied, "if you 


\section{The Culture of Greenhouse Orchids}

had to find names for half a dozen species daily, you would not trouble yourself to correct small mistakes. We are too glad to hit on a new descriptive title of any sort in this age of the world."

The amateur must make up his mind to learm those awful polysyllables. And he will find that it is not really difficult, even though his memory be not strong. The outsider thinks it a desperate task, but he may notice that very few who grow orchids fail to recollect genera-I might say none. Names of species bother all of us sometimes. I have heard great authorities, who could not afford to allow that recollection failed them at the instant, make the wildest shots.

The reader, therefore, may take heart of grace. In a few weeks he will find himself chattering about Zygopetalums and Epidendrums as fluently as a veteran. To know the meaning of the long words will assist him, and $I$ append a translation in every case.

But I have taken a liberty which will shock the purists. "In Latin prose of any elegance," said Dr. Johnson, "English names require to have inflection given to them." Macaulay was very hard on Crofton Croker for not understanding this remark. "Every one who knows anything of 


\section{Orchid Names}

Latinity knows"-in short, knows that the man who does not see it at a glance cannot properly be called a reasonable being. I expect similar treatment from the critics, who, of course, will not read this apology. For I have mutilated the inflections - that is, one class of them.

Doubtless many readers have observed that the personal names attached to species of plants are inflected upon two different systems; as, for example, Dendrobium Devonianum, and Dendrobium Gibsonii, and some probably have been unable to detect or to learn the principle of this distinction. It is an arbitrary rule, indeed, but useful. The name of a discoverer is put in the genitive case; the name of an individual, bestowed for compliment's sake, or because the plant flowered under his protection, is transformed to an adjective. The examples just cited are characteristic. Mr. Gibson travelled at the expense of the Duke of Devonshire, and a Dendrobium he discovered is called Gibsonii ; another which he discovered was named in honour of the Duke; not "Devonii," therefore, but "Devonianum " or "Devoniense."

These titles are correct enough by the rules of Latin grammar. But we do not talk Latin, and our instincts revolt against the double " $i$." In the case of a monosyllable, like Odont. Rossii, many 


\section{The Culture of Greenhouse Orchids}

people submit; but is there one, even among botanists, who says "Gibsonii"? Those responsible persons write it so indeed, but few others; and everybody says "Gibsoni." Therefore I have taken upon myself, in a book designed for the public, to disregard the Latin Grammar, and use that form of words to which the public is accustomed. 


\section{POTTING ORCHIDS}

Within the last few years Belgian orchidists have introduced a new system of potting, so radically different, not only from the practice elsewhere, but also from the ideas or conceptions hitherto admitted, that all the world laughed to hear of it. Most English gardeners are laughing still; at this time of writing (January, 1901) not a hundred, perhaps, have made experiments for themselves. Therefore it seems best to expound the orthodox system without further reference, at present, to the new heresy. After all, the old fashion gives results as good, if properly applied. But greater skill is needed to produce them, and the expense is greater.

It was the custom formerly to hang up imported orchids, or to lay them in a shady corner, until they began to make roots, for fear that they should rot. We understand now that when they arrive in fair condition, this delay wastes their strength. They have rested enough on the voyage. Better 


\section{The Culture of Greenhouse Orchids}

to plant them at once and keep them slightly damp-that is, not dry. Very few will rot if healthy, whilst many shrivelled and perished under the other system.

The number of species which will not thrive as well in a pot or pan as in a basket is small, and of those none are "cool ;" upon the other hand, many object to a block or a raft-evidently because the roots cannot be kept moist enough when bare. Some Odontoglots and Oncidiums, however, will not flourish unless near the glass, with the air circulating freely round them. It is necessary to hang up these, and desirable, for the effect, to hang up a good many others. They may be in baskets or pans. Suspended pots look clumsy.

We must use the smallest quantity of potting material which will suffice to keep the roots damp. When the skilled gardener obtains a plant of great value, such as demands the greatest care, he will set it among bare crocks to recover strength, and so let it remain till it has rooted. Baron Schröder secured, at a long price, a tiniest morsel of Cypripedium insigne Sanderce when there was but one other plant in the world. Mr. Ballantine, his gardener, pronounced at once that it would surely die in any sort of potting material. He fixed it among chips of earthenware in a thumb pot, which 


\section{Potting Orchids}

was placed in a larger pot full of moss, and hourly, or almost, its condition was inspected. For twelve months the little treasure gave no sign of gratitude, but it lived; then on a sudden its dormant energies burst forth, and with such vigour that in four years it became a noble plant. If all our orchids could be treated in the same way, they would astonish us. But we cannot give the ceaseless attention required. I tell the little story only as an illustration of the abstract rule. It teaches that if we must use peat and moss, at least we should use no more than is necessary.

Whether pot or pan be used, three-fourths of the depth should be filled in with crocks or charcoal, which are readily soaked and capable of holding damp, though the water itself passes off instantly; so we get the best approximation to bare living wood in this respect. Those nodules of burnt earth which builders use are most effective, but the advantage over potsherds is not great enough to compensate any extra trouble in procuring them.

Lately, however, some of our leading growers have discarded crocks of every sort, using instead the dry roots and stems of bracken, or rather the shells of them, which abound in good peat. With these, broken and pressed together, they half fill the pot, and then proceed as usual. In the hands 


\section{The Culture of Greenhouse Orchids}

of a careful gardener, who thoroughly grasps the conditions of this system, it works admirably. And it spreads fast. But several amateurs of my acquaintance have abandoned it in haste after trial. A slight excess of water, which would have no result where crocks are used, causes fungus among the bracken roots-and that is deadly. On this account, while recognizing the great merit of the innovation skilfully applied, I do not recommend it to those for whom I write.

It will be found convenient to fix a stake of bamboo in the middle when potting species which have large pseudo-bulbs, such as Odont. Edwardi, Onc. curosum, etc., before beginning to lay in crocks. It should be jammed firmly among them. If wanted to hold the plant steady, it is there; if not, it can be withdrawn.

Over the potsherds spread a layer of moss half an inch thick; it keeps the drainage open and the roots moist. Upon this set your orchid, holding it in the left hand while filling in the compost. Thus one retains it at the height desired, with the "eye" above the surface; if buried, it is apt to rot.

Gardeners generally are not particular about the compost they use for Odontoglossums, because, I think, orchid-peat is dear, and these plants will put up with the refuse. An amateur, who was uncertain 


\section{Potting Orchids}

at the moment whether he possessed two or three thousand plants of $O$. crispun alone, told me once that his gardeners use only the dust riddled out in preparing the peat for Cattleyas and Dendrobes, mixed with Bedfordshire sand; and I believe they do very well-under skilful management. Nay, I once bought some Odontoglots, planted, so far as I could see, in garden mould, and they were by no means discreditable. But the only moral of such cases is, how much finer they would have been had a grower so able used the right materials.

I advise the amateur to get "orchid-peat," if he can afford it. The ordinary kind is a conglomerate of bracken, ling, grass, and sand, but that we require consists of bracken-roots only, a mass of fibre, with very little sand, and none of that unctuous mould which gardeners call "fat." There is not very much of it in these islands, unfortunately, and none is found, they say, elsewhere. It is costly, therefore, in proportion. If he will not go to the expense, let him avoid, at least, the grossly "fat" sorts, and use a greater quantity of Bedfordshire sand.

Pull the peat to shreds; chop up an equal quantity of living sphagnum moss; throw in Bedfordshire sand, and mix together. The compound thus made will be elastic. It cannot " cake," even 


\section{The Culture of Greenhouse Orchids}

if your gardener be so ill-advised as to ram it hard. The sphagnum will keep an even moisture all through.

With this fill your pot or pan up to the brim, so that the orchid stands upon a little hill in the centre; its old dead roots will generally keep it firm. Water cannot lodge around it so elevated. Trim off the straggling fibres of peat with scissors. Have picked sphagnum ready-that is, green young heads selected one by one. In this process slugs are captured; at all times, in dealing with moss, one must recollect that these terrible enemies dwell therein. Slice off a quantity of the green young heads and work them into the surface. They will grow; they give off damp vapours, which the plant evidently likes, and they look pretty.

In compost thus described all the many species of cool orchid will thrive, though some of them prefer an addition of fibrous loam. Such are noted in their place. But when nothing is said to the contrary, this is the potting material understood.

It is "the ideal thing," no doubt, to re-pot cool orchids every year, after flowering - that is, as soon as they begin to push new roots. Those who can afford the time should take note. But repotting every year is not necessary. The material must never be allowed to turn sour-that is the 46 


\section{Potting Orchids}

principle. Under any circumstances, however, the moss should be renewed when it gets sodden, but with care, for it may probably be full of roots. Often the moss will grow to an inconvenient length ; in that case it may be shorn with seissors.

I pass to the new system. Like other inventions, it was begotten by necessity. Belgian peat is useless for orchids, and the thrifty horticulteurs of Ghent and Bruges would have got no sleep o' nights had they been obliged to pay English prices. Looking round for a substitute, they tried the cushion of moss and fern which clings to old walls. It answered fairly, and it cost nothing. Very gradually the most observant came to perceive that plants did better when the cushions had been gathered under the shadow of oak woods, where the earthy matter in them was composed of rotten leaves. Pondering this fact, some daring spirit was led to try the earthy matter pure and simpleterre de bruyere they call it. And so, gradually, the proper treatment was discovered.

This variety of terre de bruyère is leaf-mould, but with a difference, or, indeed, several. It is found only near the coast, in a district comparatively limited, swept by the lively breezes of the North Sea. They are loaded with salt and fine sand, much finer than that on our shores. The 


\section{The Culture of Greenhouse Orchids}

leaves are of oak alone. It is alleged that growers who could not easily obtain the proper sort have tried beech-leaf mould - with disastrous results. It persistently bred fungus. Certainly the terre de bruyère which we receive from Belgium is a curious kind of earth, unlike any that I have seen in England. It must be stacked for two years to kill fungoid growths; but this is done before exportation.

Baskets are discarded; the vessel, whether pot or pan, should have no holes except the one at bottom. It must not be filled to the brim; leave three-quarters of an inch or so. Hitherto it has been supposed that the roots of an orchid like to feel the air; therefore baskets were used, and pots had holes in the sides, and the compost was very lightly spread. All a mistake! In that space of three-quarters of an inch or so above the mould, press chopped moss firmly, never less than half an inch thick, for the express purpose of excluding air. It seems to be a flat defiance not only of ancestral wisdom but also of common sense; but when we see that the outrage is not resented it becomes necessary to find a reason. And that is not difficult. Doubtless orchids like to have fresh air about their roots, but far more strongly they dislike to have sour or decaying matter there. 


\section{Potting Orchids}

Peat and moss were chosen because they resist decay so long. But if the roots be sealed up, so that air cannot reach them, evidently the germs of putrefaction must be excluded. As an enthusiastic supporter of the new heresy put it to me, the "chopped moss serves the same purpose as the paper stretched over a jam-pot."

Under these circumstances your plant must not be raised above the pot, on a little hill, as it used to be. The chopped moss may be level with the brim or below. It will soon take root. But those who like to see their plants green and neat from the beginning, as they were under the old system, may crown the moss, as formerly, with living heads.

The leaf-mould treatment is applied to all orchids without distinction, and with all it appears to be equally effective. But the system of watering differs. We have nothing to do here with stove or intermediate species, but I may mention that the water given to Cattleyas, Dendrobes, etc., should be only enough to soak through the moss and just damp the mould beneath. This is managed by using a very fine rose. Cool species, however, want almost as much water as if grown in peat.

It will be found that roots do not climb out of the pots so commonly as they did under the old method. 


\section{The Culture of Greenhouse Orchids}

I have heard an enthusiastic advocate declare that if sufficient depth of chopped moss be provided, they never rise above it, so attractive is the leafmould to their appetite. He exaggerated, but it is true that the roots are much more inclined to keep within the pot-and this is clearly an advantage if they draw sustenance from the mould; even if they do not, it is a convenience. For straggling roots get broken, dry up, fall a prey to slugs if there be any about. On this last point I had evidence a day or two ago. A monstrous slug found its way to my Odontoglots somehow. Had they been potted as formerly, it was big enough to do much mischief. But before I caught a glimpse of its slimy track, at midnight, it had passed from plant to plant over half a shelf, seeking what it could devour-and found scarcely a bite, for all the roots were covered up. Another curious fact asserted is that roots do not cling to the earthenware inside, and so do not get broken in repotting -an enormous advantage. Personal experience inclines me to believe that they do not cling so often or so strongly.

We return to our cool orchids. The leaf-mould treatment is quite as effective with them as with warm species; and all that has been said above applies, except the rule for watering. Odontoglots- 


\section{Potting Orchids}

and Oncidiums when growing-must be kept moist all through, and therefore they want almost as many crocks as in the old style, not one only. In fact, the treatment of cool orchids is little altered under the new system in this respect. Add about twenty per cent. of chopped moss to the leaf-mould. Belgians are not to be persuaded that the plants do not find actual sustenance in terre de bruyjere, whatever botanists may say; and therefore they must have plenty of it. Of course, the half inch of chopped moss on top must be added to exclude the air, as in other cases. 


\section{ORCHID PRICES}

Some years ago Mr. Ballantine, who has charge of Baron Schröder's peerless collection, made some remarks upon the beauty and value of Cypripedium Sanderce, which were published in the Pall Mall Gazette. The comments of that lively journal tempted me to write a couple of letters in explanation which may properly be quoted here. In the first place, they contain some facts of general interest; in the second, they point the moral thereof.

"SIR,-Mr. Ballantine is modest in describing Cyp. Sandera as 'finer by far than any other "Lady's Slipper" known,' and his estimate of one thousand guineas should be understood as a conventional phrase for priceless (1894). But the true story of the plant is more interesting than that you have heard, and not less dramatic. I chanced to be at St. Albans when it opened, and we have not nearly reached the last chapter.

"Messrs. Sander had imported a vast quantity of 


\section{Orchid Prices}

Cypripedium insigne, perhaps the cheapest of all orchids. Many had been sold 'in the rough,' the remainder were potted, and they filled a house of no small size. Most of them were showing flower at the time of my visit, but none had opened, and I strolled along with scarcely a glance at such familiar objects. But that is not the frame of mind befitting an orchidologist-I was younger then. Mr. F. Sander, who accompanied me, scrutinized every plant, and on a sudden, without pausing in his talk, he picked one up, surveyed it with interest, and laid it aside. I asked an explanation. 'Why, look,' said Mr. Sander, 'the natural colour of the flower-stem is brown, isn't it?'-there were some hundreds in sight, brown every one-'but this is pale green. There is some significance in that. I have seen very many thousands of Cyp. insiyne, but I never saw a green flower-stem before.' So the curiosity was treasured and tended, and in due time it showed a golden bloom instead of the normal green. This was $C_{y p}$. ins. Sanderce-unique. Others resembling it have turned up since, for collectors are instructed to seek green flower-stems; but none that approach the original.

"The sensation was prodigious. Messrs. Sander cut the plant in two, and, to aroid jealousy among 


\section{The Culture of Greenhouse Orchids}

their customers, they sent one half to public auction, when Baron Schröder bought it for 72 guineas. The other half they designed to keep and propagate. But Mr. Measures, of Streatham, a very great collector, would not be refused, and presently he secured this half for 100 guineas. The year following he cut it in two, selling one piece to his brother, also a great amateur, for 100 guineas; next year cut what remained into three, sald one portion for 100 guineas - to whom, I forget-kept one, and sold back the third to Messrs. Sander for 250 guineas. This is the true tale. Baron Schröder's piece has never been mutilated. As you say, it is 'indescribable and incomparable.'

"I may cite a few other instances. The case of Cyp. Stonci platytonium is, perhaps, the only parallel to this, but a volume would not exhaust our orchid legends. That plant also came unannounced, in a consignment of the ordinary $C y p$. Stonei. Sir Hugh Low cherishes a fond fancy that he sent it from Borneo in one of his parcels, but the record is lost. Platytonium made its appearance in the collection of Mr. Day at Tottenhamassuredly he paid but a few pence for it. At the sale of his plants in 1880 , two small bits were put up: Sir Trevor Lawrence bought one for $£ 147$; 


\section{Orchid Prices}

Baron Schröder the other for $£ 106$. Baron Schröder also bought the one offered for sale at Mr. Day's death, paying $£ 15912$ s.

"Mr. Day had given a piece to his sister. That also came into the market after his death, but it had never flowered. Curiously enough the trustees refused to guarantee it for more than three years, and Baron Schröder was allowed to carry it off for 160 guineas. The guarantee expired this season; immediately afterwards it flowered and proved true.

"The most valuable orchids as a class are the albino varieties of species normally coloured. I will confine myself to these. The first instance that occurs to me is the Cattleya Skinneri alba, which was one of the seven spotless champions exhibited by Messrs. Sander at the Orchid Conference. A good number of these exquisite monstrosities were found in the early days, all in the same neighbourhood, and it is supposed that they were seedlings of one plant which had escaped the vigilance of the Indians; for those people are not less passionately fond of the albinos than we, and they carry off every one they discover, to replant it on the trees surrounding their church, or on the roof itself. They are only to be bought now from the Cura, or to be stolen-which, in fact, is much the 


\section{The Culture of Greenhouse Orchids}

same thing, for the holy man dare not ask his congregation to part with their treasures.

"For this particular specimen, Hübsch, the collector, gave his gold watch and two mules. It was sold to Mr. Harly for 280 guineas.

"An albino Saccolabium Blumei turned up among a number of the ordinary kind imported by Messrs. Heath, of Cheltenham, who sold it to Mr. Lee, of Leatherhead. Baron Schröler bought it at his famous sale for 150 guineas. The Baron possesses two of these wonders, for he obtained a second from Messrs. Sander for 178 guineas. His also is the albino Erides Fieldingi, probably unique, but I have not heard its history.

"Mr. Blunt, a coffee-planter in Brazil, found a white Cattleya Mendelli, when travelling for amusement in Colombia. He sold it to Mr. Day, who cut the plant in two, and disposed of the half to Mr. Philbrick, Q.C., for 100 guineas. The remainder he divided, and at his sale the pair went together for 280 guineas.

"When in Paris, once on a time, Mr. F. Sander received a telegram informing him that a Cattleya Triance, one of an unconsidered batch, had opened a flower of the normal colouring, but glorified beyond belief. He returned home at once, telegraphing Mr. Lee, of Leatherhead, to meet him and behold 


\section{Orchid Prices}

the marvel. From the door of the long house Mr. Lee caught sight of it. He was a man of few words, and he only said, 'How much?' The bargain was struck in the doorway at 250 guineas. This plant was divided into five pieces afterwards, and Messrs. Sander offered 600 guineas for the lot. They had increased to seven when Mr. Lee's collection was dispersed, and they fetched 700 guineas.

"At the very first sale of Dendrobium Schroderianum, a small grower, who huys cheap lots, secured one for 26s. It proved to be white. A young American gave him a cheque for 115 guineas, sending it as a pretty present to her father.

"An albino D. Findleyanum turned up last year. Mr. Ashworth made a wonderful bargain in obtaining it for 50 guineas. White $D$. nobiles are not uncommon-that is, comparatively-but only one has yet been found quite pure, and that appears to be lost. All others have a faint touch of sulphur on the lip. The best come from the Langtang Mountains. All are lovely, but $D$. nob. virginale, the first discovered, is still without a rival. Fifteen guineas will buy a nice example of the other varieties. At this moment there is in flower at St. Albans the grandest of white Dendrobes-Sanderce: very large, bearing thirty or forty flowers on each stem, snowy white, saving a touch of mauve 


\section{The Culture of Greenhouse Orchids}

in the throat. But this is a species, not an albino -absolutely new and unique, unheard of even, no price can be set on it. Orchidists may be relieved to hear that a trusty man is on his way to collect myriads-if he can find them.

"One or two little stories to encourage the thrifty amateur. Among the first importation of Odont. crispum which Messrs. Sander despatched to the Continent, a lucky Frenchman obtained a piece for a few francs, which proved to be Odont. apictum, still unique. Messrs. Sander bought it back at such a long price that there was no extravagant profit in the 150 guineas which Baron Schröder paid them. The first Odont. vexillarium superbum appeared in a lnt which Mr. Bath, of Footscray, bought at an average of $10 \mathrm{~d}$. each. He disposed of it at auction to Sir Trevor Lawrence for 72 guineas. Messrs. Sander once sold a quantity of Odont. Pescatorei at 2s. 6d. each (about); an amateur at Reading found among them a natural hybrid of Odont. Pescatorci and Odont. trizmphans, which he returned to St. Albans in exchange at the rate of 60 guineas. But there is really no end to such cheerful legends."

A second letter:- "Sir,-Companions of our pleasant mystery point out that the uninitiated may find confirmation of a gross popular error in 


\section{Orchid Prices}

my article on 'Orchid Prices' published on the 29 th November. Rearing of multitudinous guineas paid for this or that variety, they may overlook the humble shillings casually mentioned as the value of the same species. It would be a result as strange as deplorable, seeing how I have always striven to demonstrate that cool-orchid growing for the modest bourgeois is scarcely more expensive than any other form of culture which demands a greenhouse. But I fear that it may be so. I ask your leave to explain. "The letter was suggested by an allusion to Baron Schröder's Cyp. insigne Sanderce, which is probably the most valuable of orchids-as yet known, that is *-and in dealing with it I naturally spoke of others which belong to the same class. But they fetch extraordinary prices because they are exceptions-'sports,' with which Nature indulges herself from time to time. The 'type' (of equal size and average beauty) is worth from $2 s .6 d$. to $5 s$, because dealers will supply thousands at that rate to order; but all the dealers in the universe could not supply one of this perfected variety-unless, of course, it were an offshoot from the single plant which $\mathrm{Mr}$.

* I leave this statement unaltered, because it was true at the date. But Cypripediums can be multiplied fast, and every mortal who possessed a bit of $C$. Sandera bas been dividing it at the earliest moment ever since. Thus, in 1901, a small plant, but healthy, can be bought for ten guineas. 


\section{The Culture of Greenhouse Orchids}

Sander discovered, as I have told. This is all the secret.

"If it be asked why such astonishing variations occur in this botanic family, while so many others reproduce themselves as methodically as peas, no one can answer. But orchidists are wont to assert that two flowers, even on the same stalk, are never identical, unless white or self-coloured. If this be not true, it is scarcely more inexact than the common statement that no two men or women are precisely alike in feature. We know that such cases have been found; and so, on careful search, identical flowers of an orchid may be discovered. But under such conditions it is not really surprising that from time to time Nature breaks right away and produces something abnormal.

"Here are a few instances. Cyp. Stonei platytcenium was mentioned in the preceding letter, but I did not name its peculiarities. The type Stonei is very pretty; it has none of the dull browns and greens so prevalent among Cypripediums. The colouring is all lively-white, striped with red and shaded with lemon green. While following the general design, almost every plant among millions differs more or less, and a single one carried variation so far as to produce a bloom twice as large as its fellows, more richly coloured, with 


\section{Orchid Prices}

petals four times as broad. This is Platytcenium. The value of it can be measured only by the sum which certain of the richest men on earth are willing to pay for a treasure which all covet. Of its legitimate parent-Cyp. Stonci-you might buy hundreds at the price a morsel of this eccentric offspring fetches.

"So the Erides Lawrencice, in possession of Sir Trevor Lawrence, brought 255 guineas. It is a very rare species. There are not more than a dozen, perhaps, in cultivation, though many Er. Sanderiana pass under that hallowed name.

"Perhaps I should do well, however, to confine my remarks to one species, and Lcelia anceps is the most convenient-cheap, familiar for sixty years, easily grown, flowering in winter, and universally admired. In the first place, no orchid has a more steady sale or a price better established. Five shillings is the charge for a flowering plant at every dealer's, and-remark-at that rate he would as soon sell one which has not yet opened its buds in this country as one which he has seen and proved to be nothing uncommon. So rare are exceptional varieties that it is not worth his while to refuse a customer who offers five shillings, on the chance that any given plant may turn out a marvel worth a hundred pounds. 


\section{The Culture of Greenhouse Orchids}

"Once upon a time, then, Messrs. Sander received above a hundred cases, containing many thousands. Among these his collector had marked four; he had not seen them in bloom, but from appearances generally be fancied they might differ from the bulk. They were put aside accordingly. Some days afterwards the late Mr. Harvey, solicitor, of Liverpool, paid a visit to St. Albans, remarked the four plants, and begged one. The circumstances were explained to him, but he persisted; and although in this instance the dealer had been warned to expect something unusual, the issue was still so uncertain that Mr. Sander gave way, asking two guineas, however, instead of the regular five shillings.

"Some time afterwards Mr. Harvey brought back the plant and sold it to Messrs. Sander for 220 guineas cash. This glorious variety is now called L. a. Amesiana, after Mr. Ames, of Boston, U.S.A. It has rosy sepals, petals with erimson tips, and a lip of darkest maroon.

"Yet another story of the same kind. Messrs. Sander once imported a quantity of Cattleya intermedia, among them one which the collector labelled 'white.' The assertion was so incredible at that time that, in reading it, men simply laughed. Mr. R. H. Measures, of Streatham, called, saw the label, and asked a price. In vain he was told that 62 


\section{Orchid Prices}

a white Catt. intermedia passed the bounds of Nature's eccentricity. After assuring himself that the collector was not a man to play practical jokes, he shrewdly judged that the chance was worth ten guineas, and offered that sum-the normal price of this species also is 5s. Under the condition, gravely imposed and accepted, that he took all the risk of disappointment, Mr. Measures carried off his prize. It was Catt. inter. Parthenia, white as snow. Others have turned up among the hundreds of thousands imported before and since, but none compare with the earliest.

"I return to Latia anceps. No one, happily, had fallen in love with the three marked specimens remaining, and in due time they flowered. First came Ballantiniana, named after Baron Schröder's famous gardener, also rosy of sepal and petal, but, unlike that other, flushed with purple at the tips. The third proved to be a very fine example of the usual colouring, not otherwise remarkable. The fourth was Schroderce-deep rose in sepal and petal, the latter purpling at the tips, with a labellum so darkly maroon that it is termed black. Baron Schröder bought it at a long price. In this instance, therefore, three plants out of an importation not less certainly than ten thousand proved to be so exceptional as to merit a specific name. 


\section{The Culture of Greenhouse Orchids}

"We come to the white varieties, which some think the grandest and most saintly of all flowers that blow. The commonest variety-still, alas! far too rare for humble amateurs-is Stella, absolutely snow-white, unless occasionally rose markings show upon the lip; but the throat is yellow, with purple lines. More treasured by the lordly is Dawsoniana. A single plant was sent home twenty years ago by a gentleman travelling in Mexico to Messrs. Low, of Clapton; not one has been found since, and from this all plants in cultivation are descended. It has white sepals and petals, and a dark lip. Sandericana is like to it, but the petals are longer and narrower, and the lip is margined with white. No less than three examples of Virginalis have turned up, snowwhite, saving a lemon-yellow throat with maroon stripes. Most glorious of all is L. a. Schroderiana, six inches in diameter, with a broad, square lip, striped chocolate-red and lined with gold. Several appeared in one of Messrs. Sander's importations ten years ago. The collector was chevied by telegrams for months, but he could never find more. There are perhaps a dozen in cultivation now.

"It would not become a Christian man to finish without telling his fellow-mortals where they may behold beauty which he really holds to be the supremest effort of beneficence. Go to Lord 


\section{Orchid Prices}

Rothschild's at Tring. A house there is devoted to white anceps, and some hundreds of spikes may be seen at one time in the season. Or go to Baron Schröder's at Egham. There also is a honse full of them; in the place of hononr, like a divinity

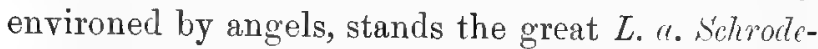
ricune, with as many as sixteen spilies of its own."

After this statement readers will perceive, I trust, that any sum paid for an orchid, however monstrous, may be reasonable. He who would have an object of excessive rarity, which a large proportion of the richest men on earth desire, must outbid them, whether it be a plant or a picture. But orchid-growers at large have no more personal concern with these than with a canvas of Raffaele's - saving always the joyous privilege to hope that such a marvel will turn up in their own small collection.

When I resolved to make my little book as useful as possible by giving the price of orchids named therein, it became necessary to chuose a system. One might obtain the quotations of the auctionroom without much trouble; but, in the first place, the majority of readers would be misled rather than assisted by such returns, seeing that they do not attend the sales nor want unestablished plants; in the second, prices at auction vary from week to 


\section{The Culture of Greenhouse Orchids}

week. To strike an average in such a case would not be practically serviceable. It seemed best, on the whole, to take the price-list of some leading dealer, and, if so, one who could be trusted to supply any demand at a moment's notice must be chosenwhich means, in effect, the tradesman who has the largest stock, provided that he sells as cheaply as others. Such conditions pointed to Messis. Sander, of St. Albans.

The price quoted refers to a single established plant, which will certainly flower in its season if properly treated; but small-growing species, such as Odont. Rossii majus, for example, are reckoned as one, whatever the number of bulbs clustered in a pot, or the number of flower-spikes they bear. Larger plants, or more in a pot, can always be obtained for a sum proportionate. 


\section{SPECIES AND CULTURE}

ADA.

This name has no significance; it was bestowed by Dr. Lindley, after a lady unknown. The genus has but two species.

Aurantiaca (orange). - Valuable for its coloura lively orange-scarlet; it would be beautiful if only the flowers would consent to open. That is a great objection in my eyes. Occasionally, indeed, one beholds specimens-grown on the Continent, or in some spots of this country where the light is strong-which show such dense garlands of flower one scarcely notices that the indiridual bells are half-shut. Peat and moss, or the Belgian system. The culture, as in so many instances to be dealt with hereafter, is that of Odontoglossum crispum, which see. Ada aurantiaca never gives any trouble.

The spike pushes from the side of the bulb when approaching maturity - that is, when beginning to take its rounded form. Six or eight flowers only can be expected, but it will bear twice as many under exceptional circumstances. They are very 


\section{The Culture of Greenhouse Orchids}

brilliant in colour, but closed except the tips, which curl backwards. Blooms in spring. Nerw Granada. A very early introduction. 5 s.

Lehmanni (Mr. Lehmann, German Consul in Columbia).-Rare. Somewhat darker in hue, and the lip white. Snmmer. United States of Columbia. 1890 .

\section{Frides. (Air-plants.)}

Of this charming genus we have only three species, unfortunately, in the cool house.

Japonicum (Japanese).- Small, as would be expected, coming from a land so cold, but the flower is not insignificant-greenish white, with small bars and spots of violet. Peat and moss, or the Belgian system. A basket close to the light is best for it, with many crocks for drainage, a little peat, and living moss. The plant is easily fixed, because it has large roots. Keep it wet while growing. In fact, it must never be dried at all, though when at rest, of course, it needs much less water. Summer. Japan. $7 s .6 d$.

Odoratum (scented).-A large free-growing plant, with creamy-white flowers, spotted and tinted with magenta. Very fragrant. Summer. East Indies, Cochin China, etc. 3s. 6d.

Itudarmm (of the Vandas, from the resemblance 


\section{Angræcum}

of its rush-like growth to that of $V$. teres and Hookicianc().-Pretty white flowers, with a touch of pink. Summer. East Indies. 42s.

\section{Angrecun.}

From the Malay Angrec, which means simply a parasite of any kind. The name has gradually been limited to one genus, which, curiously enough, is peculiar to Africa and Madagascar, excepting the species described - the only cool one.

Falcatum (sickle-shaped). - This dainty little plant comes from Japan, many thousand miles away from all its kindred, and we may assert with confidence that none are found in the space between. Was it introdnced by those skilful and enthusiastic gardeners so many centuries ago that it has run wild and changed its appearance?-for no species like it has been found hitherto in Africa. If so, it must be credited that the Japanese once traded as far as Madagascar at least. That becomes more probable when we remark that they have a species of Frides, and one of Dendrobium, similarly diminutive. Both of these latter genera, indeed, are Asiatic, but their nearest representatives flourish two thousand miles and more to the southward.

Fulcutum may be grown in a pan, block, or basket. It must be near the light. On a block it 


\section{The Culture of Greenhouse Orchids}

needs water daily while growing-twice a day in hot weather. The other methods, therefore, are more convenient. If a pan be used, it must be three-parts full of crocks, a little peat over them, and abundance of living moss. Fix the plant securely, by copper wire if needful; but cut away the wire as soon as it is rooted. Keep it thoroughly moist while growing, and slightly moist while at rest.

The flower is very small, but very elegant and sweet-scented, white, with a long "spur" or "tail" -the peculiarity of the genus Six, or even more, are produced on a short spike. Winter. Japan. 1846. 10s. $6 \pi$.

\section{Barkerta.}

(Named after Mr. George Barker, an amateur. N.B.- Barkerias are now included among Epidendrums.)

Those who love to see the big tender roots of orchids rejoicing in the pride of youth and strength, find Barkerias specially fascinating. They have that charm more conspicuous even than others.

Most people grow these pretty slender plants on blucks. The anthorities at Kew have a fancy that they do best when tied to sprigs of thoru or apple set in a basket of moss. Probably situation is the point of real importance. If Barkerias can be 


\section{Barkeria}

granted a place where they get several hours of sunshine on the hottest day, yet without risk of burning, and where ventilation is free, though the atmosphere be always saturated with damp, it matters little how they be established. But those conditions imply that they shall be close to the glass, and therefore a block or basket is necessary in most houses.

Differences also may be observed in treatment. Some recommend water twice a day in summer, and once a week at least in winter. Doubtless this answers in their case, but it would be too much generally. One may put it more safely that Barkerias should be kept soaking while in strong growth, dried off grailually in late antumn, and granted but very few waterings through the winter. Under that treatment, indeed, the plants will shrivel alarmingly, but when the moisture is renewed in spring they plump ont and thrust their dainty roots abroad with a corresponding vigour. I presume, in fact, that they shrivel equally in those houses where they are not so thoroughly dried, because there is less moisture in the air; otherwise, apparently, they would not get sufficient rest. The temperature must not be less than $50^{\circ}$ in winter.

The flower-spike pushes from the top of the pseudo-bull. 


\section{The Culture of Greenhouse Orchids}

Elryans.-Dark rose, lip flat and sponn-shaped, white freckled with purple, towards the end a great square blotch of crimson. Spring. Mexico. 5 s.

Lindlcyana (Dr. Lindley, the great botanist).--A much taller plant, with a general resemblance to the above; but the colour is purplish, and the crimson blotch upon the lip has a white centre. Autumn. Mexico and Costa Rica. 5s.

IIclanocanton (black stem).--Rosy lilac, the lip reddish purple, with a patch of green in the middle. Summer. Costa Rica.

Shinneri (Mr. Ure-Skinner, who discovered it).The showiest of the genus. Its spikes may be two feet long, bearing twenty or thirty rose-coloured flowers of good size. The lip is paler rose. Winter. Mexico and Central America.

Spectabilis (handsome). - The plant is small, but its flowers the largest of any, eight to ten on a spike; rosy lilac, lip white at the throat and down the centre, with red dots, margined and tipped with rose. Summer. Mexico and Central America.

Bifrenarta. (Double band.)

Bifrenaria Harrisonia.-This is the correct name of the familiar Lycaste Harrisonice. I mention it under that title. 


\section{Bletia}

\section{Bletia.}

\section{(Don Luis Blet, a Spanish botanist.)}

Only one of this genus is usually grown in the cool house ( $B$. hyacinthina), but all those named will do very fairly. They are terrestrial orchids, needing fibrous loam and leaf-mould, with enough silver sand to make the compost porous. Terrestrial orchids, unlike epiphytes, take mourishment from the material in which they are planted, and enough of it must be given. Therefore a pot of good size should be allowed them, and it is not to be three parts filled with crocks, as in the other case. Two inches at the lottom will suffice, then a lixyer of moss and the compost, not rammed hard. The bulls should be just covered.

Bletias must be very wet while growing. When the flower-spike shows, manure-water may be given with advantage twice a week, but very much diluted. After flowering, the bulbs need perfect rest. They may be repotted in January, but very little water should be given till the young growth appears.

The flower-spike pushes from the base of the bulb when mature.

Campanulatu (hell-like). - Not showy, hut pleasing in colour. Purple, with white lip. Flowers irregularly. Mexico, Peru. 


\section{The Culture of Greenhouse Orchids}

Hyacinthina.-This species is hardy in some warm districts. It bears many flowers of good size, rosy purple, with a white lip, streaked, spotted, and edged with crimson. The most popular of the genus. China. 1802. 2s. 6d. to $10 \mathrm{~s}$. $6 \mathrm{~d}$.

sherrattiane (Mr. Sherratt, gardener at Knypersley).-Very pretty, and nuch taller than the others. The spike is often three feet high, with twelve large flowers, bright rose, the lip darker, its white throat traversed by three orange lines or ribs. New Grauada. 1867.

Vurceunda (modest). - Not impressive, but always interesting as one of the two orchids first cultivated in this country. Cypripcdium spcetabite, from the United States, was the other, both recorded in 1731. B. verecunda is tall, with branching spikes, many-flowered, reddish purple. Florida.

Brassia.

(Named after Mr. Brass, botanist and African traveller.)

Verrucosa (warty) is the single cool species of this genus. It is grown with peat and moss, or Belgian leaf-mould, in a pan, well watered in summer, and well dried in winter, but the bulbs must not be allowed to shrivel. The flowers are many, of large spread, but curiously narrow. 


\section{Cattleya}

Natives term the genus "Squid Flowers," perceiving a resemblance to the cuttle-fish in their long thin arms; but it is not striking in this species. The sepals and petals are pale green, spotted with black; $l_{1}$ white, covered with small green "warts," or knobs. It is not to be recommended, perhaps, where space is limited. Late spring. Guatemala. 1838. 3s. 6r.

\section{Cattlera.}

New species of this grand geuus-which takes its name from Mr. Cattley, of Barnet-are still leeing discovered, but there is little hope that the cool house will receive an addition to its solitary representative there. We must be content with-

Cattleya citrina (lemon-coloured); and it is a beauty. This plant persists in growing head downwards, for the reason, as is alleged, that it clings to the under side of branches. I have seen no confirmation of the statement, which looks improbable, since Cattleya citrina evidently loves the sun; but we must not rely upon mere probabilities in dealing with orchids. Some growers as persistently set it the right way up, and it does very well for a time, though obviously struggling to hang its young bulbs over the edge of the pan or basket. In the long run, doubtless, this unnatural 


\section{The Culture of Greenhouse Orchids}

position would ruin it, but there is a general impression that Cattleya citrina will not live more than a few years anyhow. I have two plants, however, bought in 1889, which will give me several flowers

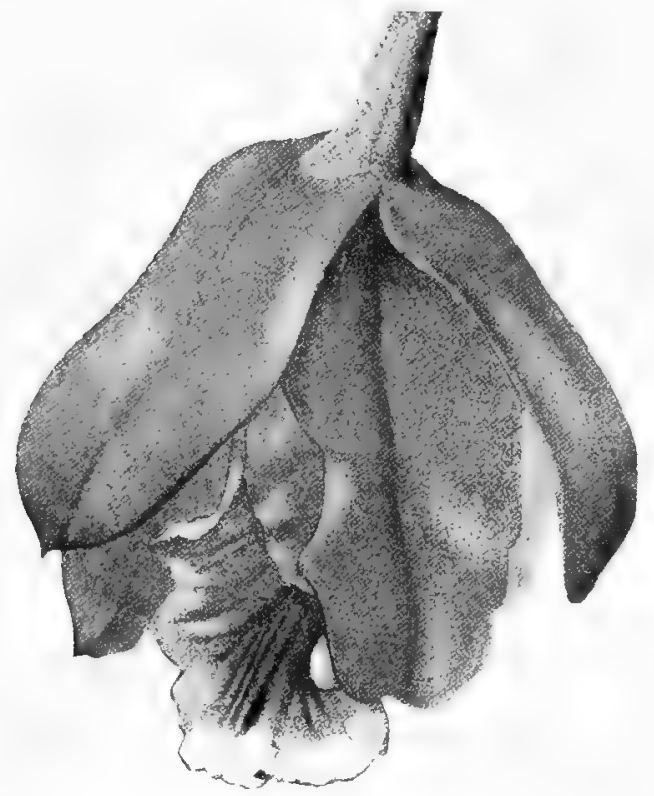

CATTLEYA CITRINA.

this spring; but they will be the last, evidently. I grow them in laskets, suspended by the two upper corners only; thus they follow their instinct. But when the bloom is opening, the basket may be 76 


\section{Cochlioda}

hung straight, so that the handsome yellow bells drop over the side in a conventional manner.

Cattleya citrina grows freely, so long as it lasts, if a place can be found for it where shade is not needed until the summer sun gets strong. In a basket, with lumps of peat and abundance of moss, suspended as I say, facing the light, it must be kept thoroughly moist until the head of the flower peeps between the leaves. I find that watering twice a week is sufficient; in fact, I do not look at the baskets between times, however hot the weather. In May I whiten the glass above them. After August one watering per week is enough. The flower begins to show early in December, and water must be diminished gradually; they want a little more attention then, for when the bud has pushed an inch or so, the plant must be allowed to dry-not to remain dry, however.

The flowers are bell-shaped, large and pendulous, lemon-yellow in colour, very fragrant. Spring. Mexico. 1838. 5 s.

\section{Cochlioda.}

(Like a snail-shell, referring to the shape of the column.)

This genus used to be called Mesuspinidium, and the old name is still applied by every one, or almost, to three of its four species. 


\section{The Culture of Greenhouse Orchids}

Cochlioda are closely related to Odontoglossum, and they demand similar treatment in all respects. Coming from the high lands of Peru, however, they like the coolest situation in the house.

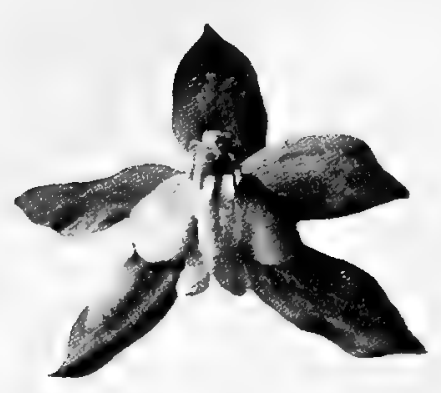

COCHLIODA NOETZLIANA.

C. Noetaliana (M. Noetzli, a Belgian amateur).This was advertised as a scarlet Odontoglossum when first brought to the auction-rooms, and though the description was inaccurate, it tuld the public what 


\section{Cœlogyne}

to expect. Sophronitis is not a more brilliant red. If possible, it should be hung up in a temperature not exceeding $40^{\circ}$ during the winter. Mr. Oversluys found Cochliada Noetaliana growing upon bushes in a situation where it must be frozen hard sometimes. Under such conditions it will push a spike eighteen inches long or more. That rarely happens in cultivation, but a wreath of ten or fifteen flowers is common enough. And that makes a spectacle to remember. The hlooms are curiously depressed from the centre outwards like a boss. The column, "like a snail-shell," is violet, and the disc golden, setting off the vivid scarlet of petal and sepal to the uttermost. Peru. $7 s .6 d$.

\section{Celogyne. (Hollow stigma.)}

So many of our cool orchids are American that natives of the old World may feel it a pleasant change to hear of a genus all their own. Cologynes dwell in the East Indies, Assam, Nepaul, especially the islands, Java, Borneo, etc. Though not so bright in colour or graceful in form as many genera of orchid, they have a varied beanty, an asthetic finish-in the proper meaning of that ill-used adjective-which appeal to the higher taste. The loveliness of Odontoglossum crispum is perfect. It may rightly be termed angelic, if angels be all 


\section{The Culture of Greenhouse Orchids}

purity and sweetness. The beauty of Cologynes is classed in another order. Some are white and gold, but among those which have stronger colouring every touch seems to show conscious thought and design; in fact, no arrangement of hues, even among orchids, has such elaboration. Yet the tints employed are amazingly fer, to produce such variety of effect. One might think that Nature resolved to show how many and how striking are the combinations of white and brown, or yellow and brown, that may be used in a single flower. Of all the great family, not more than half a dozen depart from this rule of colouring-but how gloriously it is diversified! And one of the very few exceptions, which have neither white nor yellow nor brown in its tones, is most striking of all. Exquisitely tender green is Coelogyne pandurata, with hairy stripes jet black. That harmony could not be surpassed.

We have no concern with these supreme marvels in the cool house, unfortunately, but it does not become us to lament. There are beanties in our department, and they mostly flower in the dull months.

Coelogynes do best when hung up, no doubt, but the larger species are most conveniently handled in pans, set as close to the glass as is safe. If the Belgian system be not used, they demand peat and moss and ample drainage, for a daily watering is 


\section{Cologyne}

not too much for them in hot weather during the time of growth. When at rest, also, they shrivel with disconcerting suddenness if dried up, and shrivelling is hurtful; but a resting season beyond mistake must be allowed. Probably, for circumstances differ, they may need water once a week at this time. The habit of flowering is mentioned in each case.

Barbata (bearded.)-A most striking flower. White, the lip densely fringed with brown hairs, and veined with hairs of a darker hne, making a crest in the middle. Flowers when growth is complete, but the spike appears months before. September and October. Assam. 1837. 7s.6d.

Corrugate (wrinkled.) - This will do in the cool house for two or three years, though it likes more warmth. White, the lip lined with yellow and striped with orange. Fluwers when growth is complete in autumn. Neilgherry Hills. 1863. 5s.

Corymbosa (Corymb signifies a peculiarity of growth, which to describe would be long).-A superb form of Cologyne ocellatc. Large white, with two yellow "eyes," margined browu, upon the lip, yellow and brown markings in the throat. Flowers from the made-up bulb in summer. Khasya Hills. 1866. 5 s.

Cristata (crested.)-Every one knows this divine 8 I 


\section{The Culture of Greenhouse Orchids}

orchid, though it may be unconsciously. Such a favourite it is, so easy to grow and so valuable in the time of flowering, that market-gardeners who "would not touch an orchid," as they say, keep a big house or more filled with it, for cutting. We scarcely see a bouquet in late winter and early spring without examples of Cologync cristatu. 'The description, therefore, may be very brief, which is comforting, for to do such beauty justice would defy my command of words. It will be enough to give a hint for the benefit of those unacquainted with the name of a flower which assuredly is not unfamiliar to their eyes. I would only say, therefore, that it is white as snow, three or four inches across, prettily waved, with a blotch of pale yellow on the lip, and lines of golden hairs marking the ridges. Six or even seven may be borne upon a spike, though three unfortunately are more usual. And they last a month.

The plant will do well enough in the cool house the year round; but if more heat can be given it while growing, so much the better. It comes from the hills of Nepaul, where the rainy season is very close and warm, and the summer terrible; during the former it flowers and makes growth, during the latter it dries up. The Cattleya house, therefore, or even the stove, suits it best while the pseudobullos are swelling, but a great difference of 


\section{Cologyne}

temperature is required when they have reached their full size. The change which Nature gires is from steamy warmth to hlazing heat, which arrests all vegetable growth. We could not possibly

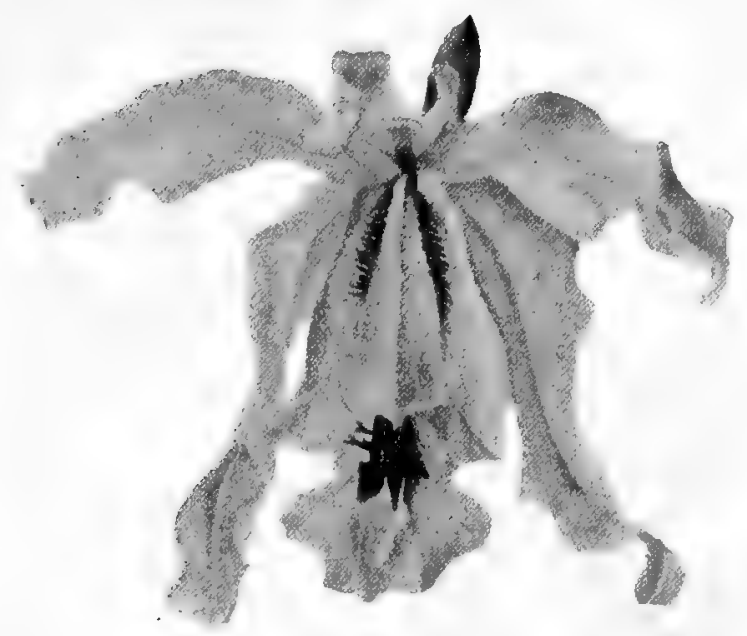

C'CLOGYNE CRISTATA.

imitate that system, as has been explained; so we reverse it, and plants are at least as happy. Instead of "resting" them by intense heat, we rest them by judicious cold. Though Coelogyne cristrto be 83 


\section{The Culture of Greenhouse Orchids}

grown among Cattleyas, it should be transferred to the cool house to flower, and the amateur need nut concern himself much if he be unable to give it more warmth at any time.

In another respect also the natural law must be brokell. We are told that the plants favour bare slabs of limestone, over which the water flows all day and night during the tremendous rains of Neparu; whilst in the heat, not less tremendous, they burn the hand. Accordingly the pseudo-bulbs, sleek as an egg while that deluge lasts, wither and shrivel to the size of marbles. If we suffered them to do so, all our skill and attention would not bring them round again. They should not be permitted to shrink at all-that is, the bulbs of the season just finished, which we expect to flower presently. The Anglo-Indian may protest that such treatment is an outrage on nature, and nobody can say a word in its defence theoretically. The plants ought to rot if kept moist at a season when they are dried like sticks at home. One can only reply "They don't," and yield the argument.

Coelogyne crisiata flowers just as the young growth is pushing, from January to March. It was introduced as long ago as 1837, and the examples we have multiply so fast that there is not the slightest call for new stock. Nepaul. 3s. 6d. 


\section{Colax}

There are several varieties, so common now that they should be mentioned.

" Chatsworth variety.-Flowers larger, more compact and in greater number on the spike. $5 s$.

" hololenca (all white).-The golden hairs are wanting.

"Lemoniana (Sir Charles Lemon).-The name is a sort of pun, for in this variety the golden bairs are lemon colour. $7 s .6 c$.

" maxima.-Flowers larger than usual, and more of them. $7 s .6 d$.

Ochrucen (ochrous).-White, with a pretty yellow horseshoe on each sille of the lip, edged with a darker tone. Strongly scented. Summer. Assam. $5 s$.

Odoratissinu.-Small, pure white, but a stain of yellow in the centre of the lip. Free flowering. March and April. Neilgherries. 1864.

\section{Colax. (A parasite-Greek.)}

We bave only one species of Colax, and that in scientific language is a Lycaste, but I use the familiar name.

Jugosus (yoked) is a special favourite with me. It has a great variety of colouring. One authority describes the sepals as creamy, petals white, transversely blotched with rich dark chocolate, lip streaked with blackish purple. Another, all creany, 


\section{The Culture of Greenhouse Orchids}

petals banded and lip striped with deep velvety purple; and so forth. I have a bloom of my own before me. It is ivory white, the petals thickly dotted with minute specks of crimson and maroon

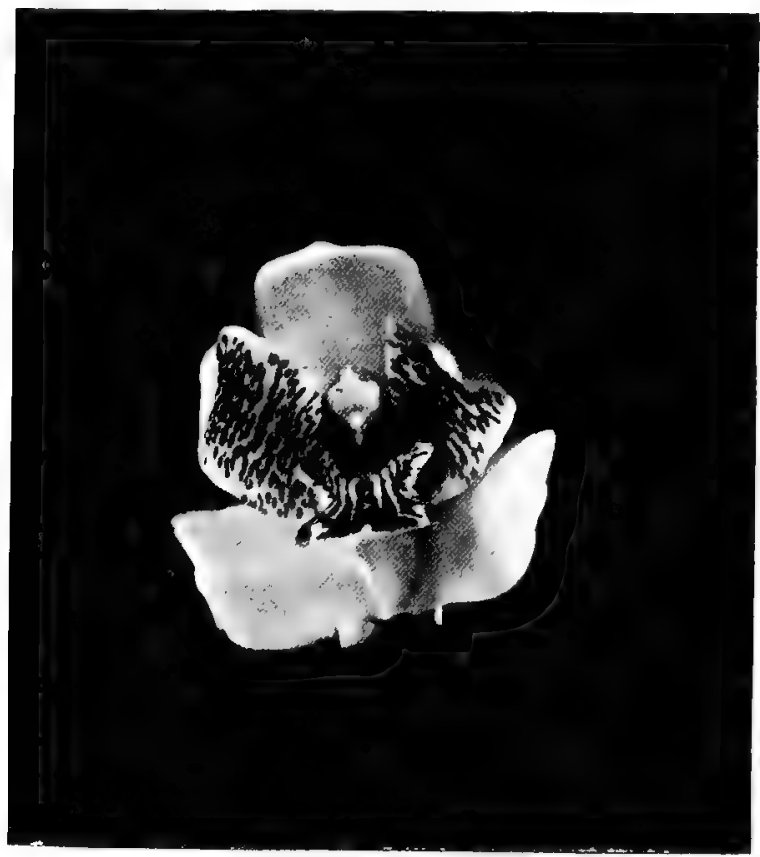

COLAX JTGONYS

-answering, by-the-by, to the description of Dr. Lindley which has been denounced as inexact-lip luroadly striped with purplish ultramarine. But the authorities are quite correct, and would be if 


\section{Cymbidium}

they disagreed much more widely. Two flowers of Cola' jugosus are never alike, but always exquisite.

M. Forget tells me that it is one of the commonest weeds in certain parts of Brazil ; upon the banks of a river he named it would be possible to gather scores in an hour. Hitherto this gem had been lodged with the Cattleyas, but upon M. Forget's advice I transferred it to the cool house, where it grows more strongly. A pot is best, with peat and moss. It requires as much water as Odontoglots while growing, and it must never he suffered to dry at all.

Colce jugosus flowers from the axil of the longer side-leaf when half grown in summer. Brazil. N.B.-Thrips have a great fancy for it.

By alliance with Zygopetalum several bybrids have been produced, called Zygo-Colax, all lovely :Z.-C. Amesianus, by Z. brachypetalum.

"Veitchii, by Z. crinitum.
" Wiganianus, by Z. intermedinm.
" leopardinus, by Z. maxillare.
" , , by Z. Gautieri.

Cymbidium. (Boat-shaped.)

Cymbidiums are large evergreen plants, demanding pots of a good size, for to shift them is an operation of the greatest delicacy. Their hig, fleshy roots are brittle as glass. It has to be done 


\section{The Culture of Greenhouse Orchids}

sometimes, for they grow very fast if comfortalle. In such cases the pot should be bound together with string, so that it will not fly to pieces when oroken. Then crack it with a hammer-place it, so shattered lut mot divided, in the larger pot, on a leel of crocks, support it, lightly, with crocks all round and lumps of peat, and cut the strings. Thus the roots, unbroken, will gradually force out the smashed sides to which they cling, and escape through the interstices. Peat, turfy loam--both in large fragments-moss, and sharp sand, are the potting materials. But the purdent amateur will never buy Cymbidiums unestablished, nor ever repot them before it is urgent. Great judgment is needed to start an imported plant. That work is best left to professionals. The Belgian system appears to be specially suited to these plants.

Cymbidiums rank among the orchids which certainly benefit by manure. A weak solution of cowdung may lie applied once a fortnight, or oftener if the plant be growing strong; but it must be stopped, of course, as the resting-time approaches. They will not bear to be dried at any season.

Affne (the word means "akin"-I do not under"stand its significance here).-- Of good size, white, the lip spotted with purple. Winter. Khasya Hills, India. $10 s .6 \pi$. 


\section{Cymbidium}

Elucrneum (ivory) grows fast and big. The flower appears from the axil of the side leaf after rest, in spring, one or two upon the spike. It is large and stately, white with pale yellow centre, the lip dotted with rose sometimes. Strongly scented. Found upon the hills from Bengal to China. 1840. 5 s.

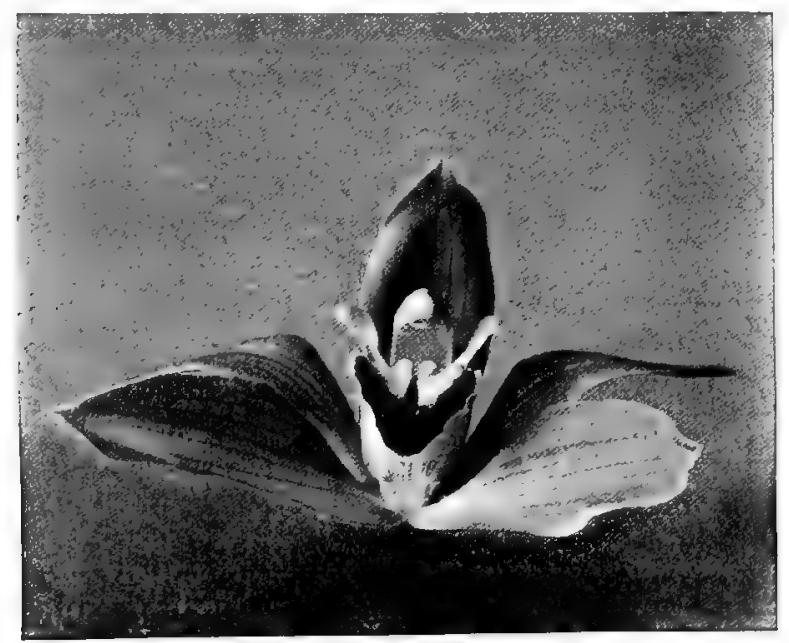

CYMBTDIOM Lowiandu. (Much rechuced.)

Lowianum.-A large species which grows very fast. The Duke of Northumberland has specimens at Alnwick, or had, four feet across, they say. The spikes push from last year's bulb three or four feet long, bearing many great flowers, varying in hue 


\section{The Culture of Greenhouse Orchids}

from pale green to greenish yellow. The lip makes a striking contrast. It is much lighter, with a blotch in the front, dark red-brown in the best varieties, paler in others, but always conspicuous. The flowers will last three months. Early spring. Burmah. 7s.6d. Figured, p. 89.

This species is certainly improved by a little weak manure-water from time to time while growing.

Mrestersi (Mr. Masters, botanist, Editor of the Gardener's Chronicle).- Tha same in colour, but atways dutted with rose, much smaller, and bearing six or more flowers in the spike. Strongly scented. January and February. Assam. 1841. 10s.6d.-

Tigrinum (striped). A very small plant comparatively, but bearing a flower of good size. Olive green, the lips white, barred with purple. Autumn. Moulmein. $21 s$.

Tracyanum (Mr. Tracy, a grower). Very large, sepals and petals greenish yellow, striped with crimson in dots; the lobes of the labellum yellow, with crimson stripes, dise white, spotted with erimson. Summer. Burmah. 105 s.

\section{Cypripedium.}

The worl means "Slipper of Cypris," one of the poetic names for Venus. In old English form, "Our Lady's Slipper." 


\section{Cypripedium}

Cypripediums are a most interesting family. They represent, as Darwin showed, an early form of orchid which Nature has improved upon and abandoned. Dependent, like all others, for the fertilization of their seed upon insects, they have survived, perhaps, the majority of those species which were adapted for their particular needs, and so their opportunities for reproduction grow constantly more hazardous.

But no plants are more comfortable in our houses. As though grateful to man for rescuing them from the slow process of extinction, they grow strong and fast with little attention; fertilized by hand, they multiply as no other orchids will, and they lend themselves cheerfully to hybridization.

All must he potted ; though not terrestrial, many are found in holes full of rotten wood and leafmould, or even in the earth. For this reason some growers mix fibrous loam with the peat and moss in which they are planted; but the advantage does not seem conspicuous. Having no pseudo-bulbs, however, to retain moisture, they demand more potting material to keep their large, fleshy roots lamp. Coarse sand, therefore, or roughly pounded rrocks and limestone, should be freely mixed with the compost, or it may get sodden; for whilst growing they can scarcely have too much water, and they must be quite damp when at rest. In 


\section{The Culture of Greenhouse Orchids}

fact, the resting of Cypriperliums is not distinct, but only comparative. The Belgian system may be used, of course.

All flower from the middle of the current year's growth when nearly completed.

Bouclli (Mr. Boxall, a collector).-Large, greenish; dorsal sepal-that which stands upright above the slipper -broadly margined with white, and spotted with darkish purple; petals and slippers stained with purple. January and February. Burmah. 1877. 5s.

Curicinum (sedge-like).-A charming flower if of a good variety; otherwise not to be recommended. Small sepals and petals, pale green with white margin, tipped rose; slipper grass green, with a row of black duts round the inside. Bolivia. 1863. 10s. 6d.

$Y$ Insigne (notable).-A species so familiar that I once remarked it among the exhibits of "window gardening" by the poorest inhabitants of Westminster; but this was the old-fashioned variety, superseded now, in which the whole flower was greenish. Not less than two score forms of $C_{y y p r i-}$ fectium insigne have been distinguished by name. The molern type from which they diverge more or less has a broad dorsal sepal, greenish below, speckled with brown, fading to a broad white margin 


\section{Cypripedium}

and tip, petals green with purplish lines, slipper green suffused with brown. It grows and flowers with singular freedom, the blooms lasting over four

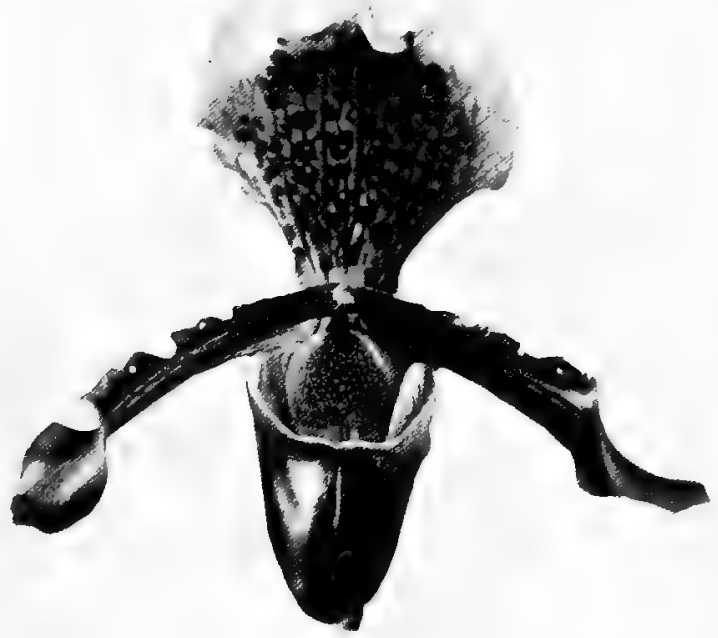

CXPRIPEDIUM INSIGNE.

weeks at mid-winter. Nepaul, Sylhet. 1820. 3s.6d.

Among the varieties, which would occupy a page in mere enumeration, I shall notice only-

"Samierce (Mrs. Sander), because that form 


\section{The Culture of Greenhouse Orchids}

is so strangely distinct and so renowned. The green throughout is replaced by clear yellow; the white of the dorsal sepal remains, but its brown spots vanish, excepting a few at the base. This unique plant turned up in an importation of many thousands made by Messrs. Sander, of St. Albans, in 1890; in my article on "Orchid Prices," supra, I have told its early adventures.

Schlimii (Mr. Schlim, a collector).-Rather small, but unusual and pretty in colouring-white, pink, and deep rose. So free in blooming that it is commonly sajd "to flower itself to death." New Granada. 1866. 78.6 .

Venustum (beautiful).-Useful, if not striking. Dorsal sepal greenish white, striped purple; petals greenish, spotted and tipped with purple; lip yellowish, tinged with purple. January and February. Nepaul. 3s. 6d.

$\checkmark$ Villosum (hairy).-Dorsal selual green, fading to white at the margin, which is set with brown hairs -hence the name; petals and lip yellowish, inclining to orange. The whole flower, which is large, shines as if varnished. Jannary to May. Moulmein. 1833. 5s.

Many hybrids have been raised from one or other of these, but in every case, I think, the other parent belongs to a warm species, and the progeny is warm. 


\section{Dendrobium}

\section{DENDRobiun. (Living on a tree.)}

Dendrobiums belong to the hottest regions of the Old World, except one Australian species and one Japanese. But in India there are three which grow at such elevations that the cool house suits them.

If the Belgian culture be not used, they should be potted in peat and moss-not more than is needful to keep them mnist, however, and that should be mixed with roughly-pounded crocks. Keep them near the light. While growing they need abundance of water, but not the excessive quantity demanded by their sisters in the stove, because the evaporation is so much less in an unheated house. The quantity found sufficient for Odontoglots is enough for them. They must have a distinct rest; but the wooded hills they inhabit even in the tropics are not burnt up like the plains. They must be watched more carefully, therefore, to prevent shrivelling. Water should be given nut less than once in ten days, perhaps once a week.

All flower from the upper part of pseudo-bulbs made last year or in years previous. Until these are quite unmistakably dead it is rash to cut them off, for buds appear in their season under the most unpromising conditions. 
The Culture of Greenhouse Orchids

There is one hybrid Dendrobium which will do in the cool house, though it likes more heat.

Cassiope (Japonicum $\times$ nobile albiflorum). Small, but very pretty, and more free in flowering

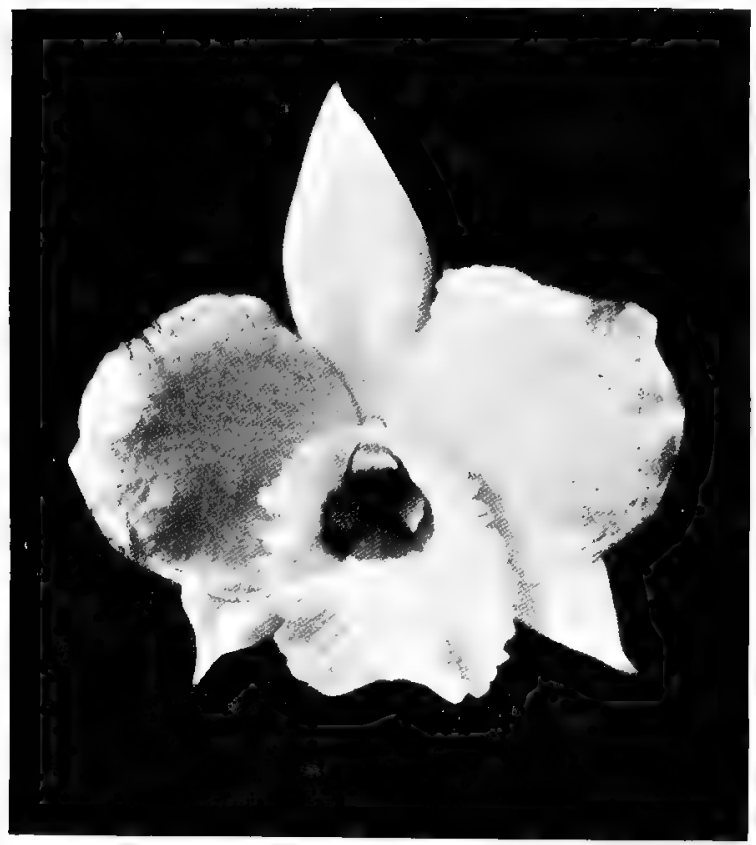

DENDROBIUDI INFUNDIBULUM

than any. White, with a purple patch on the lip. $5 s$.

Hilli. Vide Speciosum.

Infundibulum (funnel-shaped),--Large, handsome 96 


\section{Disa}

flowers, white, with a yellow or orange bloteh on the lip. April to June. Moulmein. 5s.

Jamesianum (after Mr. James Veitch).--Similar, but not quite so large, and the inside of the lip cinnabar-red. April to June. Moulmein. 5s.

Japonicum (Japanese).-Small, but very jretty. Pure white. Scented. Japan. Summer.

Kingianum,-Small, white, striped with violet. Spring. Australia. 10s.6r.

Moniliforme is a synomyn for Japonizum.

Ochreatum.-Orange, with a large red spot in the lip. April and May. Moulmein.

Speciosum (beautiful). $-\mathrm{A}$ species with very stout pseudo-bullss like cows' horns. Many-flowered and scented. Creamy white. It is best to keep this in the open air from July to October. Flowers January and February. The variety Hilli is much larger and stronger in all ways. Queensland. 1824. 5s.

\section{Disa.}

(Meaning unknown-a word invented by Bergius.)

Some Disas are found in tropical regions of Africa-they belong exclusively to that continent -but always on mountain-sides, where they enjoy a temperate climate. As a matter of fact, all those 


\section{The Culture of Greenhouse Orchids}

in cultivation are natives of Cape Coluny or Natal. But they are woefully disproportionate to the number of species existing there, most of which would be welcomed with enthusiasm if there were any chance of growing them. But they defy us as yet, saving two or three; and Mr. Watson, C'urator of Kew, an expert who speaks with the authority of a traveller, does not encourage the hope that we shall find means to conciliate them. It is difficult, one might say almost impossible, to reproduce artificially any approximation to the conditions under which these plants live at home.

A good many, indeed, even of the stubbornest, have been persuaded to flower now and again; but it was evidently an accident, resulting from circumstances which the triumphant operator is mable to recall. I myself rank among these. At a time when orchid-growing was still a mystery to me, I purchased some bulbs of $D$. connuto, planted them with innocent confidence, watched them grow and grow without surprise. Not till they were in bloom did I learn, by the excitement of Mr. Godseff, who chanced to pay me a visit, that I had achieved a feat un paralleled. There was no internal evidence, for a dingier object, to be called a flower, could not readily be found. But promptly it was begged for Kew, and most cheerfully despatched. Of course, I 


\section{Disa}

I had not noticed the exceptional conditions which must in some way have caused this success.

Other species of which record is preserved in our gardens may have flowered in the same irresponsible manner, perhaps. I shall not tempt my readers to waste their money by giving even the names; those of an alventurous turn can easily get the information.

Disas are terrestrial orchids, tuberons and deciduous, growing at home upon veldt or marshy uplands or in the beds of streams. The four species which I name belong to the second class. Dank clouds keep them tolerably moist even while resting. They should be grown in shallow perforated pans, for offsets spring very freely, and often they like to push through the holes instead of forcing their way to the surface; but the crown of the tubers should be raised well above it. The material is peat and moss in equal parts, with a little sand. Rotten manure may be added, or it may be given with the water when they are growing strong. They throw up a leafy spike from the crown of the bulb.

Cooperi. - Small, but pleasing. Rosy white, with a long anrl conspicuous "spur." Summer. Natal.

Grandiflora. - It is a mercy that this, most 


\section{The Culture of Greenhouse Orchids}

gorgeous of all the species - not to say of all orchids - gives no trouble generally. There are houses, indeed, where it will not flourish under the most skilful treatment, as there are others where it persists in thriving like a weed with very slight attention. The reason is mystery, but the fact is not surprising when we recollect how many Disas refuse to live with us on any terms. Accident often reveals a situation where the plant finds itself at home when perhaps all that seemed likely have been tried in vain; it may b3 an outhouse or an old frame. Accordingly there are amateurs and nurserymen who enjoy great renown for their success with Disa grandiflora; but they commonly own that the cause is as much a secret to themselves as to any one. In France and elsewhere the same juzzle is noted. But all this refers to a wild exuberance of growth. In most houses the plant will "do" with reasonable care, and the amateur may always cherish a hope that his will prove to be one of the faroured situations.

Disc grandiflore lives upon Table Mountain, and nowhere else, as is asserted, in South Africa, Every autumn those grassy slopes take fire, and constantly the universe is agitated by an announcement that the plant has been exterminated-burnt up. Such a disaster, they say, is possible, but 


\section{Disa}

hitherto the reports have been most pleasantly convicter of falsehood next spring. Disas have mure to dread, apparently, from collectors, private and professional, than from accident. So fast they

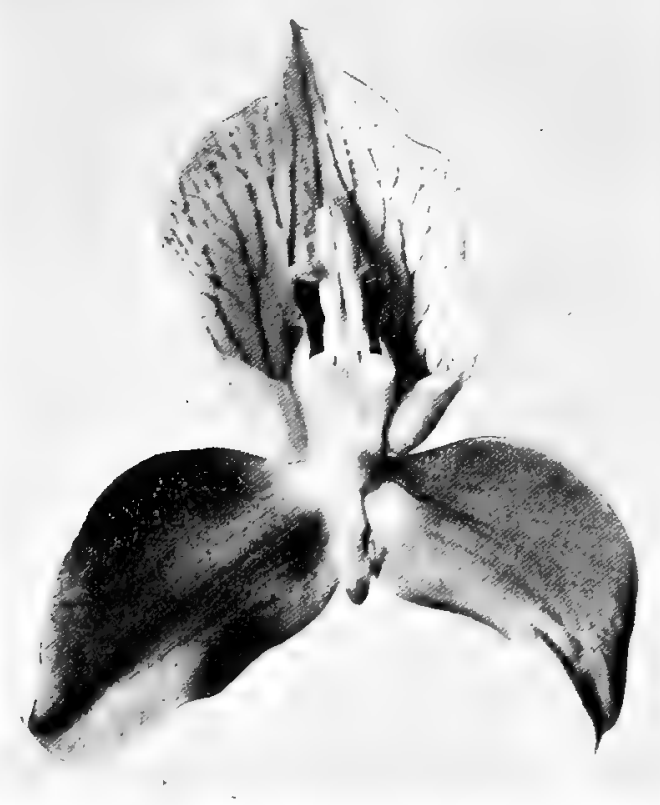

DISA GRANDIFlora. (Much reduced.)

were vanishing once that the Government, or some other most estimable authority, forbade gathering even the flowers under a heavy penalty. That is some ten years ago, and the rule, so far, is out of IO I 


\section{The Culture of Greenhouse Orchids}

date; but permission is still required, nominally at least, to dig up the tubers.

It may be asserted that those who have failed to grow Disa grandiftora tolerably well in the Odontoglossum house-for many try it in frames or out-of-doors, which is necessarily hazardous, though most effective when it succeeds-gave too little air, or too little water, or too much sun. Perbaps they neglected to keep due watch for red spider. The watering these plants require when in full growth is so constant that the most judicious gardener would not think of giving them enough unless warned. We trace the influence of the heavy clouds which travellers report on Table Mountain in this unquenchable thirst. They begin to grow in late winter. In March the pot must be soaked once a day; in April, twice; when the hot weather sets in, three times, unless the sky be very dark; on a sunny day of June, when the buds begin to show, even this will not be enough - they take four daily waterings with gratitude.

Those who observe Disa grandiflora will not readily be convinced that spontaneous generation is impossible. Though red spider is not fond of the cool house, though it never gave trouble before, so soon as one of these plants is introduced, it makes its appearance, unless the syringe be used 


\section{Disa}

freely. One must never forget this peril. Green fly and thrips also attack them; but that is a matter of course.

When the flowering is over, they begin to rest, and it is well to put them in an open frame, in the shade. Much less water should be given. But at all times they must be moist.

Scarlet is a hue very rare indeed among orchids, but Disa yrandiflora shows it. That is the general effect of the blooms, three or four inches in diameter, which crown a leafy spike, one to two feet in length. The number of such spikes which a strong plant will throw up is surprising, and each bears one or two or four flowers in proportion to its vigour. But, in fact, the great side sepals only are scarlet; petals and lip, insignificant, are orange, and the dorsal sepal, curling over like a hood, is rosy, with crimson veins. It flowers in June and July, lasting for weeks. Table Momntain. 182\%. 7s. 6ct.

Kevensis (grandiflora $\times$ tripetuloides). $-\mathrm{A}$ eharming flower of good size. Rose pink, spotted with rerl, petals yellowish, with crimson markings. 5 s.

Lengleyensis (racemos $\times$ tripetaloides).-Small, rosy, with red spots. 5 s.

Premier (Veitehii $\times$ tripetaloides).-Deep purplish rose. $15 s$. 


\section{The Culture of Greenhouse Orchids}

Racemosa (branched). -Like grandiflora in habit and culture. Many-flowered. Purplish rose. South Africa. 1887. 7s. 6d.

Tripetaloides (as if bearing three petals).-Flowers rather small, but in great number, creamy white, flushed with pink and dotted with rosy purple. Summer. South Africa. 1889. 7s.6 $l$.

$V$ eitchii is an exquisite hybrid produced by Messrs Veitch from grandiflora $\times$ racemosa; not so large as the former, with the rosy tint of the latter, but more brilliant. 15 s.

\section{Epidendrim. (On a tree.)}

Orchids in general were termed "Epidendrum," when first they came under notice of the lotanist, and this genus is still the largest recognized. But in the cool house we have very few species. Peat and moss or Belgian leaf-mould. They must not be dried when resting. All flower from the top of the pseudo-bulb.

Cockleatum (like a cockle, referring to the shape of the lip).-Sepals and petals green, curving backwards. Lips small, almost black, with paler rils; hollow, like a shell. It is rather curious than pretty. Central America. $5 s$.

Elrgans.-Better known as Burkeria elegans. 


\section{Epidendrum}

Medusce.-Better known as Nanodes Medusce.

Myrianthum (ten thousand flowers).-So rare that I should not name it were not the list of coul species so short. Tall and slender, bearing a pyramirl of small but most lirilliant red flowers at the top' of its reed-like stems in summer. Guatemala. 21s.

Nemorale.-I name this among cool species only because it is named in all other books. My own experience teaches that it should rather have a place in the stove. But, as I have often said, circumstances differ-and those great authmities cannot he wrong. At least, it should be hung close to the glass, and shaded only during the hottest hours of the day. The reader must understand that I do not advise him to purchase this species for the cool house.

Virgatum (twig-like, alluding to the flowerspikes).-So like $E$. vitellinum in growth that they are easily mistaken, luat very different in blowm. It lears a multitude of small flowers, green and brown, on tall branching spikes. June. Mexico. 5.:.

Vitellinum majus (resembling yoke of egg in hue; one of the feeblest shots in orchid nomenclature, which is an amusing record of bad marksmanship).- This variety is distinguished from the plain, old-fashioned vitellinum by greater size and importance, and also by the season of flowering. 


\section{The Culture of Greenhouse Orchids}

Since it appeared, therefore, the latter has almost vanished-not exterminated, but suppressed by the laws of trade. No dealer will volunteer the information that his goods are not as fine as any in the market.

But the flowers are delightful, large or small. Their colour, brilliant orange-scarlet, strikes the eye among the whites and lrowns of the Odontoglossum house most pleasantly, and their shape is graceful. A spike will bear as many as twenty blooms, an inch and a half in diameter, almost as compact as those of a hyacinth, and they last in perfection for two months. I have noticed a very effective way of growing them. If each flowering plant he placed hy itself in a small pan, a number may be arranged, as the buds open, in a large pot, side by side; a dressing of live moss will not only conceal the pans but give a pretty green surface. As the earlier spikes fade they may be replaced, and thus one may have such a steady concentrated blaze, from May to the end of July, as will astound the inexperienced.

It is consoling to recall that E. vitellinum majus was found a troublesome species in the last generation. Not one is easier now, and if a very simple change of treatment have had such good results in this case we are encouraged to hope that species 


\section{Epidendrum}

which still defy us may be conciliated in like manner. But it must be owned that the difficulties are much more formidable generally.

Our fathers used to dry E. vitellinum majus too

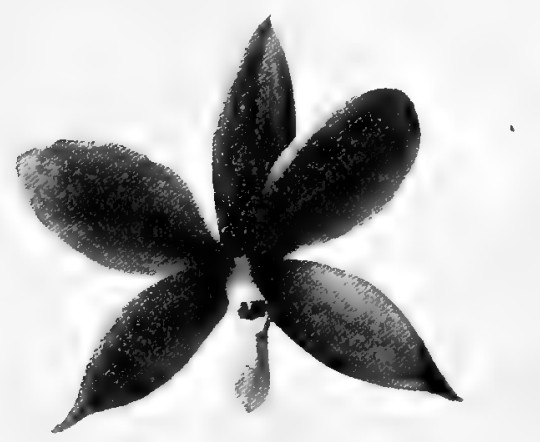

EPIDENDRCM VITELLTNOA.

much, supposing it similar in its needs to Letiat anceps and such Mexican orchids. But it flourishes on much higher ground, partaking of the nature of Odontoglossums in some degree. A distinct season 107 
The Culture of Greenhouse Orchids of rest must be granterl, however; otherwise it will continue to grow, the flower-spike will not start, and year by year it will diminish. Upon the other hand, if kept too dry the spike will wither. If the

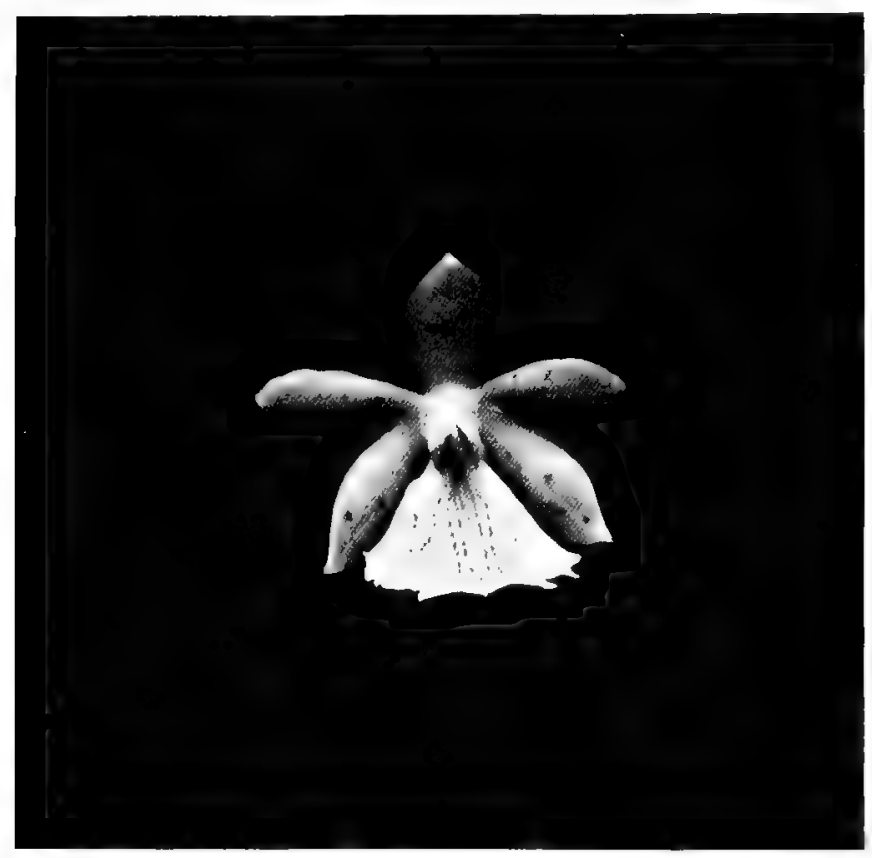

FPIDENDRUM WALISISI.

plants be examined twice a week in winter they will be preserved from excess either way.

'The flower-sheath is developed hefore resting, and it begins to swell in January, or even earlier, 108 


\section{Houlletia}

perhaps, if all be well; but more water is not needed on that account until spring.

E. vitrllinum pure and simple flowers in autumn. Its colour is not so brilliant.

The harsh leaves warn us that both like sunshine, lout shading is necessary at midsummer. May and June, or autumn. Mexico. 1840. Vitellinum, 3s. 6 . ; majus, 78.6 .

"Wallisi (a collector).--Small, but very pretty, and unlike others. Sepals and petals yellow, speckled with maroon; lips white, with dotted lines of purple. Flowers at all seasons. Colombia. 10s. $6 d$.

\section{Hovlletia.}

(II. Houllet, Curator of the Jardin des Plantes.)

This small genus has only one cool representative. The spike rises from the base of the pseudobulb.

Odoratissima should be treated like an Odontoglossum, but kept somewhat drier in winter, for it rests. It is curious and striking, agreeally scented; flowers large, dull red, mottled closely with lines of darker hue. The lip is very singular, white, ending in a broad barled blade, of shape exactly like a "Neolithic" arrow-head, attached by a slender neck. 


\section{The Culture of Greenhouse Orchids}

A pair of red horns at the base give finish to its uncanny appearance. New Granada. 1851. 5s.

\section{Lelia.}

"Lielia" is a word without meaning, the pretty feminine form of the Latin patronymic "Liclius." It may be added, for the lenefit of those who would know further, that the most distinguished hearer of the name was Caius Lielius, surnamed the Wise, friend of Cicero, and father of two lovely girls, whom this charming group of flowers commemorates.

Lrelias which will do in the cool house, saving two or three, are IIexican; which is to say, in brief, that they demand the strongest light and all the sunshine which can lie safely allored them. As a rule, therefore, they do best hung up-smallgrowing species on a block; large in a basket. But if a place as light and airy can be found on the shelf, they flomish equally well in pots. Use the smallest quantity of peat and moss which will keep them damp, but if the Belgian system he favoured proceed as usual. It is well to bear in mind that they are more at home among the Cattleyas while growing - a hint to give them the warmest quarters in the cool house.

Doubtless the sky of Mexico is the most brilliant 


\section{Lælia}

in the world; the intense craving of all plants from that country for light tells us so much. Even in the rains, the dull season, it must be lucid to a degree beyond our conception. That is the time when the Lelias grow and flower naturally, but we must urge them along when our light is strongest.

The seasons are sharply defined in Mexico, and the rainfall prodigious. We have been told by an expert that $L$. anceps has scarcely a dry moment for eight weeks, at least. It must not be forgotten that these plants at home stand on a bare bough, whilst ours commonly have peat and moss round them, which hold the wet; but the conclusion is that they should never be allowed to dry in the slightest while growing. In fact, they speak for themselves very quickly; the fresh green tips of roots which encircle the pot fade with disconcerting rapidity at a touch of drought.

But the rest after flowering is severe in proportion; until they begin to push new roots in spring they ask not a drop of water, if the house be kept as moist as it should be. At that time, say February, they should be repotted. All flower from the top of the bulb when growth is complete.

Before going further I must sound a warning note. Upon my personal experience I would not include any Mexican Lalias among plants grown in the cool 


\section{The Culture of Greenhouse Orchids}

house. Certainly they would do no good in $\mathrm{my}$ own. Upon the other hand, I find them in every book I have consulted. We may conclude that in a house facing south and west, hanging close to the glass and scarcely shaded, they will be comfortable enough. I have put a memorandum against those to which I refer.

Acuminutr (pointed).-Small comparatively, white or palest violet, with a fine purple blotch in the throat. $A$ beauty among beauties. December and January. Ranges from Mexico to Guatemala. 1840. 5\%. But observe the note supra.

Allick (whitish). - Singularly graceful in form and colouring. Five to ten flowers, or even more. White, lip tinted in various hues from pink to mauve. December and January. Mexico. 1832. 5s. But observe the note supra.

" bella.-An exquisite variety, in which the sepals and petals are tipped with rose. The lip also is rose.

Anceps.s (double edged).-Of all strongly coloured flowers this is the most exquisite. Its rosy sepals and petals, its crimson-purple lip with yellow throat, have a velvety tenderness mmatched even among orchids. December to January. Mexico. 1834. 6s. Observe the note supra.

" alba.-The albino variety, of which there 


\section{Lælia}

are several forms:--with a yellow blotch upon the lip (virginalis); or with mauve lines upon it (Williamsi); or the central lobe mauve with purple

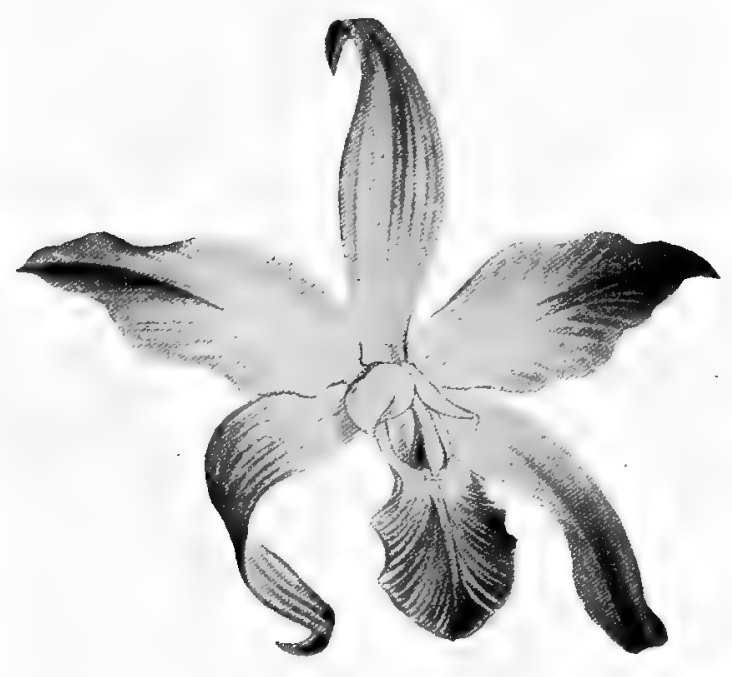

L无lia adtonnalis. (Hulf natural size.)

lines (Duwsoni). It is needless to compare the beauty of these sisters. Individual taste must decide. Enough to say that those who prefer white 


\section{The Culture of Greenhouse Orchids}

flowers may exalt the albino even above its coloured fellow. It must be added, however, that these white varieties are somewhat reluctant to bloom. As among animals, wan included, the floral albino lacks vigour of constitution. Again, I myself do not reconmend the reader to try any of these in the cool house. Figured in plate.

Autumnatis (autumnal).-Very pretty and very useful. Deep rose, the lip paler. Many-flowered. Late autumn. Mexico. 1836. 5s. Observe the note supra. Figured, p. 113.

" atrorubens (darkest red).-A grand variety, much more common of late. Dark crimson, the lip still darker in its middle lobe; white at the sides. A very striking flower. $10 s .6 \%$.

" alba,-So rare that we name it only for its supreme loveliness. An albino, pure white, saving a stain of yellow on the lip.

Duycena (after Mr. Day, of Tottenham, whose name occurs at every page in the annals of orchidology).Distinetly cool. The pseudo-bulb is very small, but the flower of good size, rosy, the lip purple, with whitish throat. This handsome bloom on such a sinall plant has the further merit of surprise. April and May. Brazil. 5s.

Dormaniana (after Mr. Dorman) will do in the cool house, but it prefers warmth. Dark olive 




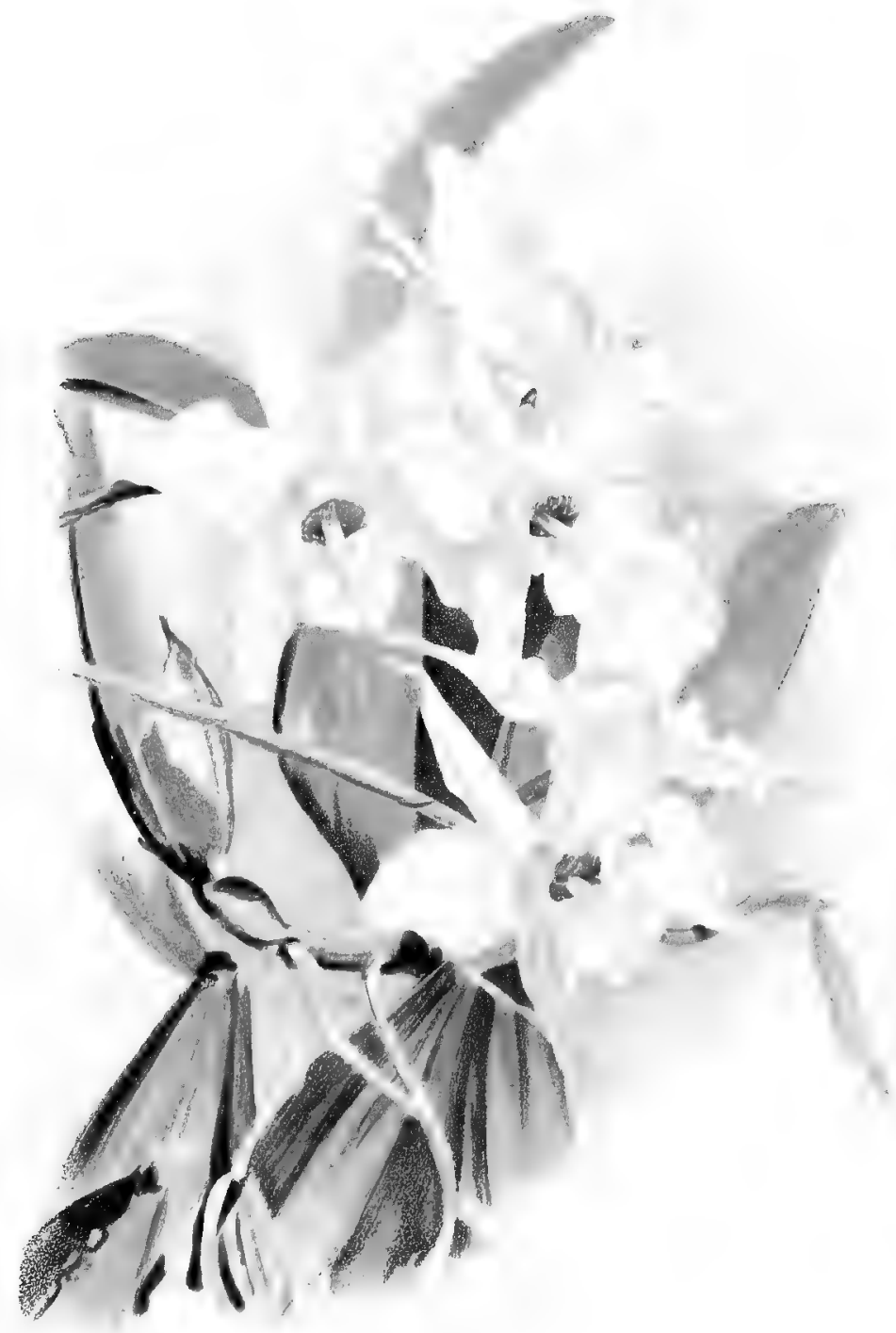




\section{Lælia}

brown, mottled with purple, lip purplish crimson. April and May. Brazil. 1876.

Flava (yellow) bears six to ten narrow yellow flowers on a long spike. The unusual colour gives it value, especially for hybridizing. Autumn. Brazil. 1839. 10s. 6d.

Furfurack (scurfy).- One of the irritating species; difficult to flower, and even to grow. It should be put out-of-doors in full sunshine, during August and September, to give it a chance. Rosy, lip darker, white at the base. September and October. Nexico. 1838.

Gouldiana (after Mr. Gould, a Transatlantic amateur).--Rare, and very beautiful. Probably a hybrid of anceps $\times$ antumnalis. Deep rosy crimson. December and January. Mexico. Olserve the note supra.

Harpophylla (sword-leaved). - Valuable for its scarlet-orange flowers, a colour so rare among orchids, but not impressive for size or shape. Early spring. West Indies. 1865. 5s. It does better among Cattleyas.

Jonghcance (M. de Jonghe, a Belgian amateur).Until 1899 this was priceless, in the sense that one plant only existed in Great Britain, belonging, of course, to Baron Schröler. Then Messrs. Sander obtained a quantity, but the collector, M. Forget, 


\section{The Culture of Greenhouse Orchids}

had not seen it in flower, nor did he recognize the growth. Accordingly the plants were sold as $L$. pumila (?) on the supposition that they might represent a large variety of that common species. It was a costly mistake for Messrs. Sander, who obtained scarcely one per cent. of the value. Several importations have arrived since the habitat was re-discovered, and L. Jongheana is common now, and, to tell truth, little esteemed. In fact, it is "a drug" in the orchid market.

The bloom is large, pale mauve, the lip whitish, margined with mauve. A number of wavy ribbons set on edge descend from the throat, golden yellow of colour - a curious effect. Flowers differ much in size and tint, and albinos seem to be commoner than in most species. A plant often makes two growths in the year, but it flowers only from that starting in autumu. March. Brazil, bordering on Peru. Originally discovered in 1842. 5s.

Majalis (May-flower, "Flor de Majo," of the natives).-The bloom is very large and striking; rosy mauve, lip white in the centre, with purple dots and markings. Flowers from the young growth in May and June. I species of eccentric habit, not diffienlt to grow, but curiously uncertain in blooming. I myself thought I understood it after two successful seasons; but later experience 


\section{Lælia}

has taught me that my triumphs were due to some imperceptible accident. It likes a bare block certainly, but that is troublesome. The pseudo-

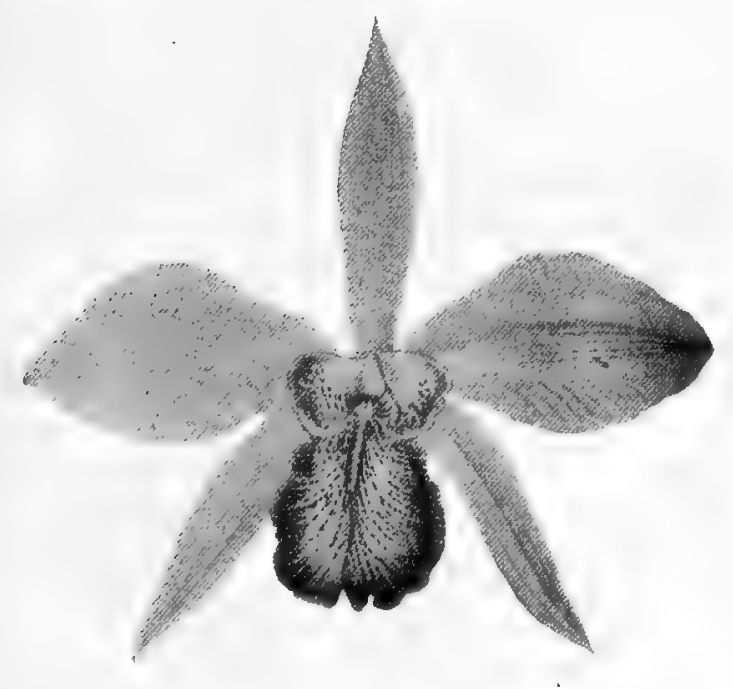

LELIA MAJALIs. (One-third natural size.)

bulbs ripen better if turned out-of-doors and exposed to full sunshine from July until the cold weather sets in. Mexico. 1838.

Monophylla (single-leaf).--A tiny plant, bearing a 


\section{The Culture of Greenhouse Orchids}

solitary flower, bright red-always pretty, but too often insignificant. In a good variety, however, the bloom may be an inch and a half across, and

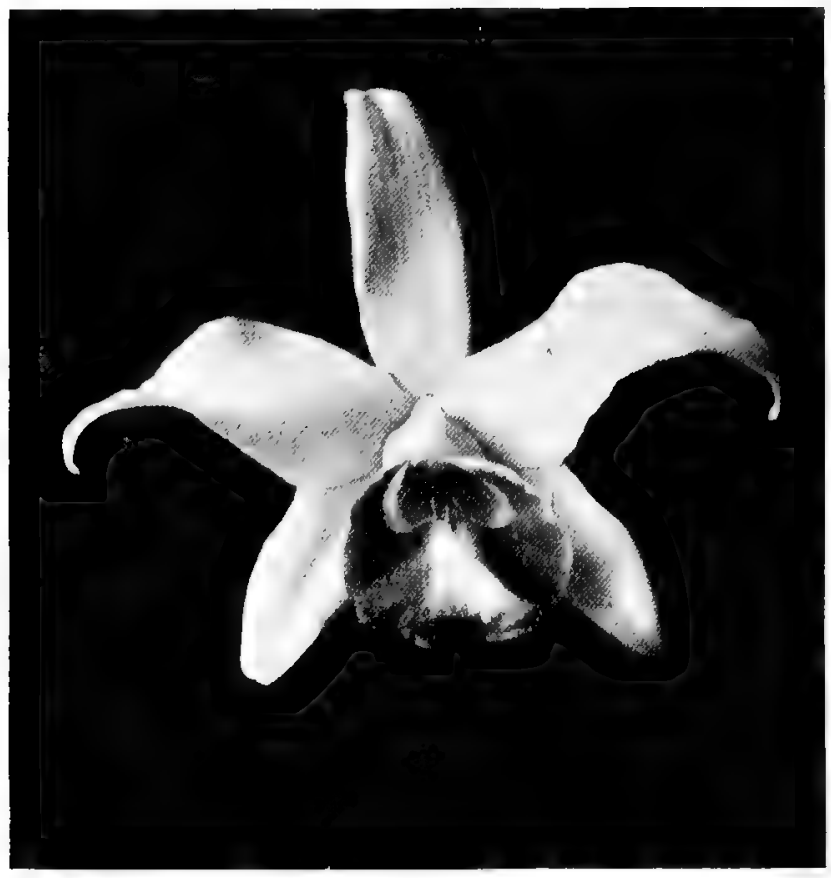

I.ELIA l'CMILA l'RAESTANS.

of that size it is very striking. Autumn. Peculiar to the mountains of Jamaica. 1880. 10s.6d.

Pumila.-Dayana, already noticed, is a variety of this, and the description applies, for they are 


\section{Lycaste}

distinguished only by a greater depth of colouring in the latter. Autumn. Brazil. 33.6\%. Another variety of pumila is-

Prcestans, somewhat larger and paler of tone. The handsomest of the three, but all are very handsome, and distinctly cool. $7 s .6 c$.

\section{Leptotes. (Slender.)}

These plants are best grown in baskets, treaterl like Odontoglossums. Only two species are cul. tivated.

Bicolor (two-coloured).-Small, but pleasing. There is, however, a want of compactness about the flower which impairs the effect unless in quantity. White, with a pretty purple stain upon the lip. Winter. Brazil. 5s.

Serrulata (toothed like a small saw).-Much the same, but larger, with lines of crimson in place of the purple stain. Spring. Brazil.

\section{LYCASTE.}

"Lycaste" is a Greek woman's name, without significance for us.

Most of this genus are cool, natives of Central America. It is, indeed, rather curious to fancy our 


\section{The Culture of Greenhouse Orchids}

orchid-houses bereft of their Transatlantic ornaments. Some thuughtful persons hold that the discovery of America was a great misfortune for mankind, and their arguments are striking. But orchid-growers who take that view must admit that there are delightful compensations.

Lycastes are wisely recommended to the beginner; they will not disappoint his unskilled efforts. No plants are more easily cultivated; the flowers are always conspicnums, and in some species very graceful; they appear in great numbers, some at midwinter, and they last mostly for a space of time unusual even among orchids.

All should be grown in pots, with peat and moss, unless upon the Belgian system. They demand a great deal of water while growing, and they must not be suffered to dry even when at rest.

The flower-spikes begin to push from the base of the psendo-bulb before the new growth appears.

Aromatica (scented).-One bulb may produce a dozen of the pretty yellow flowers. Spring. Mexico. 1828, 5s.

Cruente (bloody) - Very similar, but larger. March and April. Guatemala. $78.6 \lambda$.

Deppei (Mr. Deppe, Mexican collector).-Less showy than most. Sepals greenish, spotted brown, 


\section{Lycaste}

petals white, lip yellow. February to June. Mexico. 1828. 5s. Figured, p. 122.

Hurrisonice (Mrs. Harrison, wife of an amateur). White, lip purple. The flowers last a prodigious

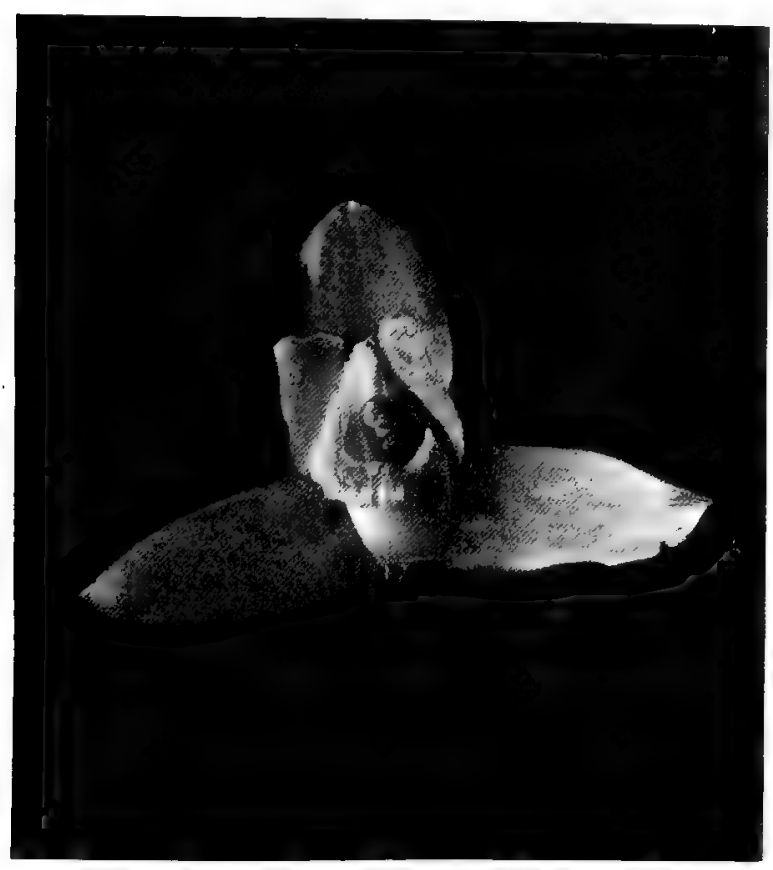

LYCASTE AROMATICA.

time, but the white turus yellow. Scented. Brazil. 1828. 5s. Known to sclence as Bifrenaric Harrisonice.

Lanipes (woolly foot).-Very large flowers and 


\section{The Culture of Greenhouse Orchids}

very many, greenish. It is not much favoured, but I like the tender colouring. September and October. Guayaquil. 10s. 6d. Figured, p. 123.

Lercantha (white flower).-A small species of

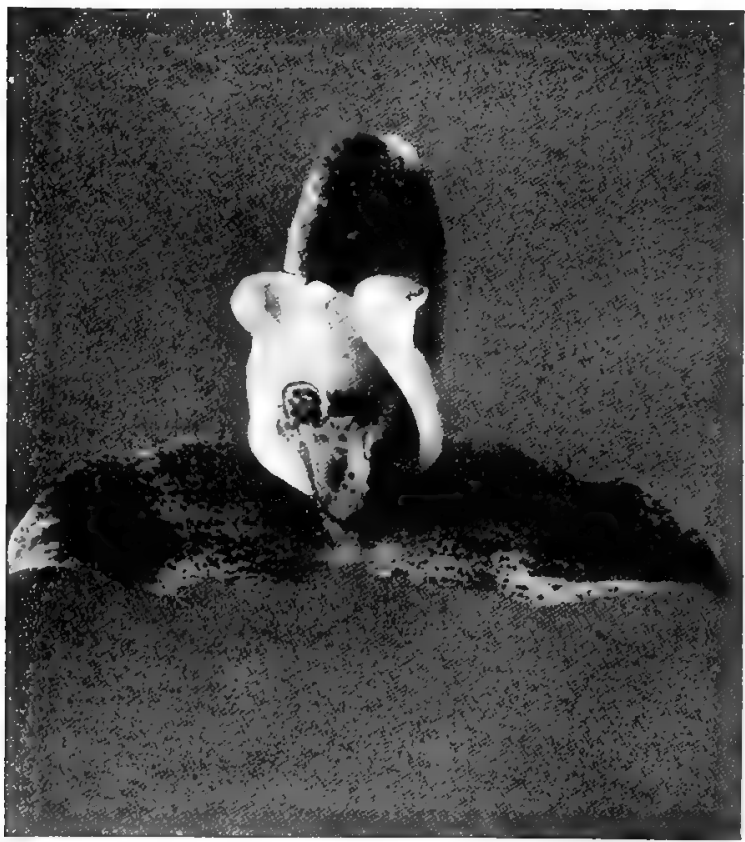

LYCASTE DEPPEI.

exquisite grace, tor rare, unfortunately. Autumn. Pale green, with white lip. Central America. $10 s, 6 d$.

Plene (flat).-Large. Sepals green, shaded with 122 


\section{Lycaste}

red, petals white with a crimson blotch, lip white, spotted with crimson. January and February. Bolivia. 1840. 21 .

Skinncri (after Mr. Ure-Skinner, who discovered

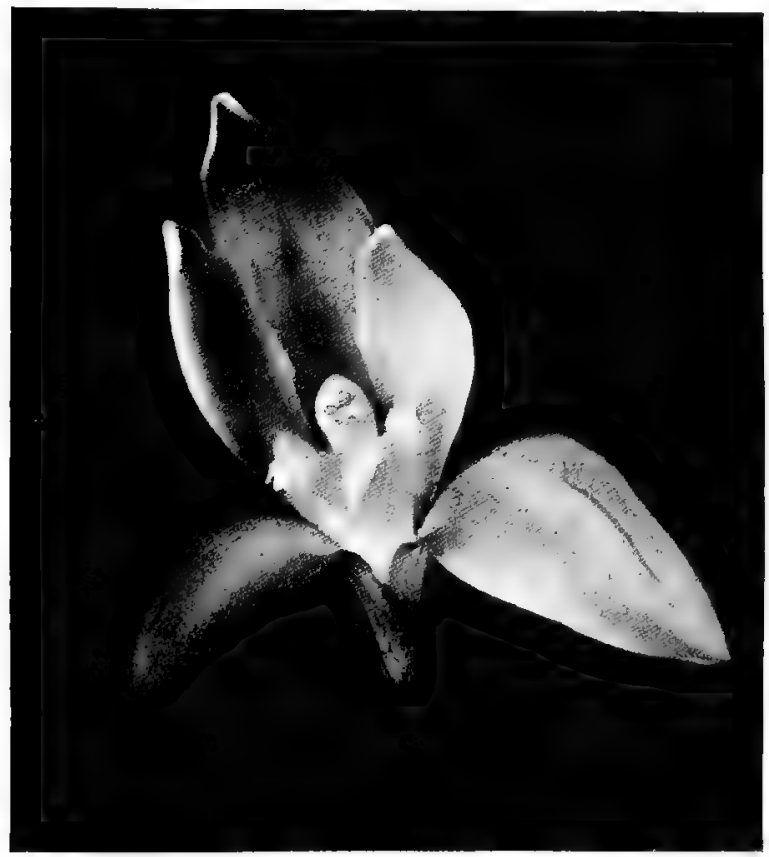

LYCASTE LANIPES.

it in 1842).-Best known of the family, and one of the most popular orchids. Its great blooms may be too stiff, and too obtrusive in colour, for an æsthetic taste, but the plant has merits incontestable- 


\section{The Culture of Greenhouse Orchids}

easily grown, profuse of flower, lasting for an indefinite time which may be reckoned by months, and at the season when they are most acceptable, mid-winter. Transferred to the dwelling-house, it

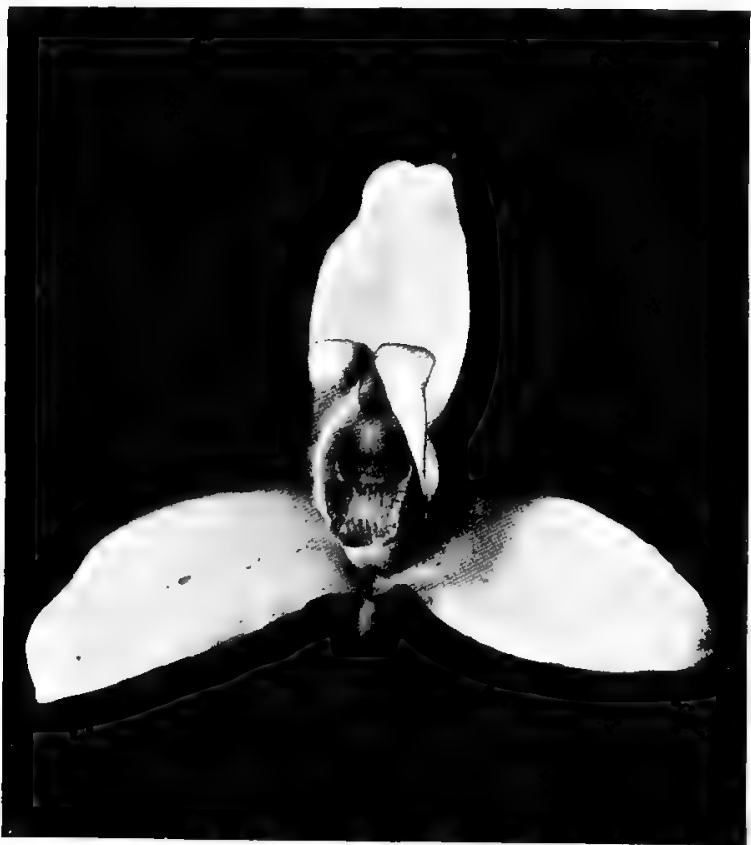

LYCASTE sKinNeRI. (Much reduced.)

scarcely suffers, and therefore some term it "The drawing-roow orchid." The variety of colouring is so great, within fixed limits, that two alike can scarcely be found; many are gorgeous, and some 


\section{Masdevallia}

even elegant. Sepals and petals range from blushwhite to deep rose; the lip is blush-white spotted with crimson, or its throat rosy, spotted with white, or the whole of it, saving the tip, is vividest crimson; with all variations possible between these extremes.

Lycastes in general may be manured with advantage, but this species is visibly improved by a very little cow-dung in the water once a week. November to May. Guatemala. 1842. 3s. Grl. But the varieties, which are innumerable, command a much higher price.

" alba, or virginalis.-The albino form. Pure white, as if carved in alabaster, but on the lip a faint tinge of yellow. A heavenly flower.

\section{Masdevallia.}

(Señor Masdeval, a botanist of New Granada.)

This genus is not universally favoured; but those who admire, love it. One of the latter class myself, I have tried to ascertain why all the world does not agree with us. No mortal could dispute the supreme brilliancy of the Harryand section, which is that most familiar, glowing as rubies, some even of the priceless "pigeon-blood" tint. They are of good size, also, and they stand erect, 


\section{The Culture of Greenhouse Orchids}

challenging notice. But they stand alone, and the conventional eye is not used to see blooms so conspicuous, so intense of hue, dotted here and there, each by itself. In a cluster now, people say, or in a garland, like Odontoglots, Masdevallias could be rivalled only in the gardens of Fairyland. Solitary, they are too startling to please. Such, as I gather, is the feeling which somewhat checks the appreciation of their loveliness.

It is not to be understood that a pot of Masdevallia yields only one flower. The scheme of Nature provides that each leaf, as it attains maturity in spring, should throw up a bloom. That does not "come off" regularly, perhaps, even at home, for we perceive that a slight mischance may diseoncert the arrangement; lout all the strong growths will flower.

Among the endless eccentricities of form shown by orchids some are more striking than that of the Masdevallia, but none more extraordinary. Dissected under the microscope, the flower proves to have three sepals and three petals, with one of the latter modified into a "lip," like all the family. But of this structure, one may say, nothing is visible at a glance. What we see is the sepals alone, expanded proportionately to the reduction of the petals and lip, which can only be identified, 


\section{Masdevallia}

as a rule, on close inspection. Also the sepals are prolonged in the form of tails, sometimes to great length.

Masdevallias are found along the western part of South America from New Granada to Peru; a very few also in the north-eastern parts. They grow upon trees, but, as I understand a story which Roezl used to tell, the Indians cultivate themthat is, the Harryana species-like terrestrial orchids. He saw a church decorated for some festival with such ropes of Mesedevallia Harryan that the most devoted zeal could not have supplied the quantity had they been gathered in the woods. The Indians took him to a spot where they had a "garden" of them, several acres in extent. It may have been a rocky area, where the soil was very thin and poor; in such a situation, perhaps, the plants would flourish as if on trees. The number of species identified is very large. Mr. Watson says "probably a hundred and fifty have been described, and additions are constantly made." But the great risk and difficulty of importing plants so small and so slender, which have not the shadow of a pseudo-bulb to sustain them during the long hot journey, deprives us as yet of many grand species known to botanists. Until their homes in South America had been opened up, and the service 


\section{The Culture of Greenhouse Orchids}

of mail steamers became frequent, it was a rare chance indeed if any reached Europe alive. Of familiar species I find that Mus. triangularis was introduced in 1843; Wagneriana in 1855. Next came the glorious Vitchii in 1868; Harryana in 1869. Nearly all the rest in cultivation are more recent.

Roezl reported an amazing species in the neighbourhood of Medellin, New Granada-that very interesting town which Philip II. peopled with Nuevos Christianos-Jews converted by the logic of the Inquisition. His Majesty thought that removal from the homes familiar for so many generations of tolerance and prosperity, under the Moors, would tend to confirm their dubious faith; and he judged rightly, for there are no Catholics more devoted than the people of Medellin. But in their neighbourhood grows a Masdevallia called La Vidua (the widow). Its leaves stand two feet high, six inches broad, "as thick as a pancake," said Roezl. The flower resembles in sbape, and almost in size, a snow-white duck, hanging with the beak downwards! Such was Roezl's statement.

He brought home one species which has not been seen since; it speedily died out. This was Livingstoniana. I have told the story in "About Orchids," but not every one, unfortunately, has 


\section{Masdevallia}

read that book. Once upon a time the great collector was travelling homeward by the Panama railway. Sixty dollars was the fare, and he grudged the money. Setting his wits to work, Roezl discovered that the company issued tickets from station to station at a very low price, for the convenience of its employés. Taking advantage of this system, he crossed the Isthmus for fire dollars-such an adrantage it is in travelling to be an old campaigner! At one of the intermediate stations he had to wait for his train, and rushed in to the jungle, of course. Peristeric elate abounded in that steaming swamp, and, to his amazement, he found, side by side with it, a Masdevallia, the genus most impatient of sunshine among all orchids, flourishing here in the hottest blaze. Suatching up half a dozen of the tender plants with a practised hand, he brought them safe to England. On the day they were put up to auction, news of Livingstone's death arrived, and in a flash of inspiration Roezl christened his novelty Mas. Livingstoniana. Few indeed, even among authorities, know where that rare species comes from. A pretty flower it is -white, rosy-tipped, with yellow "tails." And it dwells by the station of Culebras on the Panama railway.

The genus contains a number of the most 


\section{The Culture of Greenhouse Orchids}

exquisite and finished marvels that Nature has fashioned for our delight. "Gems" is no conventional epithet for them. They have the hues and almost the glitter of precious stones, in such dainty setting as man could not conceive, nor hands execute. But supreme beauty of this order is only granted to us on the minute scale. If the jewel-points were enlarged, their colours would not be less lovely, but they would not sparkle; though the workmanship were not less perfected, it would not astonish to the same degree. These wonders, therefore, are reserved for happy men who can disregard show; because their houses are big enough to include a proportion of "curiosities," or because, happier still, they love a tiny floweret, scarce perceptible at a yard's distance, as well as those stately blooms which cannot be overlooked if within the range of vision. That readers who belong to neither class may not be tempted to buy plants they do not want, however wonderful or lovely, I mark these species with a warning "Gems."

All the Masdevallias named are "cool," of course. But the grower whose Odontoglossum house is apt to run down into the forties on a wintry night will find some of them unsatisfactory. These I note. Very often, however, one end of the house 


\section{Masdevallia}

will prove, if tested, to be several degrees less cold than the other, because nearer to the furnace, perhaps, or for some occult reason. That may probably be just the temperature wanted for species which exact a trifle more heat in winter. A minimum of $50^{\circ}$ suffices for them.

No Masdevallia in cultivation will bear hot sunshine.

They grow in moss and peat-not more than sufficient to keep the roots moist_and a very damp atmosphere all the year round; in fact, the Odontoglossum house is altogether suited to their needs, if it be kept at a minimum of $50^{\circ}$.

The Harryance group and many others do best in pans, not pots. It is hard to understand why the depth of the ressel in which they grow should make a difference when it is filled with crocks proportionately; but experience proves that it does, somehow. The warmer species, however, have pendent blooms, and they should be planted in baskets. I distinguish these in each case.

In summer, Masdevallias must be always wet, and in winter they cannot be allowed to dry up. Some, indeed, must be distinctly moist the year round, even of those which grow in pans. As this is vastly important, I affix the warning "Always moist" in such instances. 


\section{The Culture of Greenhouse Orchids}

For those noted as requiring "Basket-warm end," it must be taken, ipso facto, that such are to be kept moist in winter and soaking in summer.

The Harryana section, however, is that which most interests my readers, probably. These plants -and all others when nothing to the contrary is stated-must be dried, though not parched, when resting, in autumm and early winter. Even in summer it is easy to water them too much. Many growers exclaim in despair that the old leaves cannot be prevented from developing those large black spots which so often disfigure them. Perhaps it is not true that they always come from an excess of water, but that certainly is the most frequent cause; and the roots promptly decay in autumn if too wet.

The flower shoots up, or pushes down, from the centre of the young leaf, as it approaches maturity.

Red thrips and green fly love Masdevallias, and they must not be combated by smoking with tobacco. Dipping in the composition mentioned is effectual, but it will not destroy the motherthrips, which have wings. "XL" exterminates, for the time at least. It does not destroy scale, certainly, for nothing will; nor slugs. These enemies must be sought patiently. If allowed to establish 


\section{Masdevallia}

themselves, they are dreadful. But that is easily prevented if the gardener keep watch from the first.

Amubilis.-Pretty and free-flowering, but small. Orange or rose, side sepals spotted with carmine. Summer. Peru. 1874. 5s.

Arminii (Mr. Armin Wagener).-Small, rosypurple. Spring. New Granada 1854. Gem. 10s. $6 d$.

Baekhousiana.-Synonym for Chinuera.

Bella.-Very effective and very free-flowering. Sepals and petals yellowish, thickly speckled with red-brown. Lip white. The red tails are four inches long, the upper one bent back and aside, the two lower crossed. It flowers downwards, and I have seen a basket so densely encircled by blooms, each two inches broad, that they looked like a turban round it. Autumn and winter. New Granada. 1878. Basket-warm end. 5 s.

Benedicti (Benedict Roezl, the great collector).-A synonym for Houtteana, which see. Warm end -basket.

Carderi (Mr. Carder, collector).--Small, but very pretty, white, with brown spots; yellow tails. Summer. New Granada. 1883. Basket-warm end. 31s. 6d.

Caudata.-Synonym for Shuttleworthi. 


\section{The Culture of Greenhouse Orchids}

Chelsoni (Chelsea, where Messrs. Veitch have their establishment).-A hybrid raised by Messrs. Veitch from Veitclii $\times$ amabilis, but common now. Orange crimson. Autumn. $5 s$.

Chestertoni (Mr. Chesterton, collector).--Small, but very striking in colour. Sepals dusky, greenish, thickly speckled with purple. The lobes of the labellum expand widely, of a clear, pale, flesh tint. Slender ribs touched with scarlet pruceed from the scarlet throat. New Granada. 1883. Basketwarm end. 21s.

Chimera (from the Greek myth).-Most impressive, though by no means loveliest of the genus. There are several varieties of this. But we are not yet introduced to the monster which Roezl failed to bring home, declared by him, in the warnth of his vexation, to be as broad as the stretch of his arms -a matter of six feet; he insisted upon three feet in cold blood. It must be wonderful, anyhow.

But Chimarce is startling enough. Reichenbach sought a name for it among the demons of mythology, and he chose "The offspring of Typhon and Echidna, which had the body of a goat, the head of a lion, the tail of a dragon, and romited flames of fire." This means, in short, that it looks uncauny. No question of that. The fluwer is not less than six inches long, with its tails, and hairy; 


\section{Masdevallia}

the colouring a rich brown in the general effect, mottled with lighter and darker tints. But on examination we perceive that the ground is creamyyellow, almost obscured by the brown blotches. The lip has slender white edges, which show prettily on that dark surface. The tails are purple.

N.B.-If the spike be not cut, it will often throw up another flower, or even two, in succession.

This must be grown in a basket or pan, and kept at a minimum of $50^{\circ}$ through the winter. It should be repotted every spring. Spring. New Granada. 1872. $7 s .6 d$.

The largest variety by far, and the best, is Chimera Sanderianc. Including the tails, it is two feet long, or even more. And the brown mottling is changed to dark crimson.

Coccinec (red).-A species so much like a small variety of the common inn a that the name is often applied to the latter. Small. Scarlet, tipped with rose. Winter. New Granada. 1878. 5 s.

Colibri (humming-bird).- The discoverer observed a bluish sheen upon the flowers comparable to the lustre of a humming-bird. It has vanished in cultivation. Rather curious than beautiful. Large, deep red-brown, touched with yellow; yellow tails. Spring. New Granada. 1875 Warm end. 


\section{The Culture of Greenhouse Orchids}

Trochilus is another name for it, and Ephippium a third. 21 s.

Coriacea (rough). - I name this only because it is often seen, which suggests the possibility that some mortals admire it; but I make bold to say that the reader would not, for $I$ credit him with a sense of beauty. Good size, greenish, spotted with purple. New Granada. 1845. $5 s$.

Davisi (Mr. Davis, a collector).-A yellow species, and valuable on that account, had it no other merits. But the flower is large, and of pleasing tint. Summer. Peru. 1875. 7s, $6 d$.

Elcphanticeps (elephant's head-a fanciful resemblance). Striking, large, lower sepals purple, upper yellow. Spring. New Granada.

Erytleruchete (red tails). - White, with a yellow tinge and dark-red spots. Summer. New Granada. 10s. 6d.

Estrade (after Donna Estrada, a lady of New Granada, who cultivates orchids. What a heavenly mansion hers might be, and is, we trust!).- Small, but wonderfully bright; upper sepal, which is strongly concave, violet above, yellow at the base; lower, violet at the base, yellow at the tips. Very free-flowering. Warm end. In summer it may probally want water every day. New Granada. 1874. 10s. $6 d$. 


\section{Masdevallia}

Geleniana.-A hybrid, raised by Messrs. Sander, from caudata $x$ ranthina, and by them named after Baron Rhuby von Gelenye, of Bohemia, a great amateur. Pale yellow, with a brown blotch on the side sepals. Spring. Warm end. 15 s.

Harryana (named after Mr. Harry Veitch).-This is by far the commonest of all Masdevallias. Its varieties are countless; I shall name only those which show a very remarkable divergence. Flowers of the normal type are large, of superb crimson hue, washed with magenta. The spike bears only one, but each leaf of the year should bloom, though such perfect results are not to be expected commonly. And the blooms stand aloft, twelve inches or so above the foliage. Whether to keep them upright by means of a slender stick or to let them straggle, is a question of taste; but if sticks be used, it is better to put them in before the spike overtops the leaves. Thus they are not seen.

Harryane is one of the most satisfactory of the genus. It will always bloom, unless grievously neglected, or-an error infinitely more frequenttoo much watered. The roots are apt to decay under any circumstances; so much so that it may be pronounced a natural habit. But they rot wholesale, and the young growths with them, if kept wet the year round. In their resting season at home the 


\section{The Culture of Greenhouse Orchids}

bark to which they cling dries completely, during the hours of daylight, at least. To reproduce this state of things exactly, and give no water at all for three months, would be perilous, but it yields

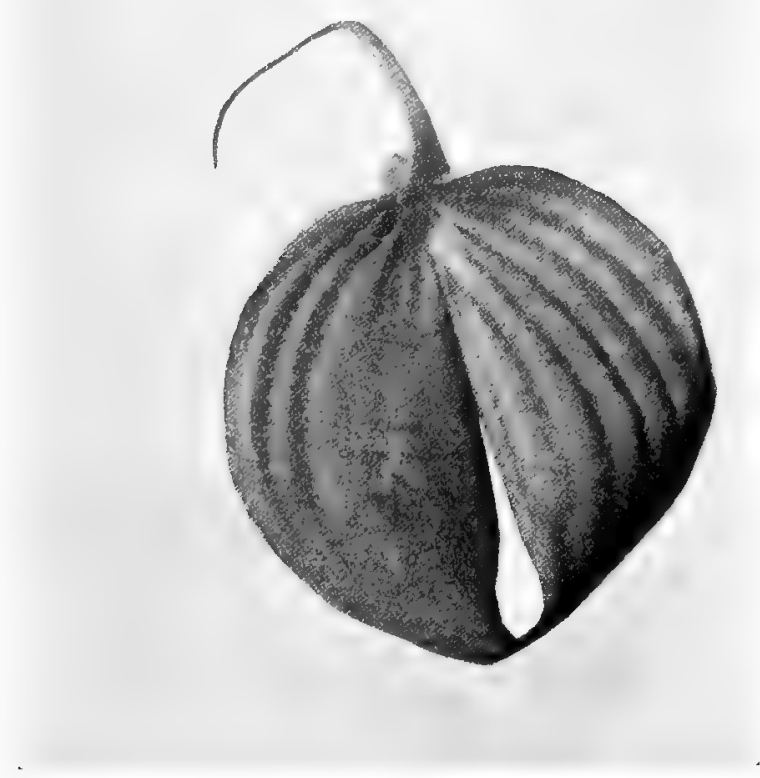

MASDEVALLIA HARRYANA.

us a hint. There are species, indeed, which must be always damp, but this is not one of them.

Spring is the normal time for flowering, but a strong plant which has done its duty in spring 


\section{Masdevallia}

may oblige again in autumn. New Granada. 1869.

Many varieties of Harryana are so rare that it is scarcely worth while to name them. The following can always be obtained :-

H. Bull's blood.-Richest of all in hue. 10s. $6 d$.

" coerulescens (bluish). - Very large crimson flowers, with a bluish tint. $5 s$.

" conchiftorc (shell-flower).-Distinguished by its shell-like form, whence the name. Singularly graceful. $7 s .6 d$.

" lilacina.-Rosy lilac. 5s.

" Lindeni (M. Linden, Belgian horticulteur).Crimson, but washed with blue. In the strauge lack of that colour among orehids, some desperate persons have called this "The Blue Masdevallia." It would be as reasonable to describe a black Zulu as purple, because in certain lights his skin has a purplish bloom. But one of the most attractive varieties. Summer. New Granada. 1872. 5s.

" purpurea.-Purplish.

"rosea and rosacea.-Rose-coloured.

"sanyuinea.-The colour of blood. $7 s .6 d$.

"vcrsicolor.-Margined, sometimes blotched with maroon.

,, violacea.-Suffused with violet. $31 s, 6 d$. 


\section{The Culture of Greenhouse Orchids}

Houtteana (Louis van Houtte, of Ghent).--Small, yellowish-white, spotted with red. Red tails. The difference between this and erythrochcete is

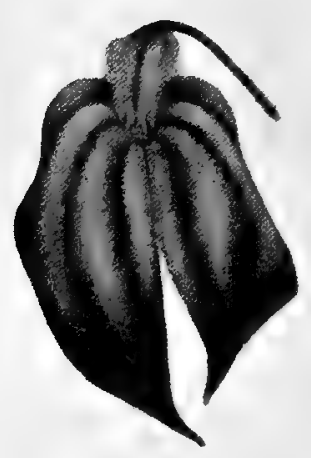

MASDEVALLIA IGNEA.

perceptible only to the expert. Warm endbasket. Summer. Columbia. 5s.

Ignea (fiery).-Orange-red, with three brosd crimson veins on each petal. A charming flower. Spring. New Granada. 1871. 5s. 


\section{Masdevallia}

Infracta.-A poor species, which I name only because it is so common. Dull purple and yellowish green. Spring. Brazil. $7 \delta .6 d$.

Lowii (Messrs. Isow, of Clapton).--Rather small, but effective. Almost white, speckled densely and prettily with purple. Tips white, and labellum purple. Warm end-basket. New Granada.

Macrura (long-tailed).-A large species, and very large flowers, but not striking in colour; less effective even than they would be if the spikes rose above the mass of leaves. Dull yellow, spotted and tinged with purple. Veins conspicuous. Winter. Basket-warm end. New Gramada. 1872. 10s. $6 \%$.

Melcnopus (black-footed).-Very small. Its little white bells are dotted with purple, and they have long yellow tails. Spring. Peru. (Gem.) 5s.

Melenoxuntha (black and gold) - A little beauty. The lower sepals are covered with an exquisite down, black in shadow, purple-brown in the light, through which glimmers the golden ground. Dorsal yellowish, shaded with brown dots. Edges and tips clear yellow. Ocana. Summer. Fiyured, p. 142.

Mooreana (named after Mr. F. W. Moore, Curator of the Glasnevin Gardens, Dublin; perhaps the most skilful grower of these plants).-Closely allied 


\section{The Culture of Greenhouse Orchids}

with mucrurc, but smaller. Warm end. Venezuela. 1884. 21s.

Nycterinu (nocturnal, perhaps from a fancied resemblance to a bat).-This often passes under the

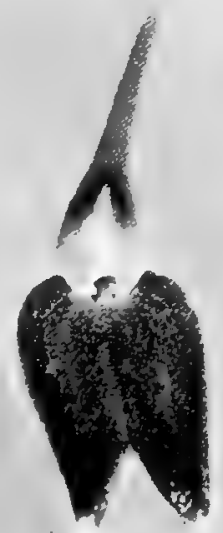

MASDEVALLIA MELANOXANTHA.

name of Chimcera, but it is not half the size. The colouring is the same, however-yellow, heavily blotched with brown, and hairy. Warm endbasket. Summer. New Granada. 1873. 10s. 6d. 


\section{Masdevallia}

Peristeria (dove),-Another species which I do not value. Large, greenish-yellow, dotted with purple. New Granada. 1880. 10s. $6 d$.

Polysticta (much dotted). - Small, but manyflowered. Palest lilac, speckled with purple. This should be kept thoroughly moist all the yearsoaking in hot weather. Spring. Warm endbasket. Peru. 1874. (Gem.)

Racemosa (branched).-The climbing Masdevallia. Travellers describe it with twenty flowers on a spike, but nobody has yet approached that number in Europe. It is as lovely as distinct. Brightest scarlet, with lines of darker hue. It must be wet the year round. Summer. Peru. 1883. 10s. $6 d$.

Roezli (Benedict Roezl, the collector).--Resembles a very diminutive Chimcera. Purplish brown. Spring. Basket-warm end. New Granada 1880. 21 s.

N.B.-If the spike be not cut, it will probably throw up more flowers.

Rosea.-Very pleasing. Of good size, bright rose and orange in colour. Autumn. Warm end - even in a warmer house if convenient. Peru. 1880. 10s. $6 d$.

Shuttlewerthi (Mr. Shuttleworth, collector).-A universal favourite. The flowers are much larger 


\section{The Culture of Greenhouse Orchids}

than would be expected in such a small plant; upper sepal yellowish, covered with red freckles; lower, rose-purple, with white spots; veins red, and long tails yellow above, green below. Thoroughly moist always, and soaking in hot weather. Spring. Warm end - basket. New Granada. 1878. 10. $6 d$.

Toverensis (neighbourhood of Tovar, New Granada).-The pure white species; it bears three, or even four, snowy flowers on a spike, of good size, and faintly scented. There is no more charming Masdevallia, though a multitude more showy. Like rosec, it prefers more heat than the warm end of the Odontoglossum house can give in winter, but those who cannot meet its wishes need not despair. In an ordinary season it does well enough, and in that case it is quite sure to bloom about Christmas New Granada. 3s. $6 d$.

N.B.-If the spike be not cut it will flower again next year, and sometimes the year following.

Tricngularis.-Poor in colour and size, but wonderfully profuse of bloom at midwinter, and wonderfully lasting - virtues which redeem its poverty. Ochrous yellow, spotted with brown. Always moist. New Granada. 1843. 5 s.

Triaristella (three bristles).-A lovely mite. Brown-crimson, with yellow tails. In the lower 


\section{Masdevallia}

sepals these spring not from the tip but from the sides-an eccentricity beyond comprehension. Summer. New Granada. 1876. (Gem.)

Trochilus.-Synonym for Colibri.

Veitchii. -Largest of all the red species, and incomparably most striking. The flowers are little less than four inches across, of the liveliest orangescarlet, with darker veins. Nature has no tint more showy, yet it is soft as velvet. The history of the plant is fascinating. Mr. Pearce brought it to his employers, Messrs. Veitch, from Peru, in 1869, but he did not reveal the habitat. Mr. William Bull engaged him to return and make a fresh consignment; but by some chance he was detained at Panama, and he could not resist the temptation to employ his leisure in a search for Cypripedium planifolium-a fine species dwelling in those parts, which has never been secured alive. Mr. Pearce failed, like others-worse, for he caught the swamp-fever. The Indians carried him back to Panama, and there he died. The secret of Mas. Veitchii perished with him. Every collector visiting Peru has tried to recover it, and natives in abundance have been inquiring ever since, but without avail. Like most of the genus, however, it propagates freely, and plants may be obtained at a very reasonable cost. They flower generally 


\section{The Culture of Greenhouse Orchids}

in autumn, sometimes in spring, not infrequently at both seasons. $5 s$.

The variety called grandiflora often measures seven inches across. $42 \mathrm{~s}$.

Vespertilio (a bat).-Very small, white, with purple dots. New Granada. (Gem.)

Wagneriana (Mr. Wagner, an amateur).--Yellow, speckled with red. Always wet. Central America. 1855. (Gem.) 5s.

Wondlandiana.-White, with purple markings. Summer. 1886. (Gem.)

Y'enthina (golden).-Yellow, with violet blotch. Summer. New Granada. (Gem.) $5 s$.

\section{Maxillaria.}

This genus takes its name from the peculiar appearance of the column, in which a fanciful eye may discern something like the jaws of an insect, masilloc. It bears a resemblance to Lycaste in growth as in flower; most of the popular Lycastes were described as Maxillarias formerly, and the trifling error is still common.

Maxillarias are all American, and cool. One or two prefer more warmth than suffices for Odontoglots in winter, but they take no harm with $50^{\circ}$ as a minimum. Such are marked in their place. 


\section{Maxillaria}

They resemble Lycastes also in tenacity of life and ease of culture. All do best in pans, with peat and moss; but I may observe that the Belgian system is particularly successful in both cases. In summer Maxillarias must be kept wet, and in winter they must not be suffered to dry up. The harsh leaves of some species warn us that sunshine is agreeable to them, but these also want shade at midsummer.

The flowers are mostly large, upright, single, and triangular in shape. Under such conditions grace is not to be expected, but they are decidedly handsome, as a rule; also they have the merit of lasting for an unusual time. The flower-spike springs from the base of the pseudo-bulb when mature.

Acutipetala (sharp petals).-Orange, with red spots. Costa Rica. Spring. $21 s$.

Candida.-White. Summer. Brazil. 10s.6d.

Dichroma (two colours).-White. Petals tinged with purple at base. Winter. Ecuador. 21s.

Fucata (painted).-A large species of characteristic colouring, and certainly impressive. Sepals and petals white at base, yellow, with red spots, at tip, and smudged with purple in the middle. Summer. Ecuador.

Grandiflore-Always admired. Large, white, 


\section{The Culture of Greenhouse Orchids}

agreeably scented. Very cool. Spring. Peru. 1850. $7 s .6 d$.

Harrisonice.-Vide Lycaste Harrisoniz.

Hïbschi (Mr. Hübsch, a collector).-White. The lip has a mauve-purple margin, two blotches, and a few dots of purple at the base. Summer. Peru.

Lcpiclota (scaly).—Of good size. Yellow. The sepals purplish-brown. Not less than $50^{\circ}$ in winter. Autumn. Ecuador. 3s. 6d.

Lutco-alba (yellow-white).-Curious and pleasing in shape. The sepals, narrow in proportion to their length, are white at the base, tawny yellow above; the two lower droop, and even reverse. The petals, much shorter, point furward like ears of an animal; white at base, clouded and striped with brown midway, yellow at tip. It flowers generally in winter. New Granada. 18t6. $5 s$.

Nigrescens (blackish).-Not beautiful, but effective for its port-wine colour; suffused on the lip with purple. Very cool. Flowers irregularly. New Granada. 1849. 5s.

Picte (painted).-So old and so familiar that it claims mention; wonderfully free-flowering, too, but not otherwise to be commended. Flowers small, yellow, dotted with chocolate; lip white, spotted with purple. Autumn. Brazil. 1832. 3s. 6el. 


\section{Maxillaria}

Proestans (foremost).-Yellow, with brown spots. April. Guatemala. 1884.

Sanderiana.-A species which made prodigious sensation when first beheld in 1884. It has the merit of size and eccentricity, even of impressiveness, but I can see no beauty. The world in general, however, still regards this as the finest of the Maxillarias. It is white, rather smudged than blotehed at the base with deep maroon, and spotted therewith. Generally grown in a basket, because the flower-stalk is rather short and the foliage heavy; thus it shows best from below. Not less than $50^{\circ}$ in winter. May. Peru. 1884. 10s.6d.

Splendens.-White; lip orange, margined with rose. Peru.

Tenuifolic (thin-leaved). -I should repeat my remarks about $M$. picta with even more emphasis. The single virtue of this species is antiquity. Small yellow flowers dotted with crimson. Spring. Mexico. 1839. 3s. $6 d$.

Turneri.-Rather small. Brown and crimson. Scented. Spring. Mexico.

Venusta (beautiful).-Very pleasing. Large; white; the front lobe of the lip yellow, and two crimson spots on the disc; side Jobes margined with crimson. Flowers irregularly. New Granada. Venezuela, etc. 1862. $5 s$. 


\section{The Culture of Greenhouse Orchids}

Mesospinidium. (Thorn in the middle.)

Botanists no longer recognize this genus, including the species it contains among Cochlioda. But for orchid-growers generally that name is confined to Noetziana, and Mesospinidium still flourishes.

Rosea.-The flowers of this species, though pretty, are so small and slender that a single plant is scarcely worth growing. Three or four in a pan, however, each with its garland of twenty blooms, perhaps, make a charming picture. Rosy, with a snow-white column. Winter. Peru. This is often called Odontoglossum roseum. $10 s .6 d$.

Sanguinea.-Much like the former, but its rosy hue inclines to scarlet. Ecuador. $7 s .6 d$.

Vulcanica.-So called from its habitat on Peruvian volcanoes. One of the daintiest flowers that blow, if a good variety-that is, large; but the biggest are only large by comparison. I have had one for several years which throws out two spikes, with an increasing number of blooms, in early autumn. Last season they were fifteen and eighteen. Rosy purple, with a touch of white in the centre. Ecuador. 10s. 6d. 


\section{Miltonia}

\section{Mrltonia.}

The genus is named after Lord Milton, an enthusiastic orchidist in the first quarter of the last century. Not many species will thrive in the cool house, unfortunately.

Miltonias prove, upon dissection, to be closely allied to Odontoglossums, but in appearance they are very different. The flowers are curiously flat, conspicuous for that reason, and large; but few in number, generally, by comparison with Odontoglossums. They spring from the side of the bulb as it ripens.

The leaves are so apt to turn yellow that it is commonly thought natural, but this is not so. Too strong light causes the disfigurement, which, however, does no harm-if it be merely a change of colour; when plants flourish in a certain spot, to move them because the leaves turn yellow is hazardous, for they love the light. It is a genus very easily cultivated.

Miltonias should be treated in every respect like Odontoglossums-kept wet in summer and slightly moist in winter, for they are always growing. No orchids, perhaps, are so cruelly affected by tobacco smoke, which is doubly unfortunate, because none 


\section{The Culture of Greenhouse Orchids}

suffer more from insects-thrips especially. But the invaluable XL does not hurt them.

Candida (white). - A handsome species. The large flowers are chestnut of sepal and petal, touched here and there, and margined, with yellow; the broad lip is snow-white, turning to ivory yellow after a few days' exposure. Autumn. 1830. Brazil. 10s. $6 d$.

Clowesii (Mr. Clowes, an amateur).-A very striking combination of colours-chestnut, with yellow blotches, deep soft violet at the throat, and pure white beyond. Autumn. Brazil. 1843. 5s.

Cuneata (wedge-shaped).-Deepbrown, tipped with greenish yellow; lip white and spreading. Late winter. Brazil. 7s. $6 d$. This species will not do in a house which falls below $50^{\circ}$.

Flavescens (yellowish), otherwise stellata (starry), is a variety of this. It bears a longer and finer spike, very pale yellow, almost white. Summer. Brazil 7s. 6d. I have a special admiration for this flower. Unfortunately, though it will live and bloom in the cool, it thrives best in the Cattleya house. So does-

I'halenopsis (like a moth). -A little gem. Sepals and petals white, lip white, splashed and spotted with brightest purple. Spring. New Granada. 1850. 7s. 6i. Also called Oncidium phalcenopsis. 


\section{Nanodes}

I do not advise the amateur to buy this plant unestablished; the most skilful of growers find it very difficult to start. In truth, it is not to be described as an easy species even then; for in one house it will grow like a weed, and in another, for reasons inexplicable, it will not live. Some authorities recommend warmer quarters in winter, which again is odd, for the species is Alpine, living at a height of 6000 feet, as is alleged. For my own part, I find that it does well among Odontoglots the year round; but circumstances differ, of course, in one house and another.

Stellata. Vide flavescens.

\section{NANOdes. (Pigmy.)}

This genus is abolished, and its single species ranks among Epidendrums; but the unlearned public does not readily admit that a plant so extraordinary, so unlike all other orchids, should not have a name of its own.

Nanodes Medusce has a cluster of short fat stems with thick grey-green leaves. The flower is of good size, leathery, with dull green sepals and petals and spreading lip, heart-shaped, dusky purple in colour, bordered by a deep fleshy fringe. In all respects it is an unholy-looking object- 


\section{The Culture of Greenhouse Orchids}

Sir Joseph Hooker describes it as "sinister"-and this fringe suggested the snaky hair of the Gorgon, whence its name. Summer. Ecuador.

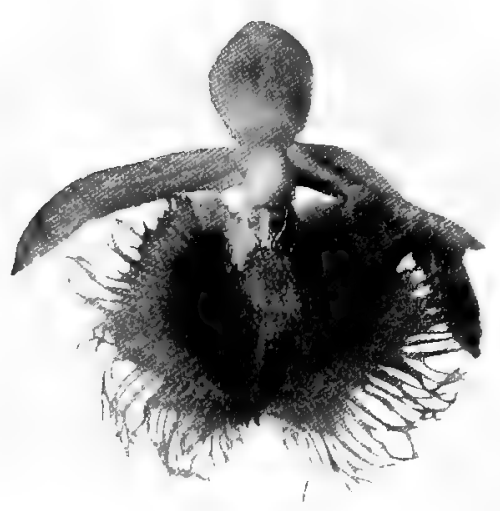

NANODES MEDUSE-EPIDENDRCA MEDUSA.

\section{Odontoglossum.}

The name of this genus signifies "Toothtongue," referring to the shape of the labellum; it contributes the great majority of plants usually grown in the cool house. A hundred species may 


\section{Odontoglossum}

be obtained at small expense, not counting varieties; and very nearly every one is as easily cultivated as a geranium. I do not propose, however, to name all of them. Of none, perhaps, can it be said that they are not worth growing; but there is a vast difference among them in quality.

Odontoglots are exclusively American, dwelling in the tropical and sub-tropical parts of either continent. Those with which we are concerned, however, live in mountain forests, not less than 5000 feet above sea-level-generally more. Many species must be subjected to frost occasionally. Mr. Smee has carried through some very interesting experiments in this matter. He found that odont. crispum, or Alexandre, for instance, was not permanently affected by exposure when the night air fell several degrees below freezing. Thirteen degrees killed it. But it must be understood that these were simply tests. Most tropical plants will bear extreme cold "once in a way." I have seen the convicts at Lahore gathering ice from pans in the Botanic Garden when tender orchids were blooming on the trees above, palms and tropic shrubs stood around, and the superintendent's house was ablaze with Bourgainvillea from top to bottom. But the frost must not be continuous. In fact, $40^{\circ}$ Fahrenheit is the minimum which cool orchids will endure, 


\section{The Culture of Greenhouse Orchids}

through the winter, without suffering; and I admit this low figure only as a solace for persons who find themselves unable to keep the house warmer during frost. At $40^{\circ}$, in the dull season, Odontoglots will take no harm, if great care be used in watering them, and the air be kept dry. A little too much moisture under such conditions discolours the leaves and threatens the young growth, for they are growing in winter. But experience shows that cool orchids do best when the house stands at $50^{\circ}$ about midnight, and from that point gradually drops till morning, but not below $45^{\circ}$. There are a few species which seldom meet with such a high temperature at home, dwelling far up the mountains. They have to make the best of it, put in the coolest place that can be found.

Living on trees, at no great height from the ground, and therefore well shaded, Odontoglots will not bear hot sunshine. It is necessary to protect them, as a rule, from the beginning of March to the end of September, but much depends on the aspect of the house and on the season. If blinds can be used, that is best, for permanent shading excludes the light when there is no sun; but to run the risk of exposure is infinitely worse. In effect, whitening the glass does very little harm, and saves much trouble. But a sort of Venetian 


\section{Odontoglossum}

blind, which pulls up and down, is most excellent of all. It may be bought under the name of "wooden shading."

Odontoglots demand as much moisture in the air as can be given, and a great deal at the roots, from March to the end of August. They must not be allowed to dry at any season. I know how difficult it is to pronounce upon the quantity of water which should be given, because the conditions of a house are so different; but at the same time I am conscious that some sort of practical hint is necessary, for very much, not to say all, depends on watering. There are amateurs of my acquaintance who syringe heavily twice a day from the time when their Odontoglots have gone out of flower till the late autumn, and go through the house carefully, watering-pot in hand, twice a week. I have heard of others who water, with a fine rose, every day, which comes to much the same thing. Such treatment is not to be recommended, but it aids us in getting an idea. Plants live under it and flower, usually, but they do not thrive. Not a few rot suddenly by times. It must be observed also that these gentlemen ventilate most freely, and rely much upon their watering to damp the air; they do not like to splash the walls and floor and everything in the house several times a day, as I advise, in summer. 


\section{The Culture of Greenhouse Orchids}

I myself syringe only after a hot day. I glance over the shelves every morning; but I know where to look for the situations where plants are likely to be dry. Not till the third day, even in summer, will the bulk of them want water. But it is necessary to understand that mine is a lean-to house facing north and south, with brickwork on either hand; and that the floor, walls, stage, everything except the plants, are deluged with the hose morning and evening, and once or twice between, in hot weather.

I trust the reader finds some guidance in contemplating these extremes. The Latin Grammar contains an appropriate motto-In medio tutissimus ibis.

If the house is to stand at $50^{\circ}$ to $45^{\circ}$ all night, the reader can judge for himself when fire-heat becomes necessary. It may be in October or November, and it may cease for good in April. There is a general rule, however-Better too cold than too hot. To "smell the pipes," as gardeners say, is a warning of danger. Tnrn the hose upon them at once, and raise a cloud of steam. Some authorities object to this practice, but not so many now, I think, as formerly. They assert that it causes the tips of the leaves to wither, especially those of the favourite $O$. Rossii. I suffered from 


\section{Odontoglossum}

this annoyance at one time, and, naturally, put it down to the cause alleged. Nevertheless, I continued to raise steam in moderation, and presently it vanished. Why it came and why it went is equally mysterious. Now I water the pipes freely, and no bad consequences follow.

The sphagnum moss upon the surface of the pots will give the amateur a hint whether or no his plants are comfortable. In the chapter on Potting I have described the two systems-peat and sphagnum in equal quantities, with a little Bedfordshire sand, according to the old rule; Belgian leafmould, with half an inch of chopped sphagnum on the top, according to the new. In either case the moss upon the surface will take root and grow if all be well. Then, should its green heads look grey, be sure your orchid wants water-or attention, at least; should they look dull and dark, it is getting too much water.

The great majority of Odontoglots flower in the spring-the wet season of their native country. Under cultivation accidents imperceptible to us will cause many to delay, which is not to be regretted by any means. But nine in ten should bloom between February and July. The pseudobulb, therefore, will be ripening from the end of November onward. If too much water be given 


\section{The Culture of Greenhouse Orchids}

during the process, instead of pushing a flowerspike, the perfected bulb will start into new growth. If not a large plant, probably it will try to escape blooming at all that year. Therefore, when an untimely growth is ripening, perhaps in the late summer, it must be watched and dried, and thus compelled to flower. All these operations are as simple as could be, even for a beginner, if he bear my hints in mind; but for want of such elementary instrnction many an amateur keeps a plant for years, healthy, perhaps, and constantly growing bigger, but not flowering. When it reaches a certain size, however, it must throw up a spike.

N.B.-It is safest to put those which should be watched by themselves.

Doubtless it is best to re-pot Odontoglots every year, at the moment when new roots are pushing; they welcome the new sweet compost or leaf-mould with delight. But that is a long job, at a time when gardeners are busy out-of-doors. There is no cause for alarm if the operation be deferred to next year, or even the year after; but in such cases watering must have been done so judiciously that the stuff is not sour. Nevertheless plants will not grow as they should if not provided with fresh material once in two years at the least.

Odontoglossums are a boon unmixed. They have 


\section{Odontoglossum}

every virtue-supremest loveliness, strong constitution, easy and cheap culture. In especial, to my fancy, their growth in winter is to be commended. January and February are dreary months for the amateur who has no orchid-house. There is work, of course, for the grardener, but not of the sort which interests his employer. Just then, however, the Oduntuglots are preparing to bloom. It is a pleasing duty to go round the house, on a dull Sunday morning, and peer into the axils of the leaves; for, if one see there the small green head of the spike pushing upwards, somewhat more water must be given. And then, if it be a new importation, unflowered as yet in Europe, one has weeks of delicious expectancy.

But even spring-flowering Odontoglots do not necessarily bloom at that season. The spike appears, as has been said, when they are finishing their growth. In the case of 0 . crispum (Alexantre), loveliest of all, and some others, that may be, actually, any month in the year. A skilful gardener makes a wondrous show in May and June. Every crispum is in bloom. But I think the amateur who has less skill at command need not envy the display. His own plants, though quite as healthy, have not been so scientifically treated, perhaps; and thus it may happen that he has some flower every month in the twelve. 


\section{The Culture of Greenhouse Orchids}

Finally, no Odontoglot lasts less than a fortnight in perfection; some last four weeks.

I have not given all the cool species. The catalogue which may be found in books of reference contains a few-very few-scarcely worth attention, some which are too costly for the modest amateur, and some so rare that only half a dozen specimens or less are known. Further, there are numberless varieties, differing, as orchids will, from the type, and every one named. For example, Mr. Bull offers twenty-three different forms of Odont. crispum (Alcuandre) in his sale catalogue. Not less than a hundred, certainly, are registered; but some of those long titles represent the single plant known to exist. It is not my purpose to treat of curiosities. Nevertheless, I shall name a few famous varieties of crispum, because they are so often mentioned, in conversation and in print, that the reader ought to know something about them.

The colours given represent the general effect; when the lip differs notably from the sepals and petals in this respect, its hue is noted.

Adricnoe.-A natural hybrid of crispum and Hennowellicumu, which seens to have sprung into fashion of late-at least, it is much more common than formerly at shows. A very striking flower always, though two specimens alike could hardly 


\section{Odontoglossum}

be found. Very neat of shape; of any shade, from white to yellow, freckled all over with varying tints of brown. Spring. Columbia.

Andersonianum (Dr. Anderson, botanist).-A

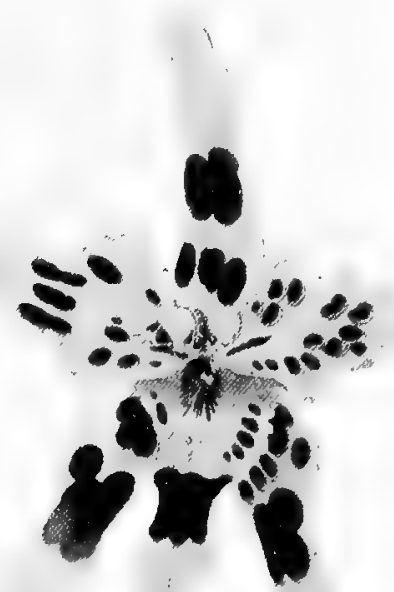

ODONTOGLOSSCM ANDERSONIANUM.

natural hybrid of crisp. $\times$ gloriosum. The varieties are innumerable. Ivory-white, splashed with chestnut-brown. March to May. Columbia. 5s. 


\section{The Culture of Greenhouse Orchids}

\section{Apiatum.-Vide crispum apiatum.}

Aspersum (sprinkled).-Probably a natural hybrid of Rossi and maculatum, much like the former, saving that the petals and lips are yellow instead

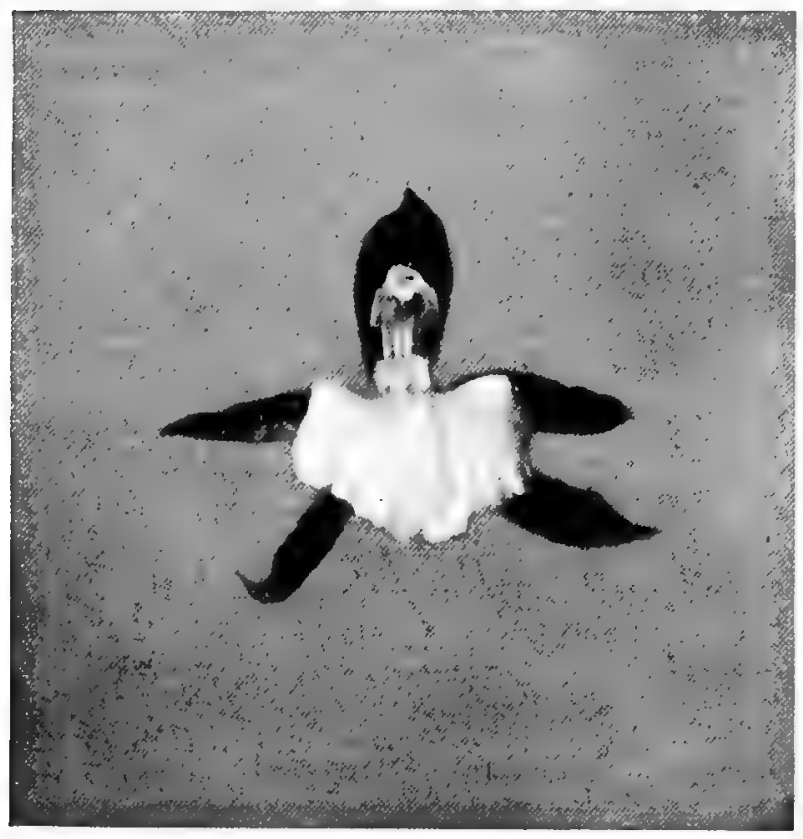

ODONTOGLOSSUM BIOTONIENSE.

of white. A lovely flower. January and February. Mexico.

Baphicrnthum.-A natural hybrid, assigned to crispum $\times$ odoratum. Ground colour pale yellow 164 


\section{Odontoglossum}

thronghout, sepals and petals blotched with brown. Spring. New Granada. $5 s$.

Bictonicuse (Bieton, seat of Lord Rolle).-A contrast to the majority in colour. Green or reddish, mottled with brown; lip rosy-white. Autumn. Guatemala. 1835. 5s. Figured, p. 164.

" album.-Very rare and very beautiful. Chestnut, with a broad white lip.

Blandum (pleasant).-White, spotted and splashed with brownish crimson. Scented. March and April. New Granada. 1871. 10s. 6d.

Curinifirum (keeled, referring to a peculiarity of shape).-A large, handsome species. Greenish brown sepals and petals tipped with yellow. Lip reddish yellow. Autumn. Costa Rica. 10s. 6d.

Cervantesii (Don Vincente Cervantes, a Spanish botanist).-Small, but exquisite. White or pale pink, the lower part of sepals and petals decorated with short broken lines of brownish crimson. It should be rested, but not dried, for two months after flowering. There are many named varieties. March to May. Mexico. 1847. 3s.6d.

" decorum.-The largest variety. The broken bars are shorter and of deeper colour. They occupy a larger space. Figured, p. 166.

Chestertoni (Mr. Chesterton, collector).-One of the many natural hybrids produced by crispum $\times$ 


\section{The Culture of Greenhouse Orchids}

luteo-purpureum. White, sepals barred, petals spotted with chestnut brown. Lip yellow, with a large splash of chestnut. Spring. New Granada. Cirrhosum (like a cirrhose or scudding white

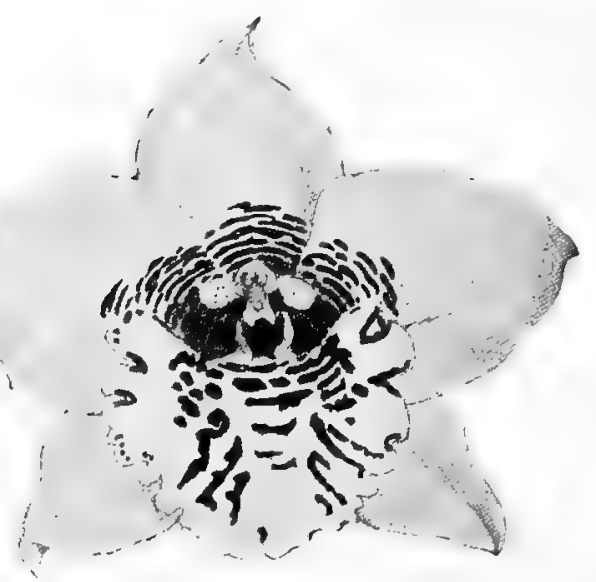

ODONTOGLOSSOM CERYANTESII DECORCM.

cloud).-A notable species. White, closely dotted with chocolate. Peculiar in shape, and very charming. Sepals, petals, and lip long, narrow, "flyaway." April and May. Ecuador. $5 s$. 


\section{Odontoglossum}

Citrosmum (lemon-scented).-One of the special beauties. Long pendent sprays creamy white, or pale lilac, sometimes speckled all uver with tiny dots; the lips suffused with mauve. But two

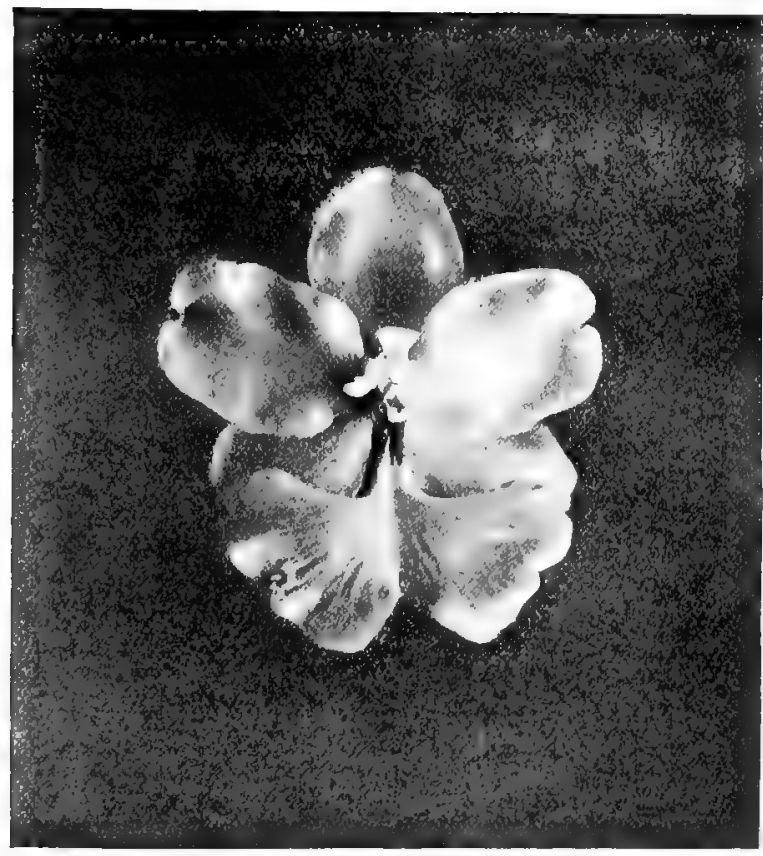

ODONTOGLOSSUM CITROSMLM.

plants alike are searcely seen. This species must be rested severely through the winter. In a moist house it will scarcely need water from the time its pseudo-bulbs approach maturity until the flower- 


\section{The Culture of Greenhouse Orchids}

spike is well started; but it must not be allowed to shrivel. Water once a month is a good general rule. If too much wetted at this time, it will not flower. The spike appears at the side of the young growth when an inch or two inches high. It must be looked for; the plant wants abundance of water then. In these respects citrosmum is exceptional ; also it loves the sun, asking only a slight shade. March to May. Mexico. 1840. 3s. 6d.

C'oradinei (Mr. Coradine, a collector).-A natural hybrid of crispum $\times$ Lindleyanum. Graceful, and comparatively cheap of late. Pale primrose, blotched with chestnut. January and February. New Granada. 1872. 10s. 6d.

Cordatum (heart-shaped). - Yellow ground, splashed and broadly tipped with chestnut; lip white, similarly spotted and tipped. April and May. Mexico. 1837. 3s. 6d.

Coronarium (crowned).-A large climbing species, peculiar in growth and bloom, copper colour, edged with yellow, and yellow lip. One of the stateliest Odontoglots. The pair of giants in Baron Schröder's collection, the noble plant of Mr. R. H. Measures, bearing eight flower-spikes this spring, are not to be forgotten by those who see them. It has the reputation of "doing badly," because, I think, imported specimens are rarely in good condition. If I 68 


\section{Odontoglossum}

well started it gives no trouble, in a basket or a raft. Spring. New Granarla. 1847. 21 s.

Crismum (sometimes called Alrimdro).-The most beautiful of flowers. White, often flushed with rose, and generally-not always-more or less spotted with cinnamon-brown. Flowers naturally from March to the end of June. New Granada. 1841. 3s. 6d. Figured in plate.

Some notable varieties of crispum, such as the reader is likely to hear mentioned, are-

"Amesianum (F. L. Ames, Boston, U.S.A.).Very nearly fire inches across. Sepals rosy, with two or three large red-brown blotches; petals white, but the surface is almost hidden by splashes of red brown. 1891 .

"Annic.-Large, rosy, closely spotted with bromn crimson. $\mathbf{1 9 0 0 .}$

" apiatum (bee-like, alluding to the heavy spots).-Unique. In possession of Baron Schröder, who has obtained three plants of it by dirision. Tery large and broad, blotehed all over with crimson chocolate. 1886.

"Cooksoni.-Enormous. Charmingly spotted with brownish crimson of a lively shade. Norman Cookson, Esq. 1885.

, Duke of Fork.-Of great size. Sepals rosy, with bright red spots; petals white, with large red 
The Culture of Greenhouse Orchids

blotches and dots. The lip has a big red patch in the middle. W. Thompson, Esq. 1899.

"Franz Masereel. - One of the best forms.

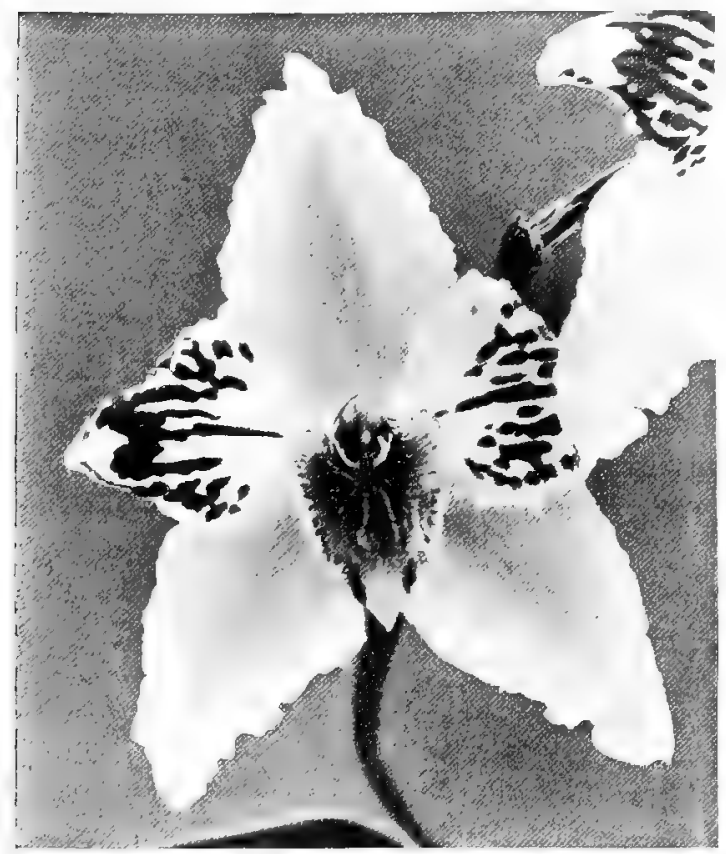

ODONTOGLOSAUA CRISPUA LADY JANE.

White, flushed with rose-purple, thickly spotted and dashed with crimson. Jules Hye, Ghent. 1894.

"guttatum.-Flowers immense; white, dotted I70 


\section{Odontoglossum}

with red. Base of lip yellow, also dotted with red. Sir Trevor Lawrence. 1884.

" heliotropium.-Bright rosy lilac, spotted with red brown. R. Brooman White, Esq. 1897.

"Lady Jane.-In this very singular example the sepals are spotless, while the petals are heavily marked with red-brown lines and dots almost parallel with the margin, giving a general appearance of streaks which unite in a blotch towards the tip. The whole flower is solid as if cut in wax, and it measures not less than 33 inches in diameter. J. Wilson Potter, Esq. Figured, p. 170. , Mundyanum. - White, tinged with rose purple, heavily blotched with purplish brown. N. Cookson, Esq. 1901.

"Pittianum.-Second only to apiatum. Both petals and sepals are almost concealed by redbrown blots, the margins and tips white. It is understood that a cheque for $£ 750$ was forwarded for this by post, and returned. H. J. Pitt, Esq. 1901. Figured, p. 172.

"Sanderce.-So thickly covered with chestnutcrimson blotehes that the white surface is hardly visible. 1892.

"The Earl.-Very large. Sepals grandly splashed with strawberry red; petals and lip have one great splash in the centre. 1900. 


\section{The Culture of Greenhouse Orchids}

Cristatellum (small crest). - Sepals and petals yellow, touched with glossy brown, lip brown, tipped and marked at the sides with yellow. Ecruador. 10s. 6u.

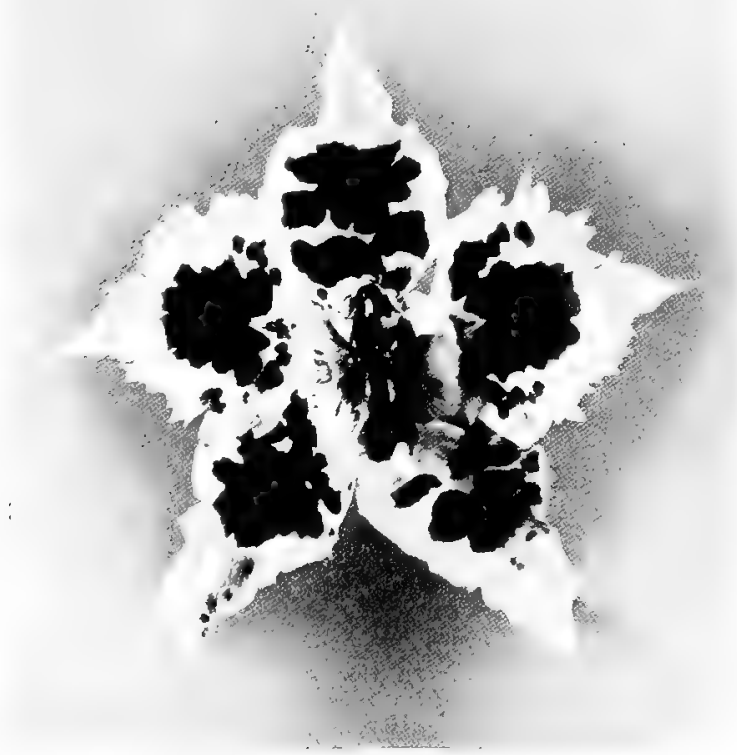

ODONTOGLOSSUM CRISPUA PITTIANUM,

Cristatum (crested).-It may be said that the colouring of cristatellum is reversed in this case. Spring. Ecuador. 10s. $6 d$.

Cuspictutum (pointed).-Natural hybrid of luteo- 


\section{Odontoglossum}

purpurcum and gloriosum. Yellow blotched with brown. Lip yellow, with a great central blotch. Spring. Columbia.

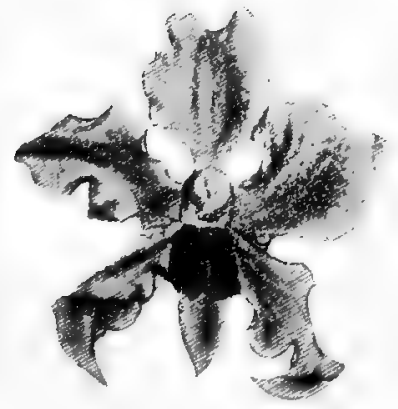

ODONTOGLOSSTM EDWARDI.

Edwardi (Mr. Edward Klaboch, a collector).-A stately species, and unique in colour. It throws up a long branching spike which bears a great number of small flowers, rich dark violet of hue, with a 


\section{The Culture of Greenhouse Orchids}

gleam of gold in the lip, singularly effective. In form they are curiously like those of the potato. Ecnador. Early summer. 1880. 10s. 6d. Fignued, p. 173.

Eleyans.-An exquisite flower; of the tenderest yellow, spotted and dashed with chocolate. Lip white, with a chocolate blotch. Spring. Ecuador. Doubtless a natural hybrid, or rather two, under the same name. The smaller varieties represent cirrhosum $\times$ cristatum; the larger and finer cirrhosum $\times$ Halli.

Excellens. -Soft yellow fading into white, with purple blotches. Always charming, and sometimes beautifnl beyond description, as in Baron Schröder's famous specimen. A natural hybrid of Pescatorci $\times$ triumphans. Late spring. New Granada.

Facetum (cone-shaped).-Perhaps a hybrid of sceptrum and Hunnewellianum. Pale yellow, heavily blotched with chestnut. I have seen varieties of this as handsome as any Odontoglot whatsoever of the coloured class. Spring. New Granada. 15 s.

Gloriosum.-A very variable species, found in company with crispun. Sometimes lovely, but, as a rule, not striking. Yellow, spotted with bright chestnut. Stongly scented. April and May. New Granada. 3s. 6ct. 


\section{Odontoglossum}

Grande.-The most showy of Odontoglots, bearing as many as six flowers, each five to seven inches across; deep yellow, barred with reddish chestnut,

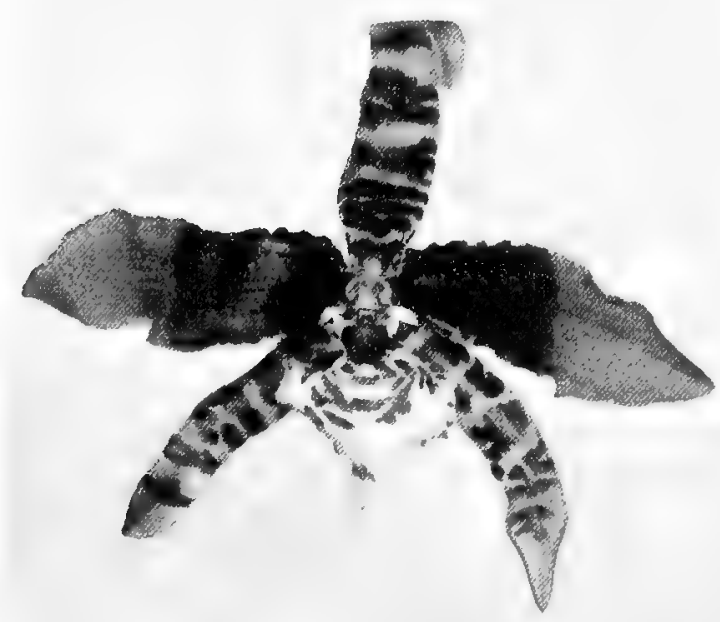

ODONTOGLOSSUM GRANDE. (One-third natural size.)

lip white, with broken bars of chestnut at the throat, and again round the edge. O. grande should be put in the warmest corner of the house. It likes sunshine, and it should be rested almost to drying 
The Culture of Greenhouse Orchids

when the bloom is past. Autumn. Guatemala. 1839. 5s.

Halli.-Large, yellow, blotched with dark brown.

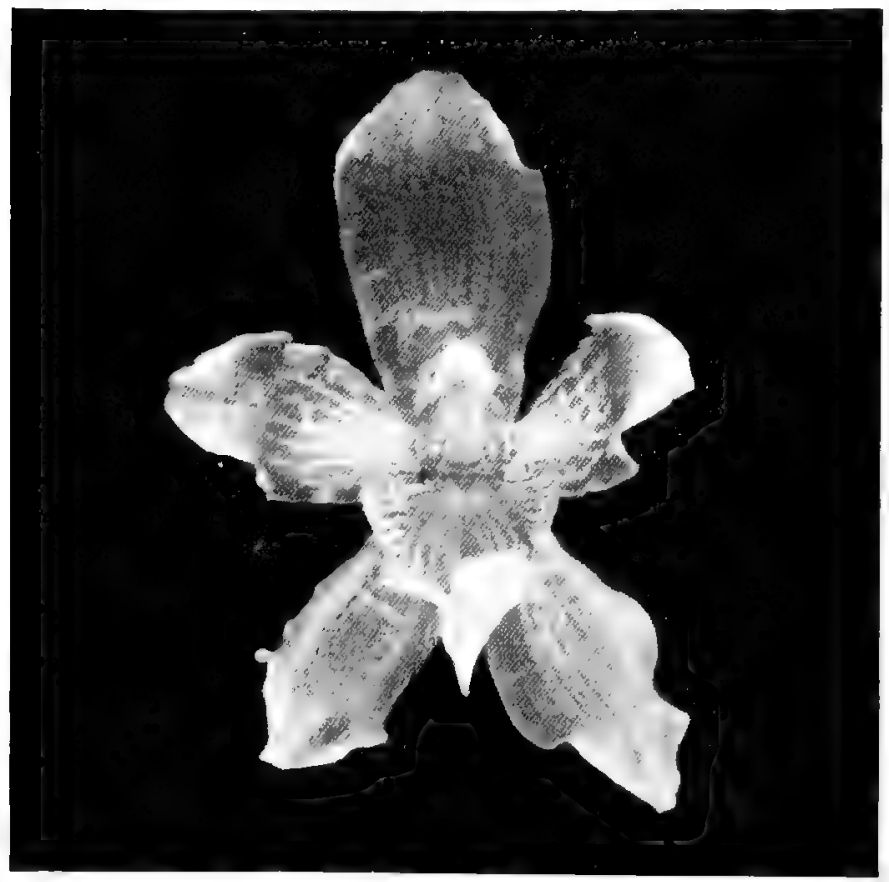

ODONTOGLOSSUM HARIYYAUM.

Lip white or yellow, spotted with dark brown, and fringed. April and May. Peru. 1864. 5s.

Harryanum (Mr. Harry Veitch).--Perhaps the wost striking of all flowers in colour, but not always

$$
\text { I } 76
$$




\section{Odontoglossum}

equally fine. A good example has dark brown sepals barred crosswise, and tipped with yellow; petals dark brown at the tip, then yellow, striped, not barred, with pale purple; both margined with yellow. The upper part of the lip has a yellow ground, closely striped with purple on each side, a cloud of purple in the midst, and a broad expanse of white below. Too often, unfortunately, the petals refuse to uncurl, and so hide much of this extraordinary display; but with care they may be forced to lie back. June to August. New Granada. 1886. 10s. 6d.

Hastitabium (spear-lip).-Greenish white, crossed with small lines of purple at the base; lip white, flushed at the throat with rose. This species likes the warmest part of the house. Scented. April and May. New Granada. 1843. 7s.6d.

Hebraicum (Jewish).-One of the hybrids of crispum $\times$ gloriosum. Yellow, inscribed, as one may say, with brown, for the marking of the petals is thought to resemble Hebrew letters. June and July. New Granada. 1879. 21s。

Humeanum.-Specially graceful in colouring. Doubtless a natural hybrid of Rossi and cordatum. Tender yellow in the sepals, barred with brown, white in the petals, spotted with brown at the base, white lip. April and May. Mexico. 63s. 


\section{The Culture of Greenhouse Orchids}

Hunnevellicanum (Mr. Hunnewell, an American amateur).-Rather small, but notable. Pale yellow, the lip white, all closely spotted with lrown. Spring. New Granada 10s. 6d.

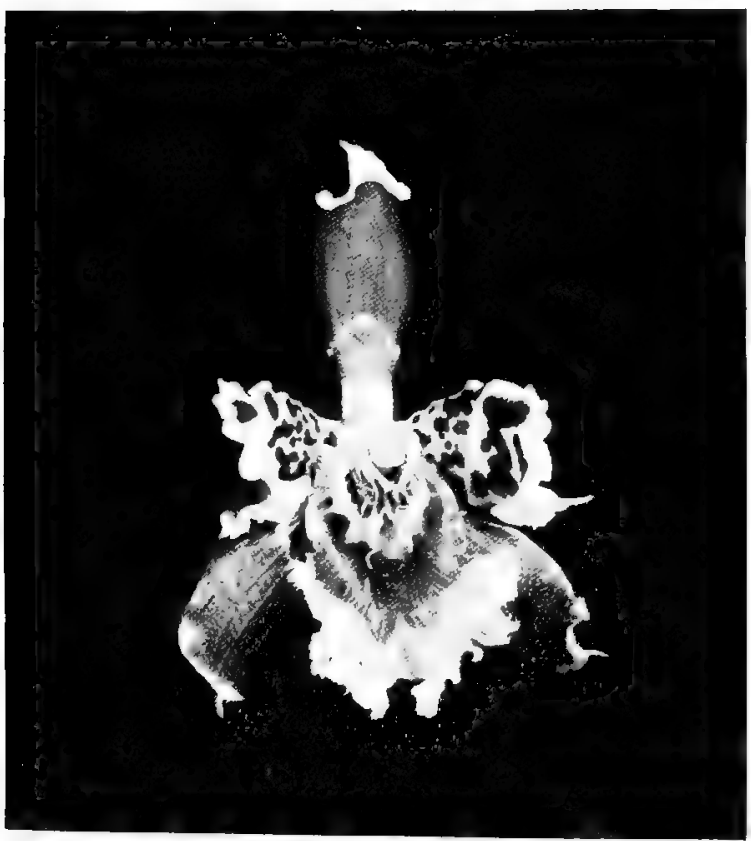

ODONTOGLOSSTM HYSTRIX.

Hystrir (a porcupine, from the shape of the crest). -A variety of 0 . lutio-purpureum, differing from the type only in form. 


\section{Odontoglossum}

Insleayi (Mr. Insleay, a gardener).-So like grande in colouring that they are not readily distinguished at a glance except by size. But Insleayi is much smaller, and the lip has a row of crimson spots along the margin. Flowers at all seasons, but mostly in autumn. Mexico. 1840. 5s.

" leopordinum-Larger and more brilliantly coloured than the usual variety. The lip also is a richer yellow, and the spots upon it brighter.

" splendens._. "Splendid" indeed, rare and costly in proportion. But it would be hard to define the vast superiority which one recognizes with equal astonishment and delight. In brief, this is a form of leopardinum glorified to the uttermost.

Kegeljani.-Vide polyxanthum.

Leter (smooth). - Greenish yellow, spotter with chocolate; lip pale lilac. Scented. April and May. Mexico. 1841. 7s. 6r. This species is difficult to flower.

Lindeni (Mr. Linden, a Belgian grower).-Pale yellow, the margins beautifully waved as if by goffering. June and July. It grows very large, and even then is reluctant to flower. New Granada. $5 s$.

Lindleyrnum (Dr. Lindley, the great botanist).-A poor flower, small, yellow, barred with brown; 


\section{The Culture of Greenhouse Orchids}

interesting only as one of the earliest Odontoglots in cultivation But it has many handsome varieties and hybrids.

Londesboroughianum.-Bright yellow sepals and petals closely barred with brown. Lip clear yellow. A difficult plant even to keep alive. It is said to do best in a warm house while growing, with a severe rest in winter. September and October. Mexico. 1876. 7s. $6 d$.

Luteo-purpureum (yellow purple).-The most variable, perhaps, of all Odontoglots. Sometimes superb, but not commonly. The type has a yellow ground, almost hidden by blotches of chestnut. The lip yellowish white. April and May. New Granada. 5s. Figured, p. 181.

"s sceptrum (sceptred).-The best variety of luteo-purpureum. Sepals all chestnut, margined with yellow; petals yellow, blotched with chestnut. Lip yellow, with a brown bloteh. $10 s .6 d$.

Maculatum (spotted).--Very like cordatum, but smaller, dull brown instead of chestnut, and yellow lip instead of white. March and April. Mexico. 1838. 3s. $6 d$.

Madrense (from the Sierra Madre).-One of the species reluctant to flower. White with purple blotches at the base. Scented. Flowers with the young growth, July and August. It is often grown I 80 


\section{Odontoglossum}

with Cattleyas, but I can guarantee that it does at least as well in the cool house. Mexico. 10s. 6d. Membrancecum.-A large and exquisite form of Cervantesii.

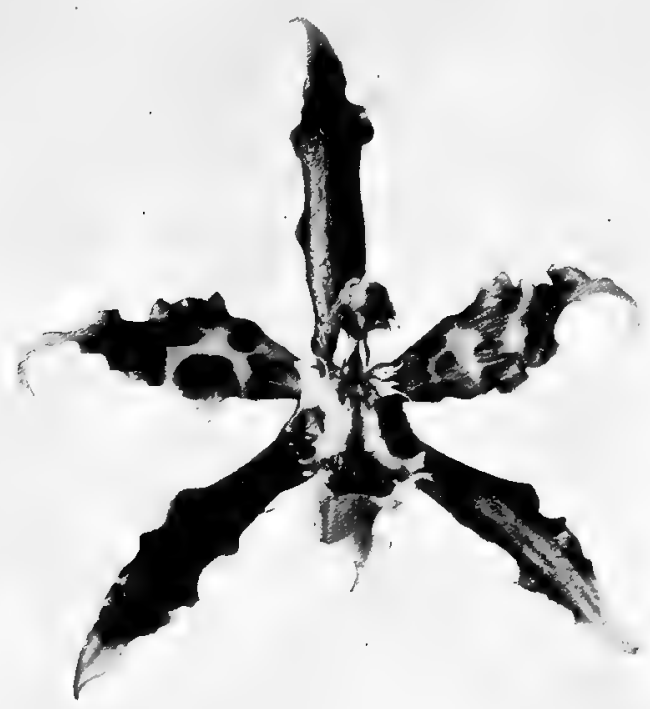

ODONTOGLOSSUM LUTEO-PURPURETM.

Mulus (mule).-A very grand hybrid sometimes, but so variable that to buy it out of flower, unless with a guarantee, is rash, seeing that it is expensive. Doubtless the parents are lutco-purpureum 


\section{The Culture of Greenhouse Orchids}

and gloriosum. A good example bears a tall branching spike with many large flowers, yellow, heavily blotched with pale brown; the great fringed lip is yellow, with a splash of brown in the middle. Spring. New Granada. 42s.

Noviun (freckled).-White, thickly speckled with rosy purple, the edges wavy. April and May. New Granada. 1842. 21 s.

Ncbulosum (cloud-like).-Large and broad. White, dotted at the base of sepal and petal and over all the lip with pale brownish red. Somewhat reluctant to bloom. Flowers with the young growth in April and May. Mexico. 5s.

Nevedense (from the Sierra Nevada).-A rare and striking species. Sepals and petals bright chestnut edged with gold. Lip of curious form, white. Spring. Columbia. 105s.

Odorctum (scented).-Yellow, blotched with chocolate. Lip white, with a similar blotch. Strongly scented. January and February. New Granada. 3s. $6 d$.

Oerstedi (Dr. Oersted, who discovered it).-A small gem, snow-white, excepting a yellow patch at the throat. April and May. Costa Rica. 1872. 7s. $6 d$.

Pescatorei (General Pescatore, an amateur).Almost a rival to $O$. crispum at a glance, and in I 82 


\section{Odontoglossum}

general effect even more showy sometimes, for the branching spike will bear fifty flowers; a hundred have been seen. White, dotted more or less with crimson. Sometimes pure white, sometimes splashed

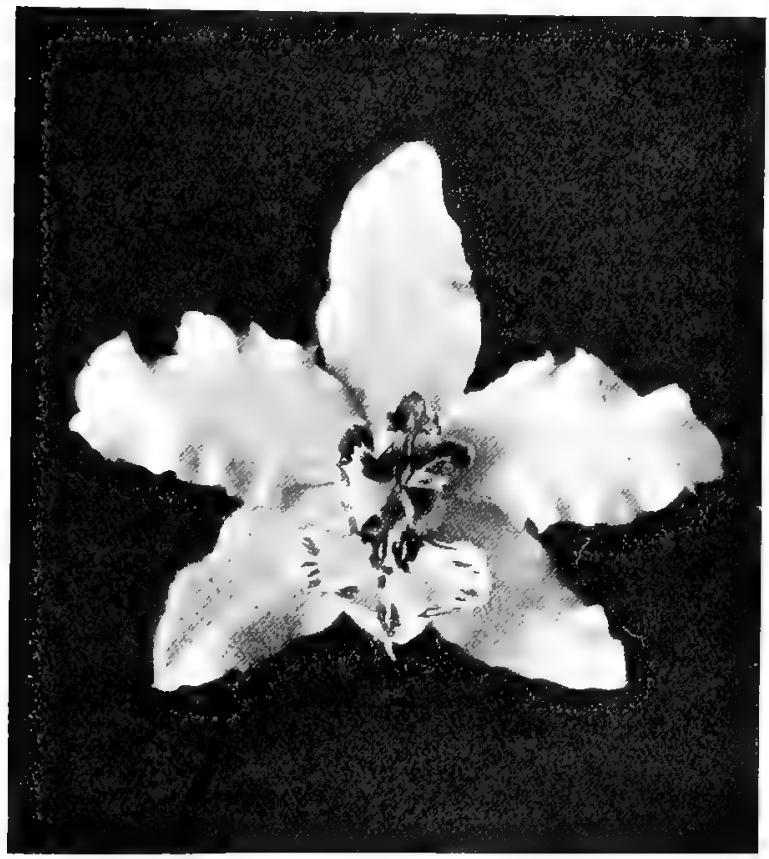

ODONTOGLOSSUA PESCATOREL.

with crimson. April and May. New Granada. 1851. The varieties are numberless. $3 s .6 d$.

Phalcenopsis.-Vide Mittonia phalcenopsis.

Polyxanthum (very golden)-Kegeljani, to be I 83 


\section{The Culture of Greenhouse Orchids}

correct.-A noble species. Its large flowers are orange yellow, boldly blotched with chocolate. April and May. Ecuador. 1878. $21 s$.

Pulchellum (pretty). - Small, but a species which has every attraction, finished loveliness, strong scent, ease of culture, winter flowering, and long duration of the blooms. Snow-white, saving a touch of gold on the lip. Perfume like Lily of the Valley. January and February. Guatemala. 1840. 3s. $6 d$.

Ramosissimum (very branched).-Most charming when the white curly flowers open well, and the colour of their spots is distinctly blue. That is not the rule, unfortunately, but the long-branched spikes always make a pretty show. A lilac variety often appears. March and April. New Granada. 1871. $15 s$.

Reichenheimi-An improved variety of 0 . loeve, more strongly scented.

Kosenm (rosy).-Vide Cochlioda sanguinea.

Rossi (Mr. Ross, Mexican traveller and collector). -A favourite with all. White, sometimes rose; sepals spotted all over, petals only at the base, with chocolate brown; lip pure white. Too often the brown is pale and weak. When the flower reaches two inches in width, it receives the title Mrrijus, but there is no specific difference. It should I 84 


\section{Odontoglossum}

be rested, but not dried, for two months after flowering. Indeed, it wants less water than wost at any time. January and February. The bloom

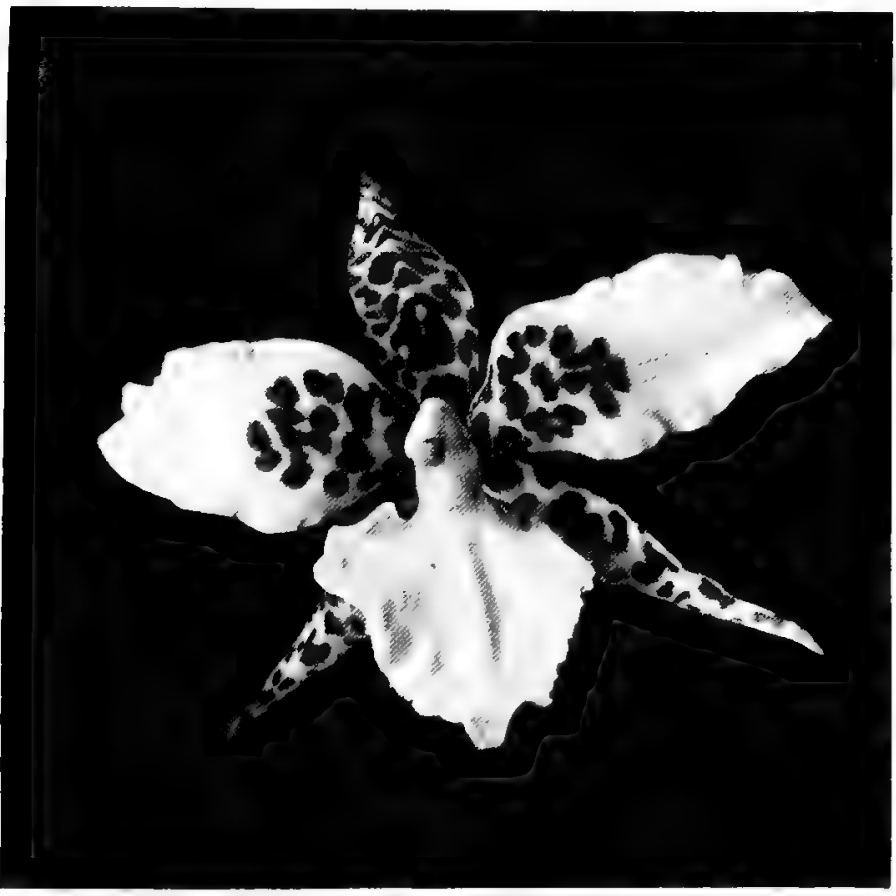

ODONTOGLOSSUM ROSSI.

will last two months, but to keep it so long is injudicious. Mexico. 1842. Many varieties. 2s.6d. Ruckcrianum (Mr. Sigismund Rucker, amateur).A natural hybrid of crispum $\times$ gloriosum. White, I85 
The Culture of Greenhouse Orchids edged with purple, splashed with brown; lip yellow, similarly splashed. The name is applied very freely, not to say recklessly, to any hybrid

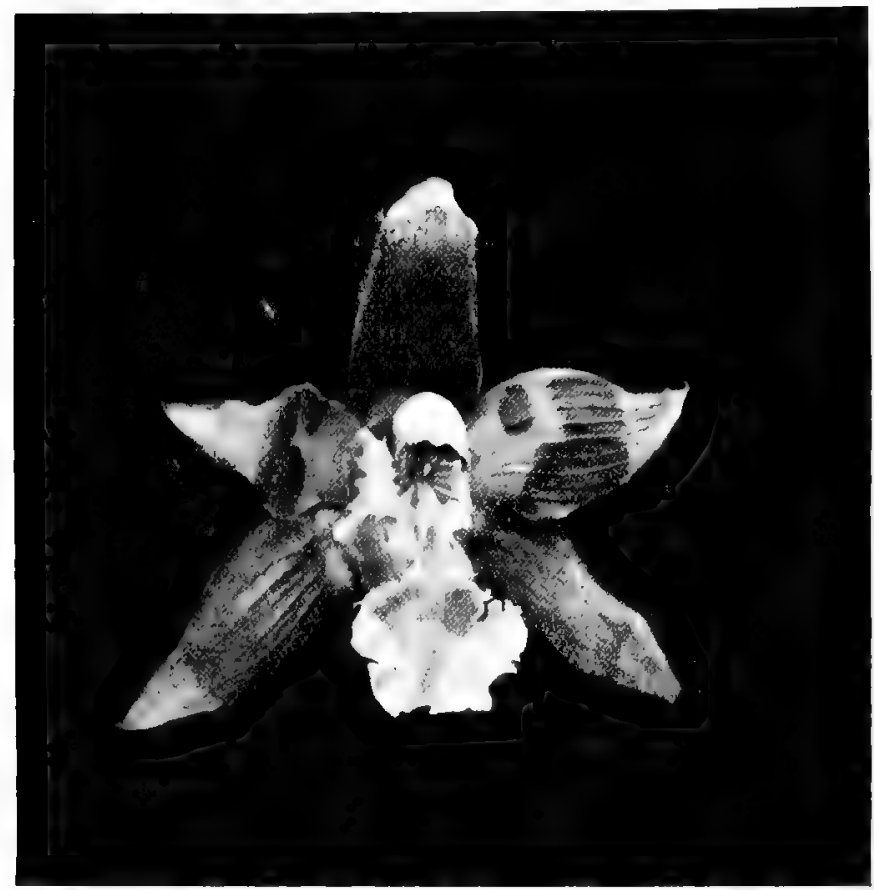

ODONTOGLOSSUM TRIPUDIANS.

approaching this description. May and June. New Granadi. 31s. 6d.

Sandcricnum (Mr. Sander, of St. Albans). - Very handsome when well grown. Pale yellow, spotted 


\section{Odontoglossum}

with brown, purple markings on the lip. A small plant is not conspicuous, but it has the attraction of a very strong scent, like hawthorn. February and March. Caraceas. 1881. 5s.

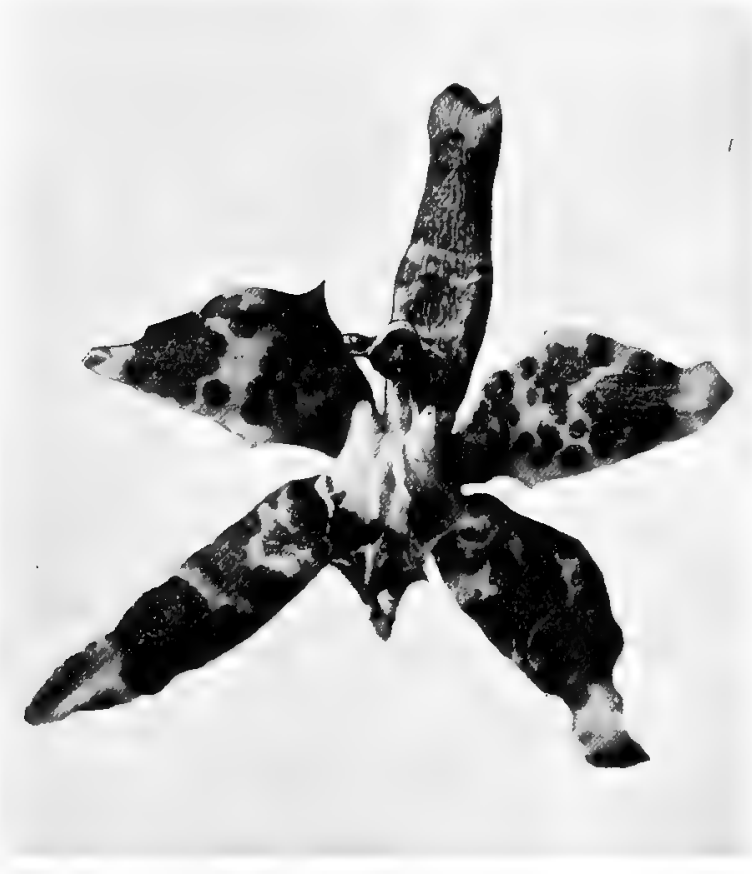

ODONTOGLOSSUMI TRIUMPHANS.

Schlieperianum (Herr Schlieper, German amateur). - Strongly resembles Insleayi and grande, but smaller. July and August. Costa Rica. 1856 7s. 


\section{The Culture of Greenhouse Orchids}

Tripudians (dancing). $-\mathrm{A}$ handsome species, of good size and distinct colouring. Yellow, heavily barred with brown; lips white, mottled with purple. Colombia and Peru. Summer. 5s. Figured, p. 186.

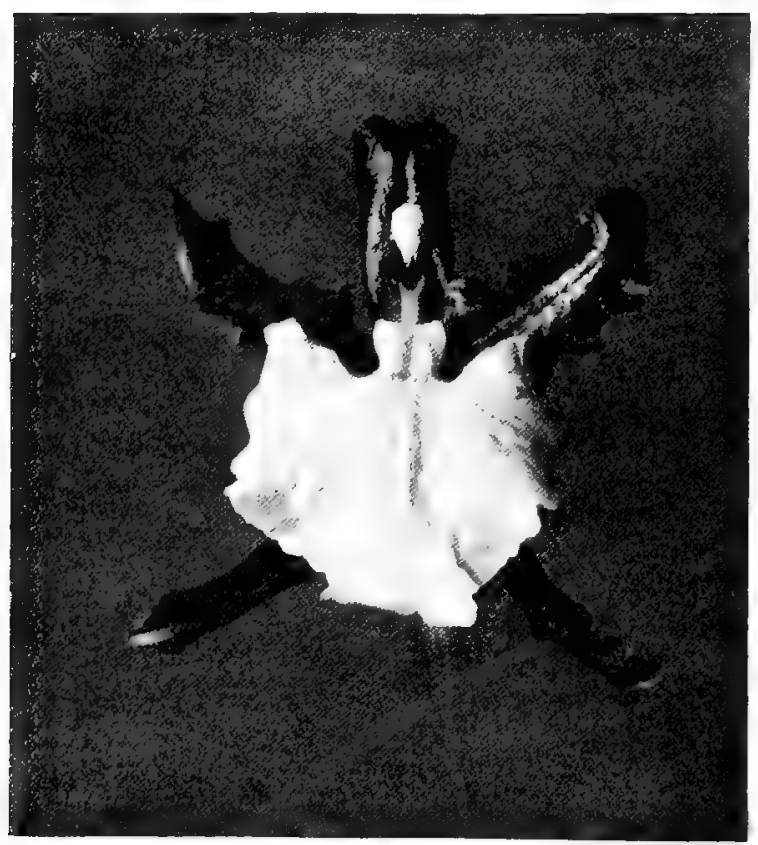

ODONTOGLOSSUM CRO-SEINNERI.

Triumphens.--Very easily grown, large, cheap, and always effective. Yellow, heavily splashed with brown. White throat to the lip. February to April. New Granada. 1860. 3s. 6d. Figured, p. 187. I 88 


\section{Odontoglossum}

Uro-Skinneri (ITr. Ure-Skinner, traveller and collector).-A species of most impressive colouring. Olive-green, blotched with chestnut; lip rosy-

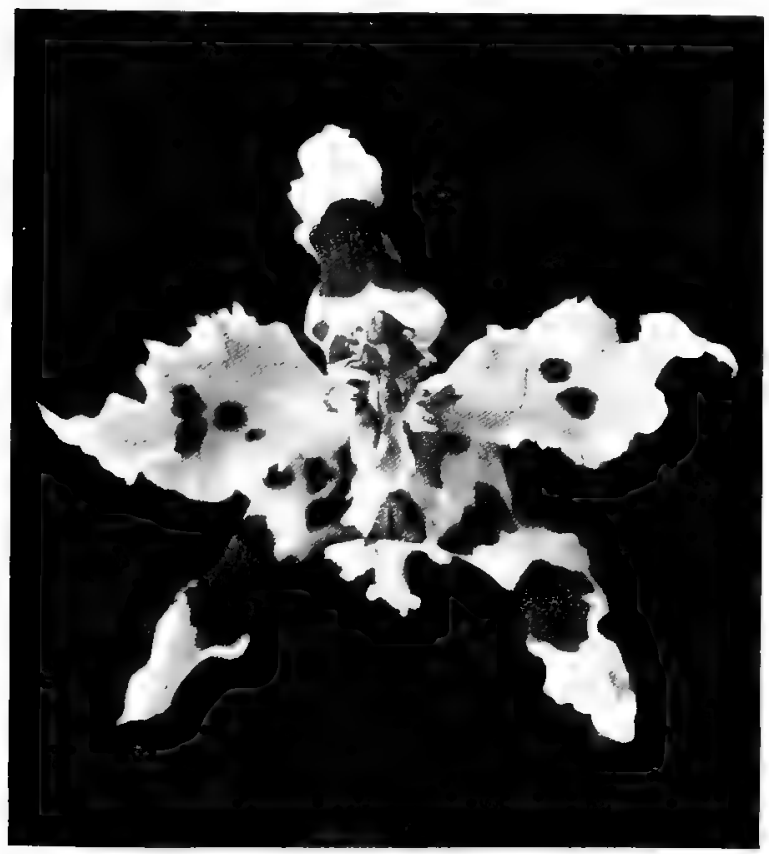

ODONTOGLOSSUM WILCKEANUM.

mauve, speckled all over with white. August and September. 1854. Guatemala. 21s. Figured, p. 188.

Wilckeanm (M. Wilcke, gardener to M. Massange de Louvrey, a great Belgian amateur) -Doultless 


\section{The Culture of Greenhouse Orchids}

a natural hybrid of crispm and luteo-purpurenm, and one of the best-one of the costliest also if good. Large. Yellow, barred and spotted with light brown; lip clear yellow. April and May. New Granada. Figured, p. 189.

\section{ONCIDIUM.}

(A swelling, from the warty tubercles at base of the labellum.)

Oncidiums rank next to Odontoglots in the number of species they furnish to the cool house. Much that has been said of the latter applies to them, but they need a distinct resting season. Oncids also are exclusively American, but the majority do not dwell on misty highlands like the Odontoglots. Some of those which we grow in the cool house are used to a higher temperature; but the genus is accommodating. All species which I name do as well there as in the warm, and some better. There are Oncids which demand great heat; but with such, of course, we have nothing to do in this chapter.

They should be potted like Odontoglots-if potted. Many are so large, indeed, as to be inconvenient upon a block, or even in a basket. As a principle, it should be remembered that Oncids 


\section{Oncidium}

prefer to have their roots free, and if they can be indulged, so much the better; but if not, as I say, the genus is accommodating. The Belgians seal them up in leaf-mould, like other orchids; but we are accustomed to think that some insist upon a block or basket. These will be noted individually.

Oncids need rest after flowering, or after finishing their growth, though they do not flower. It is commonly said of most that they will not thrive for more than three years; the reasun is generally that they do not get sufficient rest.

The very great majority of Oncids-something like 80 per cent.-are yellow in the general effect of colour. This makes a pleasing contrast in the house. I have described many of the Odontoglots as yellow, because it is difficult, and waste of time besides, to express shades of colour minutely. In fact, the tone is never bright, not even in the case of polyxanthum, and nearly always it is interrupted by spots or blotches. But the yellow of the Oncids is pure, though sepals and petals are generally charged with markings of another hue.

Aurosum (golden), properly cxectuatum (hollowed). -A special farourite of my own, but much less common than it should be. The pseudo-bulbs grow very large, but they need not attain a great size before flowering. The spike is long and branched, 


\section{The Culture of Greenhouse Orchids}

having many flowers, an inch or more across, of singularly graceful shape. Sepals and petals pale yellow, lip golden, all barred at the base with pale red. September and October. Ecuador. 1839. 5s.

Barbatum (bearded).-Small-indeed, very small -but exquisitely pretty. I do not find it difficult to grow, but it thrives better among Cattleyas. Sepals and petals greenish, outlined with a mottling of brown. On each side of the lip is a wing of brightest gamboge closely speckled with brown. Between them the "beard," also yellow. Block or basket. September and October. Brazil. 5s.

Bifolium meijes (two-leaved).-Bifolium plain is too small for attention. This larger variety, majus, is yellow, mottled with brown-lip pure yellow. May and June. Buenos Ayres. 10s. 6 $t$. It does better in the intermediate house.

C'undidum.-This is commonly called Palumbina candida-one of those orchids which, for some growers, have a charm incomprehensible to the majority. Pretty it is beyond dispute; Reichenbach described it in one of his enthusiastic bursts as "a flight of snowy doves." The flowers are small, however, and not many, though the great length of the lip, by comparison, makes them very distinct. This species should not be rested, but if the peat gets sodden its roots quickly decay. In spring, 


\section{Oncidium}

also, when the new shoots appear, they are apt to rot if water lodges in the crowns. Flowers with the young growth. Mexico. 1843. 5 s.

Cheirophomm (hand-bearing). - Small, but most

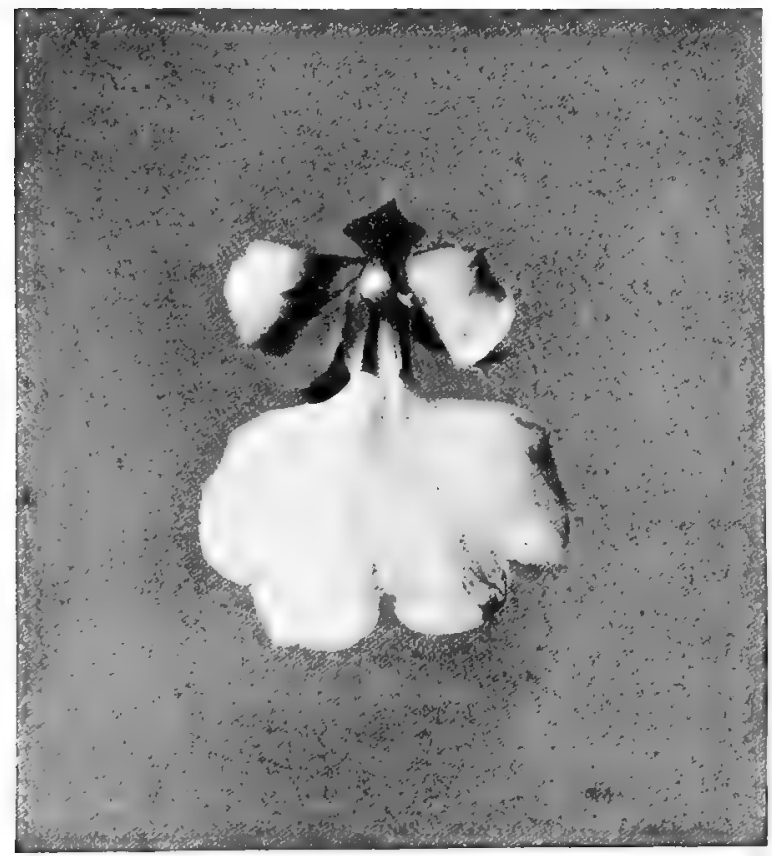

ONCIDITM CONCOLOR.

elegant. A gem. Primrose yellow. It must be hung close to the glass on a block or basket. December and January. Ecuador and Central America. 1856. $7 s, 6 d$. 


\section{The Culture of Greenhouse Orchids}

Concolor (single-coloured).-One of the most exquisite of flowers, conveniently grown in a basket because its spikes are pendulous. All tenderest pale yellow, with a tinge of green. A pril to June. 1837. Brazil. 5s.

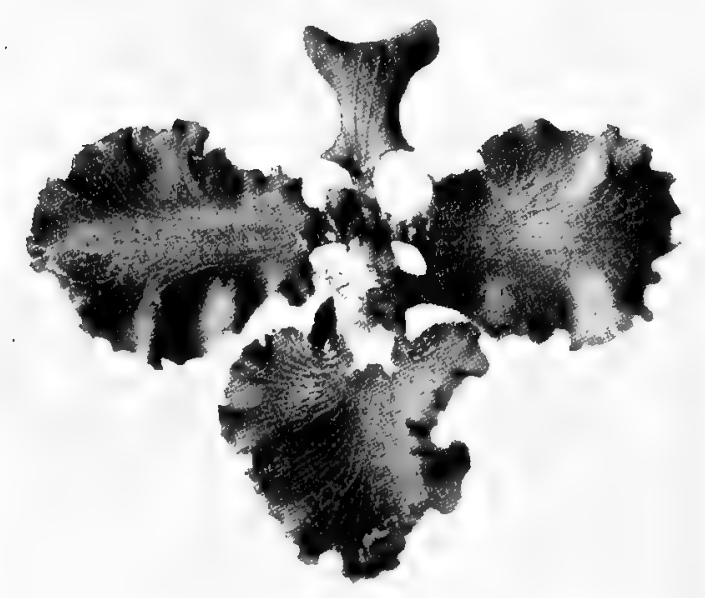

ONCIDIUM CRISPUM.

Crispm (curled).-One of nature's boldest triumphs in colouring. The branched spike has ten to fifty large flowers, most gracefully waved, 194 


\section{Oncidium}

copper brown, edged with gold, and broadly decked with gold at the throat. Block or basket, for this species dislikes to have its ruots confined. Flowers in autumn generally. 1830. Brazil. 3s.6cl.

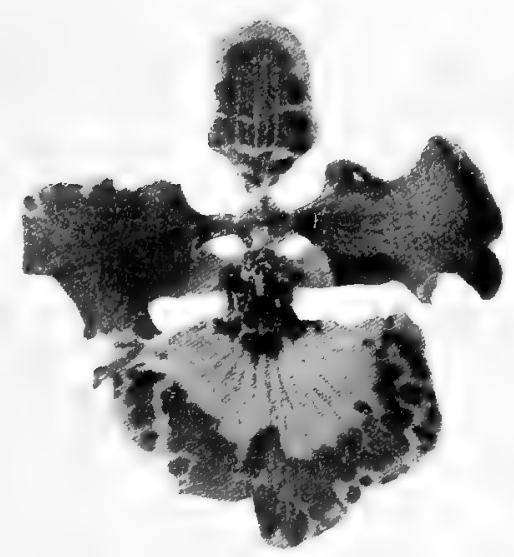

ONCIDIUM CURTOM.

Grandiflom is a larger and finer variety. 10s.6 6 .

Crcesus.-A rare and striking species. Sepals and petals brownish, lip bright yellow, with a great I95 


\section{The Culture of Greenhouse Orchids}

black spot romud the erest. Summer. Brazil. 1872. Does better with the Cattleyas.

C'urullutum (houled). - Valualule for its rare and striking arrangement of colour, though small. Olive

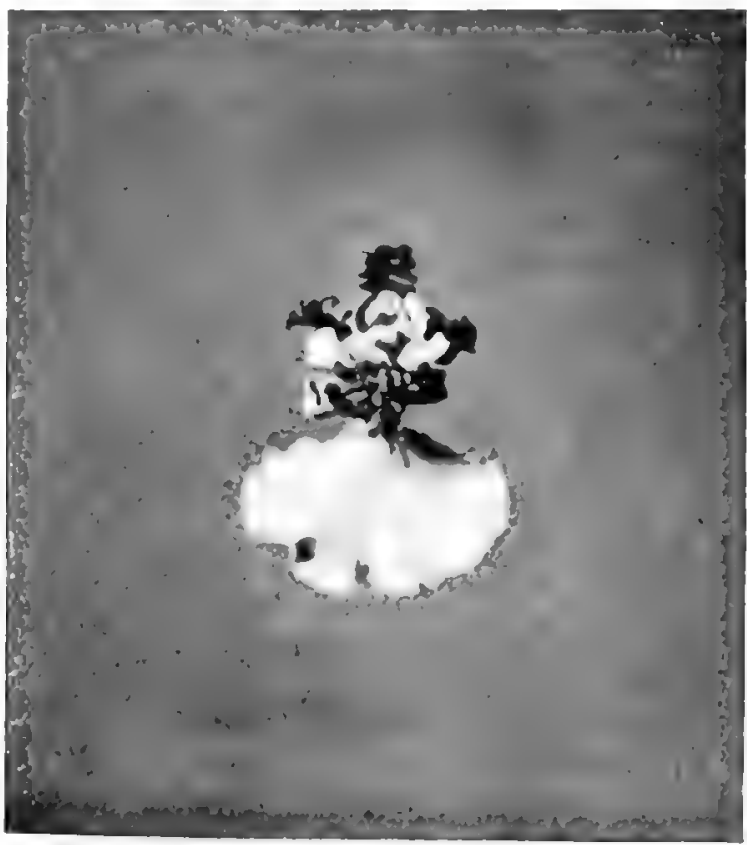

ONCIDIUM TLTXUOSUM.

green, sputterl with purple: lip prale rose, less profusely spotted. Very cool. April aud May. New Granada and Peru. 10s. $6 d$.

Curtum (short).-Brown, closely barred with 196 


\section{Oncidium}

yellow, lip yellow, with a mottling of brown about the edge. It likes a block, or at least a basket. A pril to July. Brazil. 1847. 5s. Figured, p. 195.

Dasytyle (thick style).--Small, buff in colour. At the throat a big shining excrescence, purple black, like a fly or beetle. Pretty, and, above all, curious. Block or basket. January to April. Brazil. 1873. $3 s .6 d$.

Iivaricatum. - Singularly free to bloom. It bears long branched spikes with many flowers, yellow and red brown. Summer. Brazil. 3s. 6d.

Excavatum.-Vide aurosum.

Flexuosum (twining).-A climbing species, admired by every one. Small flowers, but many of them. Yellow, closely barred with brown, lip broad, golden yellow. Best grown on a tree-fern stem, or a long block planted in a pot, where its very straggling, slender roots can find moisture. May to July. Brazil. 1818. 3s. 6d. Figured, p. 196.

Forbesi (Mr. Forbes, gardener to the Duke of Bedford in 1837).-Allied to curtum. Large, rich yellow, very heavily blotched with chestnut, margined with yellow, A great favourite. "We can never meet the demand for On. Fordesi," says Mr. Sander. (N.B.-Thrips also are specially fond of it.) Block or basket. April to July or autumn. Brazil. 1837. 5s. Figured, p. 198. 


\section{The Culture of Greenhouse Orchids}

Gardneri (Dr. Gardner, a famous traveller in Brazil, 1836-41).-A very fine form of curtum. Petals chestnut, outlined with a mottling of gold;

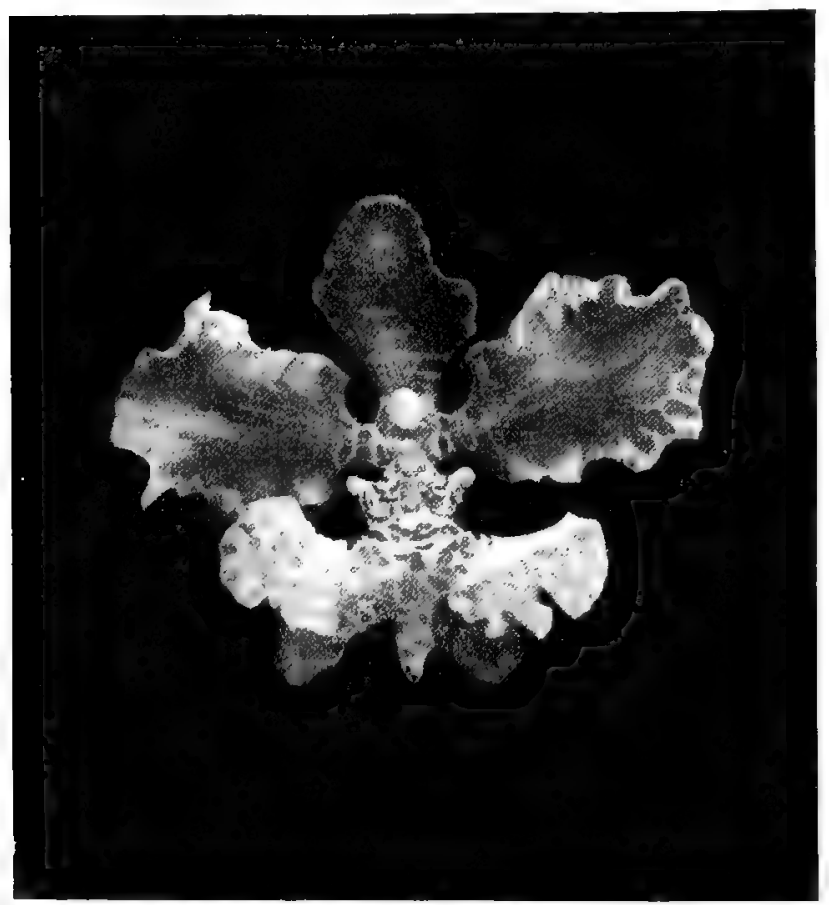

ONCIDIUM FORBESI.

sejals gold, barred with chestuut; lip gold, with chestnut round the edges. June and July. Brazil. 1843. 7s. 6d.

Gravesianum (Mr. Graves, an American amateur). 198 


\section{Oncidium}

-Allied to Onc. crispum, but smaller. Dark brown, margined and streaked with yellow. May to July. Brazil. 1890. 5 s.

Incurvem (incurved).- -1 very striking species, with small flowers, but a vast number. White or rosy, barred with purple; lip pure white. The branching spikes should be carefully trained, so that the flowers form a mass. September to January. Mexico. 1845. 3s. 6d.

" album.-The white form. Lovely beyond description, but very rare.

Lencochitum (white lip).-A special favourite of my own. Yellowish green, spotted with brown; lip snow-white. Flowers from early spring to late summer. Guatemala. 1835. $15 s$.

Limminghei.-Very small, greenish, barred with brown. Lip yellow, dotted with red. Block. Summer. Venezuela.

Loxense (Loxa, in Peru).-Very handsome. Sepals dull yellow, blurred with chocolate; petals chocolate, margined with yellow; lip deep orange. Flowers May and June. Peru and Ecuador. None have been imported for many years, and it is rare as valuable.

Lucasianum (Mr. Lucas, an amateur). - Very pleasing. Long branched spikes, with many flowers of gond size. All ganboge yelluw. Summer. Peru. 1890. 10s.6 $t$. 


\section{The Culture of Greenhouse Orchids}

Macrcunthum (large flower). - Stateliest of Oncids. Very large; sepals golden, tinged with bronze; petals gold; tiny white lip, with wings of bright mauve. Conscious of its beauty, it is by no means eager to bloom, and the long twining spike grows very slowly-an incubation of twelve months is recorded; but the flowers last a time proportionate. The spike, which may be ten feet long or more, should be twisted back carefully so as to form a cluster of bloom. It does best upon a piece of fern-stem set in a pot. May to August. Peru and Ecuador. 1867. 7s.6d. Figured in plate.

The variety hasliferum (spear-bearing, from a peculiarity of the lip) is larger, and even more finely coloured.

Marshalliamum (Mr. Marshall, an amateur), -A noble species, which we do not yet understand thoroughly. It rarely thrives beyond the third season. Many-flowered; large sepals, yellow, banded with purplish brown; petals yellow, with brown blutches down the centre; lip golden. Basket. April and July. Brazil. 1866. 7s.6d.

Micropogon (little beard).—Small, but very bright and graceful; commonly pronounced difficult to grow, however. It loves the sun, and in winter it must be placed in the cool end of the Cattleyas house, receiving very little water. Thus treated 

. 


$$
\text { . }
$$




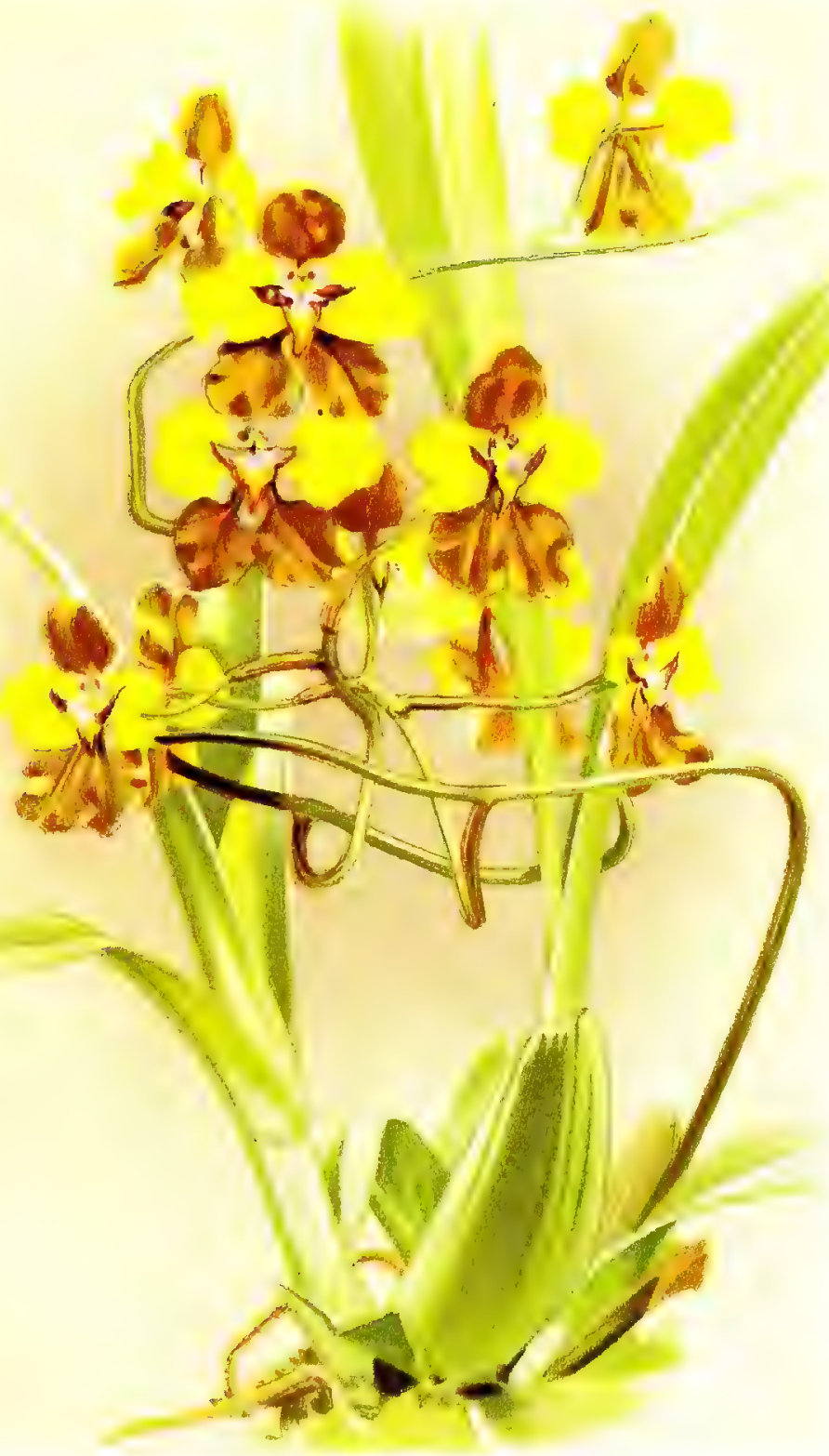





\section{Oncidium}

it is quite happy. Yellow, the sepals blurred with brown. April and May. Brazil. 1853. 5s.

Nubigenum (cloud-born).-More correctly named cucullatum, or olivaceum, var. nubigenum. A little gem-the coolest of all orchids under cultivation. A variety of Onc. cucullatum. White, with purple markings. Ecuador, where it flourishes at an elevation of 11,000 feet. Spring.

Olivacerm.-Vide cucullatum.

Ornithorynchum (bird-beaked).-One of our oldest orchids, and one of the loveliest; very showy also in a mass, though the individual flowers are minute. Mauve, in varied shades. Strongly scented. January to July. Mexico. 1826. 3s. 6d.

Phalcenopsis (moth-like).--Singularly beautiful, but difficult to grow. White, splashed and barred with violet. May and June. Ecuador.

Protextum (edged).-So like Onc. crispum that they are often confounded, but much smaller. Scented. Flowers April to August. Brazil. 1876. $5 s$.

Refcxum (reflexed).-Bright yellow, barred with brown. July and August. Mexico. $5 s$.

Saint-legerianum (a collector).-A most charming species. Sepals and petals yellow, with brown markings. Lip broad, all brilliant yellow. But its special beauty is the large magenta crest, doubly 


\section{The Culture of Greenhouse Orchids}

effective un that golden background. Flowers with the young growth in summer. Brazil. 1890. $5 s$.

Surcudes (flesh-like). - Very useful and pleasing. Flowers of good size; sepals and petals chestnut, blotehed and tipped with yellow; lip bright yellow, with chestnut spots. I have seen it at St. Albans with spikes eight feet long, profusely branched, learing many hundred flowers. March to May. Brazil. 1849. 5\% It does better with the Cattleyas.

Serratum (saw-toothed round the edges). - Very striking. Chocolate, edged with yellow. The petals curl over, forming a ring, as if for insects to light upon. Like all the species with a very small lip, as Onc. nacranthum, it does not flower readily; but, like the rest of them, its very long spikes, thickly set with bloom, reward our patience. November to January. Peru. 1849. 10s。6d.

Sicsilc (stalkless).-Another of the small-lipped class. Large primrose flowers, speckled at the base with cinnamon. April and May. Mexico. Does better with the Cattleyas.

Sphacclatum (scorched).-A large, free-growing species, yellow, splashed with chestnut. April and May. Mexico. 3s.6d.

Spilopterum.-Vide Saint-legerianum.

Spricei (Mr. Spruce, a traveller).-Peculiar for its 202 


\section{Oncidium}

rush-like pseudo-bulbs. Yellow, blurred with red. April and May. Brazil. Does better with the Cattleyas.

Suprobicns. $-\Lambda$ species of the small-lipped section.

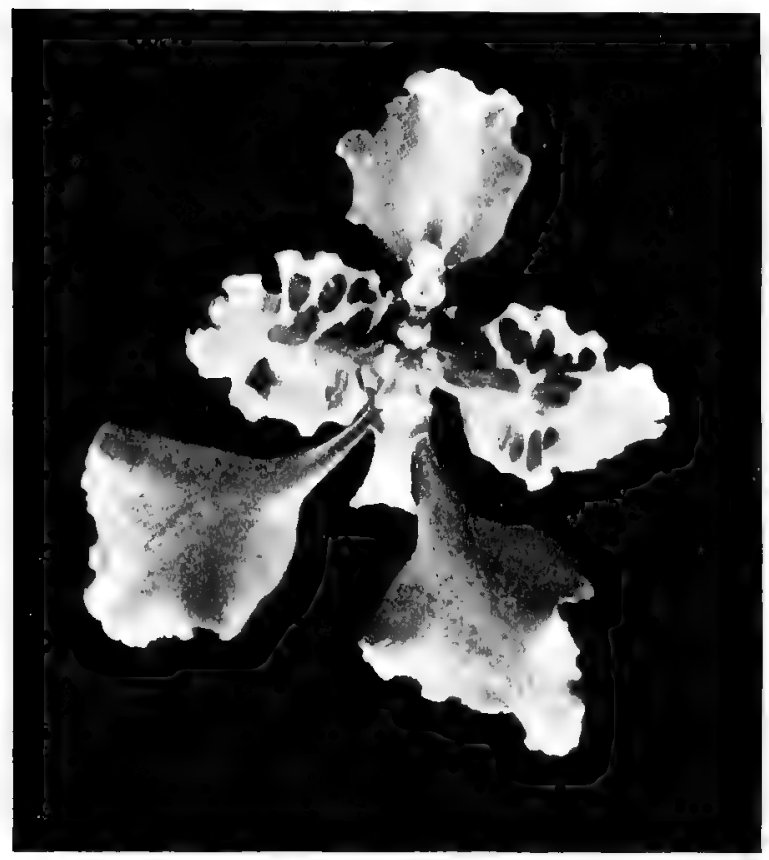

ONCIDIUM TETRACOPIS.

Sepals purplish brown, edged with yellow, petals yellow, with bars of purplish brown at the base, lip purple. A most attractive flower for the resthete. May to July. New Granada. 1872. 10s. 6d. 


\section{The Culture of Greenhouse Orchids}

Tetracopis_-Large flowers on a branching spike. Sepals chestnut; petals yellow, spotted with chestnut. Small yellow lip.

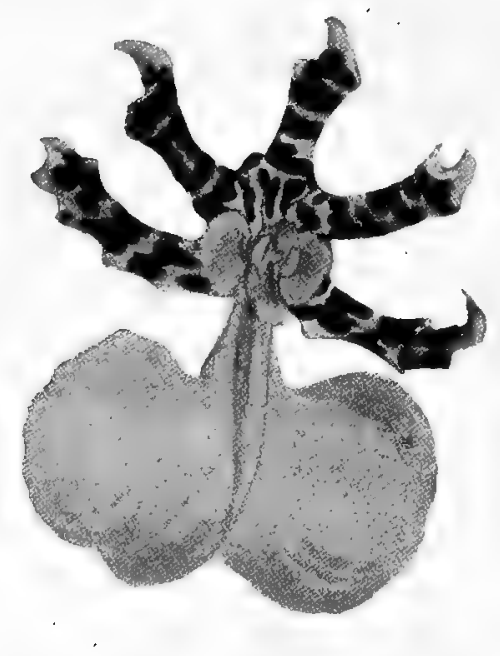

ONCIDIUM TIGRINOM.

Tigrinum (tiger).--A glorious flower, but one of those which few keep beyond the third season. Like so many Mexican species, it demands sunshine, which we dare not give under glass to the 


\section{Oncidium}

degree requisite. But we are improving; I myself have older plants, which increase year by year. Drying them too much is the common fault. I give them water once a week while resting. Brightest primrose-yellow, sepals and petals barred with chestnut brown, sometimes almost black; lip very broad, of the clearest primrose. Scented. Autumn. Mexico. 1840. 5s. Does better with the Cattleyas.

Undulatum (wavy).-Of the small-lipped section. Sepals bronze; petals white, blotched with mauve; lip purple. May and June. New Granada. 10s.6 $\%$.

Unguiculatum.-A large species, not generally valued, because the flowers come out one after another, but on that very account useful. The tall branching spike will give a handsome "buttonhole" daily for weeks in the dullest season of the year. A variety of tigrinum, which it resembles in colour, but less showy. Mexico. December and January.

Varicosum (warty).-The smaller and less striking type, of which Onc. Rogersi is a grand variety. July to August. Brazil. 1850. 5s.

, Rogersi.-The most conspicuous of cool-house orchids, bearing sometimes a bundred flowers, two inches across, with small sepals and petals mottled pale cinnamon, and a great lip of the brightest 205 


\section{The Culture of Greenhouse Orchids}

possible gold. Though it does well in our houses, rarely can we match the enormous psendo-bulbs and the giant spikes it made at home. To judge by my own experience, however, this is no mis-

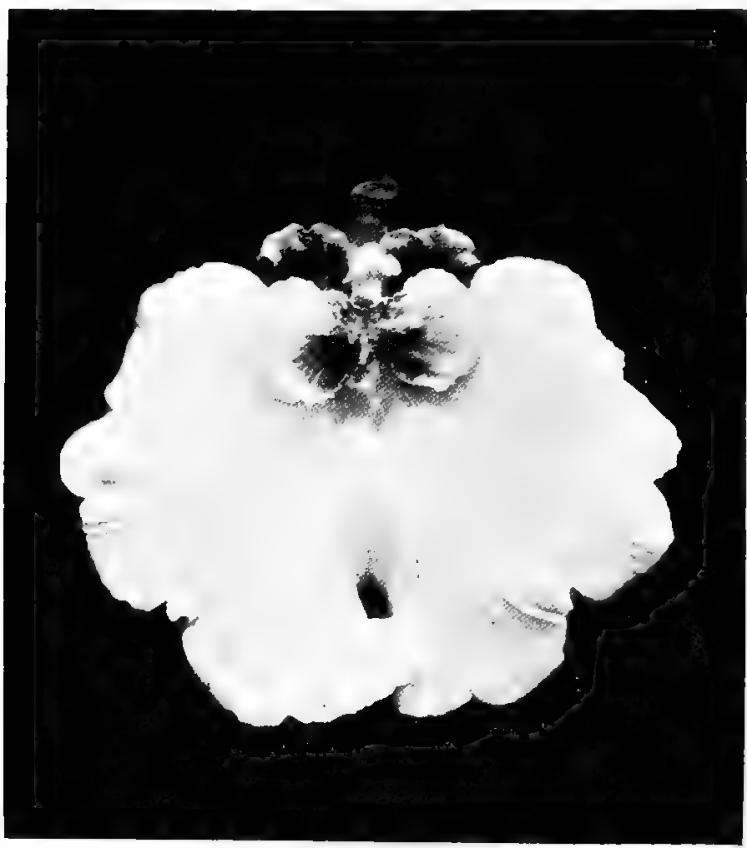

ONOIDIUM VARICOSUM ROGERSI.

fortune. More than once I have raised spikes five feet long and thick as a lead pencil; but the branches were only two or three, short and sturdy, and the number of flowers much less than a spike 


\section{Pilumna}

balf the size will often bear. Basket. July to Christmas. Brazil. 1850. 5s.

Wentworthianum (after Lord Fitzwilliam).Yellow, barred with deep brown. Profuse of flower. Guatemala. 7s. 6r.

Palumbina. (Vide One. candidum.)

\section{Pilumana.}

A genus hardly to be distinguished from Trichopilia; in fact, most of the species formerly assigned to it are now classed under that title. Cnstom, however, still retains the three described. They must be cultivated like Odontoglossums. The flower springs from the side of the bulb when mature.

Fregrans.-An attractive species, easily grown. It bears three or four large flowers, palest green of sepal and petal, snow-white of lip, with a yellow blotch at the throat. Strongly scented. Winter. New Granada. 1856. 3s. 6d.

Laxa (loose).-Less effective, but producing more flowers, and as sweetly scented. Sepals and petals dusky green, lip white. Summer. United States of Columbia. 1841. 2s. $6 d$.

Nobilis.-A larger variety of fragrans, and in so far even handsomer. Winter. New Granada. 3s. 6u. 


\section{The Culture of Greenhouse Orchids}

\section{Pleione. (A sea-nymph.)}

This genus of orchid is one of the few which has acquired an English name somehow; gardeners call it the "Indian crocus," not altogether unreasonably. Pleiones do not find the attention which is their right. There is no display the year round at Kew more brilliant than that they offer in their season, which-another merit-is commonly in the dull months. But flowers, like books, have their fate, as the Latin proverb says. Pleiones are not fashionable.

Of course, there is a reason, and one not hard to discern. Since the flowers have no leaves to set them off, they must stand quite close together, or there will be ugly gaps. That is scarcely an objection if all the bulbs grow properly, for each will bloom. But a busy gardener is apt to overlook plants which may be put anywhere out of sight to rest when the leaves have died down. Too often he does not notice the flower peeping beside the withered bulb-not from the top. It demands water imperatively then, fails to receive it, and withers. So the earliest blooms are lost, and those ugly gaps follow of necessity.

Pleiones are so easily grown that one may say 208 


\section{Pleione}

they never fail unless by neglect, or, the other extreme, misdirected attention. This latter danger threatens them when starting into growth. When the flower is done they should be repotted in fibrous peat, loam, and chopped sphagnum, with abundant drainage and silver sand, the psendo-bulbs well above the soil-or, of course, leaf-mould, on the Belgian system. Pans are best for effect. But after this operation, unless the compost be very dry, they need no water until the young routs are well established, a condition proved by the appearance of the new leaves. When the time for watering arrives, however, it must be given very freely. They will not bear to be dried while growing. Liquid mantre twice a week suits them, but much diluted.

In a damp house and a shady position they ask no water at all from the moment that the leaves begin to wither. No rule can be laid down on this point, beyond the broad principle that the pseudo-bulbs must not be allowed to shrivel.

The flower is single and large, opening at the tip of a very short spike. It pushes through the soil, as has been observed, at the base of the old pseudo-bulb.

Readers will perceive that these are not plants to cultivate singly. Though large and gorgeous 209 


\section{The Culture of Greenhouse Orchids}

of colour, they should be many in a pan to be effective.

Hookeriana (Sir Joseph Hooker, the great botanist).

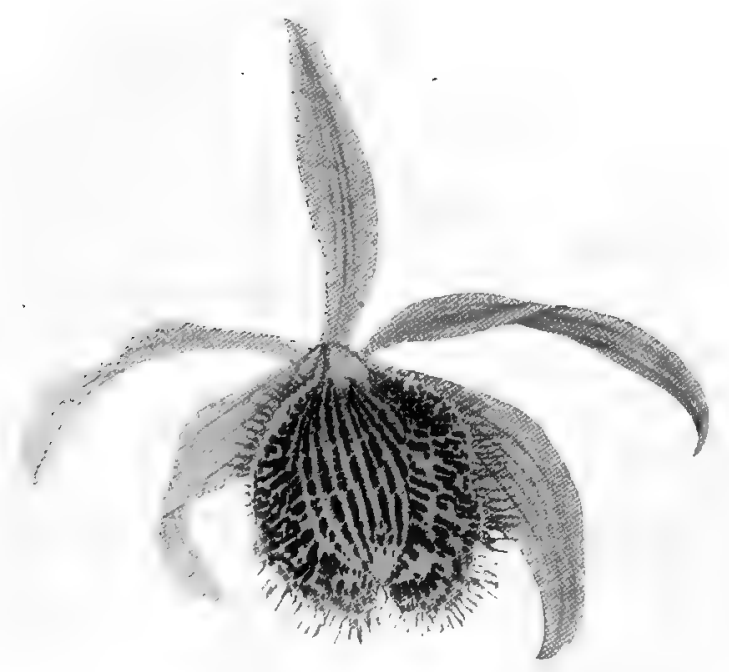

PLEIONE HUHILIS.

-The smallest species in cultivation. Peculiar in the respect that it flowers with the young growth, not before. Bright rose, lip white with yellow 


\section{Pleione}

throat, and pale brown spots on the disc. Spring. Himalayas. 1878. 58.

Humitis (lowly).--Loveliest of all, perhaps; but all are lovely. Very large, white, with a rosy tinge; the great spreading lip veined with brownish crimson, and handsomely fringerl. Spring. Nepal. 1850. 3s. 6rl. Figured, p. 210.

Lagenaria (bottle-shaped).-The species most commonly seen. Rosy lilac, lip paler or even white, finely blotehed with crimson in front. November. Himalayas. 1850. 2s.6 $d$.

ILaculato (spotted).-White, the lip blotched with crimson and veined with purple. November. Himalayas. 1850. 2s.6c.

Procox-Vide Wallichiana. 2s.6d.

Reichenbachiana (Professor Reichenbach).-This has two flowers sometimes, rosy lilac, lip white, with crimson lines and spots. November and December. Moulmein.

Wallichiana.-Large. Crimson, with a broad yellow streak down the lip, and five white ridges or veins. Winter. Procox is a smaller and paler form of this. Himalayas. 1840. 2s. $6 d$. 


\section{The Culture of Greenhouse Orchids}

\section{Pleurothalitis. (Side-blooming.)}

There are many species of this genus, some remarkable for beauty, but of the minute class. Peat and moss, or the Belgian system. They will not bear to be dry at any time, and when growing they need much water.

Insignis.-Of good size, but, unfortunately, not one of the prettiest. Greenish-white, with a few purple stripes. Lip dark purple. New Granada.

Roczli.-This is the finest species, making spikes a fuot long, which bear ten to twenty-five small flowers of deepest purple. New Granada. Spring.

\section{Promentea.}

This genus is now merged in Zygopetalum, but everybody uses the old name. There are two species, both delightful. Books class them among intermediate orchids; but, after many years' experience, I can vouch that they grow at least as well in the cool house-in fact, they could not possibly grow better. Small bulbs do not bloom so freely, I confess; but they soon get big. Peat and moss, or the Belgian system. Much water while growing; while at rest they must be damp. 


\section{Promenæa}

Citrina (lemon colour).-The graceful flowers are very large for a plant so lowly, all bright, soft yellow. But the lobes of the lip are dotted with

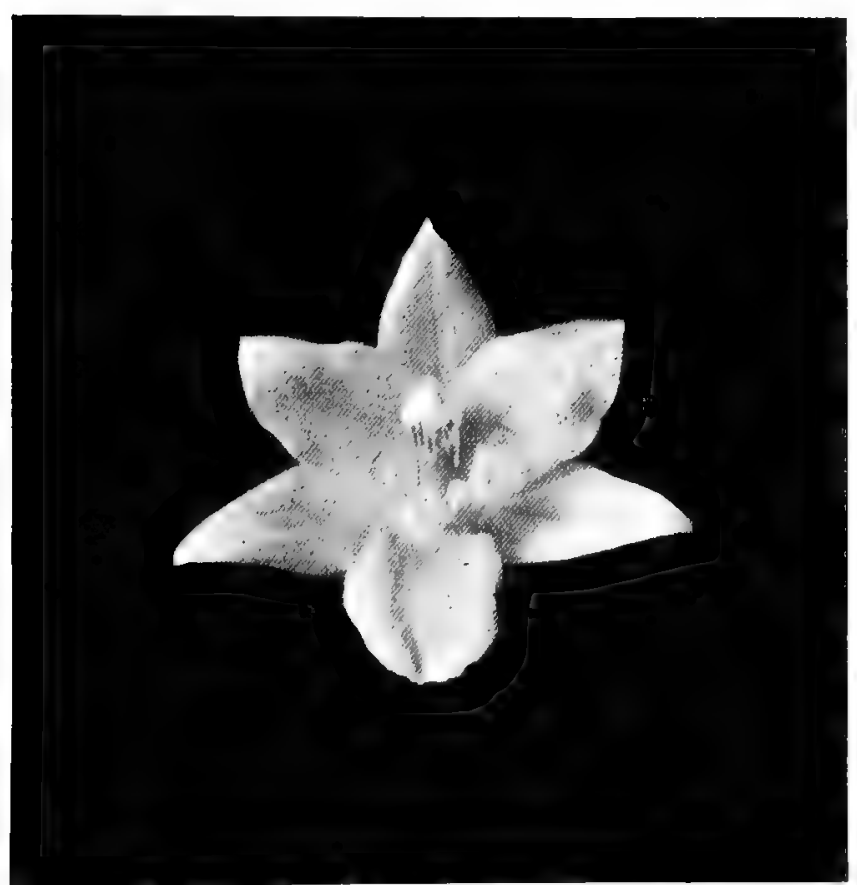

PRONENAA CITRINA.

brownish red, and the inside of the column, which is conspicuous, shows a lining of the same tint. July and August. New Granada. 1838.

Stapeloides (like the curious Stapela of Mexico). 


\section{The Culture of Greenhouse Orchids}

-Not less pretty, but in another style. Sepals and petals green, mottled with purple. The lobes of the lip are similar, but the dise is purple, touched with yellow. July. Brazil. 10s. 6 d.

\section{Restrepia.}

(After Joseph E. Restrep, naturalist and traveller.)

These plants are to be classed among pretty curiosities; the amateur who loves a bloom which catches the eye has no concern with them. They have a single leaf, broad and leathery, without pseudo-bulb. A solitary flower pushes from the stem just below the leaf when mature. The treatment of Odontoglots is agreeable to them in all respects.

Antenniferc (so named because the petals and dorsal sepal are narrowed to the likeness of threads or insects" "feelers" - -antenna).-This is the largest of the genus in cultivation, though small enough. The flower resembles an oblong tablet, an inch or more hy half an inch, produced by the union of the side sepals - an arrangement which louks like an exaggerated lip to the careless observer. Its colour is dusky yellow, thickly speckled all over with minute crimson dots, still thicker and more minute 


\section{Sophronitis}

on the true lip. Winter. New Granada. 1869. 10\%. $6 u$.

Elegans resembles this very closely on a smaller scale. Winter. Venezuela. 1850. 7s. 6d.

Pandurata (fiddle-shaped-of lip).-Smaller still. White, with crimson dots. Winter. New Granada. 1890.

\section{Sophronitis. (Modest.)}

One species of this genus is invaluable. There are very few scarlet orchids in cultivation-only Cochlioda Noctzliana in the cool house besides this. Epidendrum vitellinum is orange-searlet; so is Loelia monophylla. All Sophronitis are easily grown under the treatment of Odontoglossums; but they do best in pans or baskets near the light.

Cernua.-A very pretty little flower, but inconspicuous unless in quantity; four to six, however, appear upon a spike. They are pale rosy-scarlet bells, touched with crimson lake and yellow in the centre. I have seen this upon a block with fifteen or twenty spikes, and then it is singularly graceful. November to January. Brazil. 1826. 3s, 6ll.

Coccinea (red).-As a rule this is, in effect, a less handsome variety of the species following, from which it is only distinguished in appearance by a 


\section{The Culture of Greenhouse Orchids}

shade of rose in its scarlet flowers and smaller size. November to January. Brazil. 10s. $6 d$.

Grandiflora.-A marvel indeed at its best, and always very beautiful. Those who would know

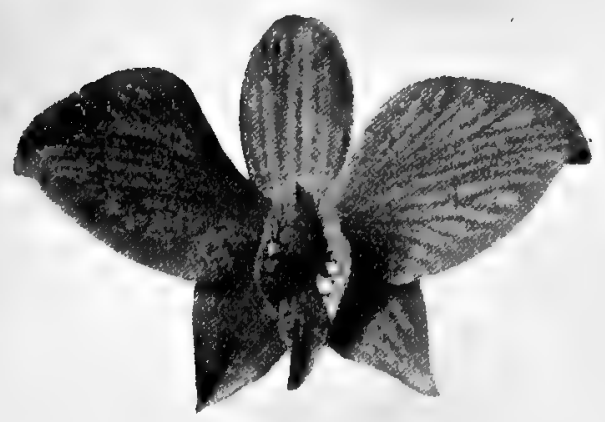

SOPHRONITIS GRANDTFLORA.

what it may he should olsserve Baron Schröller's picked specimens. They light up the house like flames. But there is a plant on record more wondrous still. Four inches across was a bloom $2 I 6$ 


\section{Sophronitis}

which Messrs. Sander once forwarded to Kew. But the species is very variable in size. Flowers measure from one inch to three, and too many of those imported belong to the former class; all, however, are dazzling in hue.

Dr. Lindley was curiously precipitate in naming the genus to which this superb species belongs "Sophronitis." He had seen but the dainty cernua, which that title well becomes, at the time, but he survived to laugh at his own mistake. Perhaps it was a sense of humour which forbade him to change the name. Certainly it is a good joke to call grandiflora "retiring."

The flower is vivid scarlet throughout, sometimes deepening towards crimson, sometimes paling towards orange. The sepals and lip are comparatively small; it is the great petals spreading on either side like wings which give the effect. But the lip between, shading into yellow and veined with scarlet, sets off their brilliancy.

They need all the light that can be given them, and therefore a basket or pan is best, hanging from the roof. The latter will be found most satisfactory. I have at this moment a four-inch pan with eleven flowers open; they last six weeks or more. Autumn and winter. Brazil. 1837. 5s.

There is a rare variety in which the flowers are 


\section{The Culture of Greenhouse Orchids}

rosy-pink. Baron Schröder has collected all he can find of these, and they make a delightful contrast with the scarlet. $10 s .6 d$.

Violacea.-A dainty little flower, but less than an inch across. Tenderest violet. December and January. 1840. 58.

\section{Trichopilia. (Hairy cap.)}

I have mentioned $T$. fragrans with its variety nobitis, and T. laxa, monder the heading "Pilumna," the old name. The species following are usually grown in the intermediate house, but I find they will do nearly as well among Odontoglots. Peat and moss suit them, and a basket, or at least a place in the fullest light; but they must be shaded in summer. Trichopilias demand much water while growing, but they particularly dislike to have their roots sodden; drainage, therefore, must be ample. In winter they are rested, but not dried.

The flower-spike pushes from the side of the bulb when ripe.

Coccinea (red).-Large, but narrow; sepals and petals dull red, with dull yellowish margins; lip trumpet-shape, dull red, with white margin. Not captivating in colour, and too short in the spike, but curious. Spring. Central America. 5 s. 


\section{Trichopilia}

C'rispa (wavy).-Much like the above, but larger; two and even three flowers on the stalk; the trumpet lips more widely opened and more handsomely frilled, the colour brighter. Spring. Central America. 1849. 21 s.

Galcottiana (M. Galeotti, collector and writer).Very pretty. The flower has various shades, from lemon to pale green, lip almost white, with touches of crimson. Autumn. Mexico. 1859. 3s.6d.

Lepida (pretty).-Resembles coccinea, but the colour is more distinctly rosy. May. Central America.

Suctvis (sweet).-A very handsome flower, sometimes three on the spike; white, the trumpet-lip yellow inside, grandly opened and frilled, gracefully spotted with violet pink. Scented like hawthorn. Spring. Costa Rica. 1848. 5\%. This does better with Cattleyas.

Tortilis (twisted).-So named because its sepals and petals are twisted like a corkscrew. They are very narrow, reddish brown margined with dull yellow; lip trumpet-shaped as usual, yellowish white, heavily spotted with rose. Summer. Mexico. 1835. 3s. 6rt. 


\section{The Culture of Greenhouse Orchids}

\section{Trichosma.}

(Three parts-referring to the lip.)

This genus has but one species, $T$. survis (sweet), a charming flower always, but few know how charming it may be. Once upon a time I saw a small pot with six spikes-nothing extraordinary in that. But each of them, nine inches high or so, had two or three branches, forming a canopy of bloom above the leaves. It was a revelation, but unique, as revelations are in these days. Nothing like it has been rouchsafed to me since.

But T. sucvis is exquisitely pretty under all circumstances. It has no pseudo-bulbs. The leaves push up in a spiral scroll, and expand at the tip of a slender stem six inches high or more-one on either side; between them the spike rises, bearing three to six flowers if it be not strong enough to branch; in that case, it will carry eight or ten, or, as in the notable instance mentioned, as many as sixteen. They are of good size, cream white, but the side lobes of the labellum-those parts which, folding over, make a tube-are daintily striped with brown. The aromatic scent is very strong.

This plant must be grown and treated like 220 


\section{Zygopetalum}

Odontoglossum crispum. In most collections the leaves are sadly disfigured by black blotches, such as appear too frequently in Masdevallias. Excess of water is the cause of this.

All who have cultivated this plant discover-if they were not warned beforehand-that when the flower-spikes begin to show it must be kept soaking or they will turn black and wither. Not unnaturally, therefore, gardeners are apt to fancy that it must always be wet. At other times, however, the amount of water given to Odontoglots is quite sufficient. If $T$. sucuvis have no pseudobulbs, it has great juicy roots which answer the same purpose.

But the reader must bear in memory that too much water can hardly be given when the flowerspike is bursting. Winter. Northern India. $3 s, 6 d$.

\section{Zrgopetalum. (Yoked petals.)}

An American genus, superb in all ways. Until we learn how to grow certain species from the Cape, these are the only cool orchids in which blue is a prevailing tint. The rarity of that colour has been noted, and all other examples of it are warm. The Zygopetalums with which we are concerned - for there are many species - 


\section{The Culture of Greenhouse Orchids}

always show a combination of green, brown, and blue, the latter generally in veins on a white ground. This gives them a striking character by itself. Also they are large, stately in growth and flower, of strong scent, and winter-blooming.

They must be potted with ample space for the great fleshy roots, which push so freely and cling so tight that the mass can never be disturbed without grave injury. Peat and moss suit them, or the Belgian system. Even more crocks than usual must be employed for drainage, because they need a vast supply of water while growing, and abundance at all times-as the extreme juiciness of their roots warns us. The spike appears almost as soon as the young growth-often a pair to each pseudo-bulb.

Mackayi is the only species allotted to the cool house in books; but all those I name will do well there, and Gauticri does much better, if the night temperature in winter be kept at $50^{\circ}$, not falling below $45^{\circ}$ towards morning.

Crinitum (hairy).-Sepals and petals green, barred with brown; lip white, with hairy dark-blue veins. Scented. Winter. Brazil. 1804. 5s. Figured, p. 223.

Gautieri (M. Gautier, a collector).-Most beautiful of all. This species is found difficult to grow, 


\section{Zygopetalum}

because most people keep it warm. I discovered, from my own experience, that it prefers the cool house; but that secret had long been known to Messrs. Sander. Zygopetulum Gunticri is a climber,

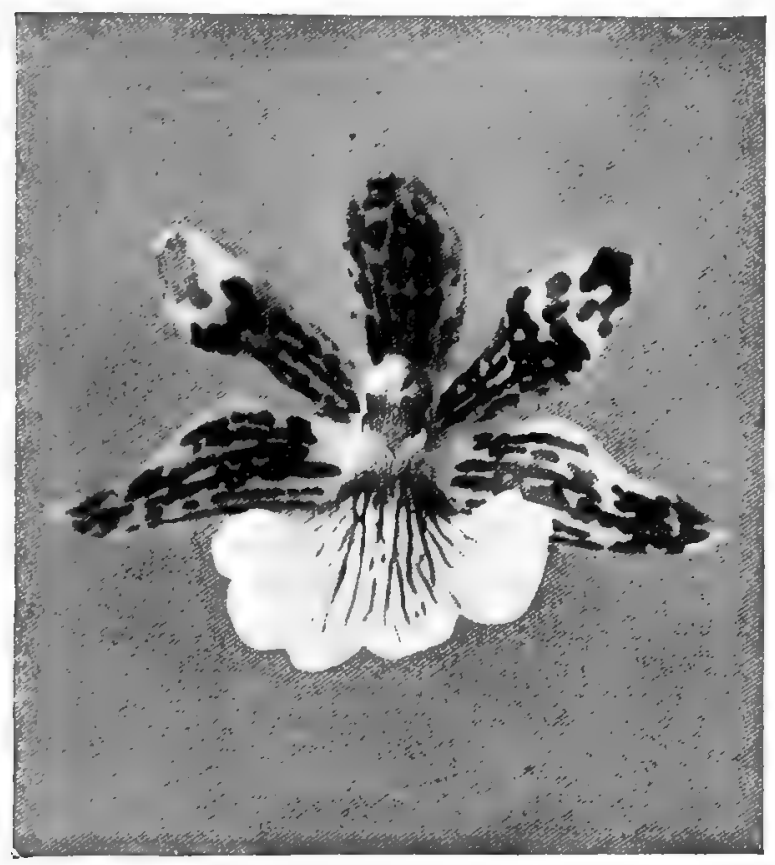

ZXGOPETALUM CRINITUM.

growing exclusively upon tree-ferns, which its roots so clasp and penetrate that they can hardly be removed. It is always imported on the fern, dead or alive. I had such a piece, dwindling as usual 


\section{The Culture of Greenhouse Orchids}

after a year or two, in my stove. The fern was handsome enough to keep, if possible, but not handsome enough to claim a place which might be occupied by an orchid. I moved it into the cool house, and forthwith the dying Zygopetalum began to recover strength. For several years it has stood beside the door, which is open till dusk in summer and autumn, in winter also as long as possible, if there be no frost in the air. And every season it gives me about a score of flowers, -green and brown, as usual, above, but with a lip all clear dark blue-a lovely tint. Autumn. Brazil. 1868. 15s.

Intermedium. - Sepals and petals pale green, blotched with paler brown; lip bluish, with dark blue veins. Flowers with the young growth in late autumn. Scented. Brazil. 1844. 10s. $6 d$.

Mrackuy majus (Mr. Mackay, of the Botanic Gardens, Dublin, who introduced it).-Much like the others described, but the flowers are larger. Scented. One of the most useful orchids we have. Brazil. 1827. $5 s$. 


\section{N D E X}

Ade aurantiaca, 67

, Lebmanni, 68

Ærides Japonicum, 68

" Fieldingii alba, story of, 56

" Lawrenciæ, story of, 61

, odoratum, 68

" vandarum, 68

Angræcum falcatum, 69

Barkeria elegans, 72

"Lindleyana, 72

, melanocauloo, 72

"Skinneri, 72

"spectabilis, 72

Bifrenaria Harrisoniæ. 72

Bletia campanulata, 73

" hyacinthina, 74

, Sherrattiana, 74

, verecunda, 74

Brassia verrucosa, 74

Cattleya citrina (fiqured, p.76),75

" intermedia Parthenia, story of, 63

, Mendellii alba, story of, 56

" Skinneri alba, story of, 55

, Trianæ alba, story of, 56
Cochlioda Noetzliana ( figured),78 rosea, 150

sanguinea, 150

vulcanica, 150

Coelogyne barbata, 81

.. corrugata, 81

, corymbosa, 81

" cristata ( figured, p. 83, 81

Chatsworth variety, 85

, hnloleuca, 85

" $\quad$ " Lemoniana, 85

",$\quad$ maximn, 85

" ochreacea, 85

" odoratissima, 85

Colax jugosus (figured, p. 86). 85

, hybrids of, 87

Cymbidium affine, 88

" eburneum, 89

"Lowianum (figured), 89

Mastersi, 90

" $\quad$ tigrinum, 90

, Tracyanum, 90

Cypripedium Boxallii, 92

, caricinum, 92

, insigne (figured, $\mathrm{p}$.

93), 92

, Sanderæ, 93; story of, 52,59

Q 


\section{Index}

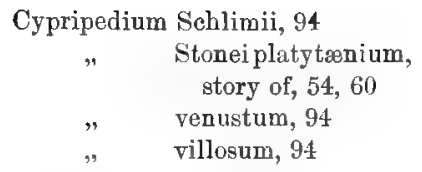

Dendrobium Cassiope, 96

Hillii, 96

", infundibulum

(figured), 96

"Jamesianum, 97

" Japonicum, 97

, Kingianum, 97

, moniliforme, 97

" nobile virginale, story of, 57

ochreatum, 97

$" \quad$ Ochreatum, 97
, Sanderæ, 57

"Sclıroderianum album, story of, 57

$\therefore \quad$ speciosum, 97

Disa Cooperi, 99

" grandiflora (figured, p. 101), 100

, Kewensis, I03

"Langleyonsis, 103

" premier, 103

, racemosa, 104

" tripetaloides, 104

" Veitchii, 104

Epidendrum cochleatum, 104

elegans, 104

Medusæ, 105

myriantlum, 105

nemorale, 105

virgatum, 105

vitellinum (figured, p. 107), 105

Wallisii (figured, p. 108), 109
Food of orchids, 3

Houlletia odoratissima, 109

Insects, 25

Insecticides, 26

Lælia acuminata, 112

albida, 112

, bella, 112

anceps, 112

alba Schroderiana, story of, 64

Amesiana, story of, 62

Ballantiniana, story of, 63

Dawsoniana, story of, 64

Sanderiana, story of, 61

Schroderæ, story of, 63

Stella, story of, 64

" autumnalis (figured, p. 113), 114

" $\quad$ atrorubens, 114

" , alba, 114

" Dayana, 114

"Dormaniana, 111

1 flava, 115

, furfuracea, 115

, Gouldiana, 115

" harpophylla, 115

"Jongheana, 115

"Majalis (figured, p. 117), 116

" monophylla, 117

" pumila, 118

" $\quad$ " prostans (figured, p. 118), 119 


\section{Index}

Leptotes bicolor, 119

Light, 5, 9

serrulata, 1.19

Lycaste aromatica (figured, p. 121), 120

, cruenta, 120

. Deppei (figured, p. 122), 120

.. Harrisoniæ, 121

" lanipes (figured, p. 123), 121

, leveautha, 122

" plana, 122

" Skinneri (figured, p. 124), 123

, $\quad$ alba, 125

Manure, 12

Masdevallia amabilis, 133

Arminii, 133

" Backhousiana, 133

, bella, 133

, Benedictii, 133

" Carderi, 133

" caudata, 133

" Chelsonii, 134

" Chestertonii, 134

" Chimsera, 134

" "Sanderiana,

135

" coccinea, 135

, colibri, 135

" coriacea, 136

, Davisii, 136

, elephanticeps, 136

" erythrochæte, 136

" Estradæ, 136

$" \quad$ Geleniana, 137

" Harryana (figured, p. 138), 137

,
Masdevallia Harryana corulescens, 139

", conchiflora, 139

" lilacina, 139

"Lindeni, 13!

„purpurea, 139

"rosacea, 139

"roser, 139

"sanguinea, 139

" versicolor, 139

" violacea, 139

Houtteana, 140

ignea (figured), 140

infracta, 141

Livingstoniana, 129

Lowii, 141 .

macrura, 141

melanopus, 141

melanoxantha

(figured, p. 142),

141

Mooreana, 141

nycterina, 142

peristeria, 143

polysticta, 143

racemosa, 143

Roezlii, 143

rosea, 143

Shuttlewortsi, 143

Tovarensis, 144

triangularis, 144

triaristella, 144

trochilus, 145

Veitchii, 145

" grandifloru, 146

vespertilio, 146

Wagneriana, 146

Wendlandiana, 146

xanthina, 146

Maxillaria acutipetala, 147

candida, 147

dichroma, 147 


\section{Index}

Maxillaria fucata, 147

, grandiflora, 147

, Harrisoniæ, 148

" Hübschii, 148

, lepidota, 148

, luteo-alba, 148

, nigrescens, 148

, picta, 148

, præstans, 149

, Sanderiana, 149

" splendens, 149

, tenuifolia, 149

, Turneri, 149

, venusta, 149

Mesospinidium roseum, 150

" sanguineum, 150 vulcanicum, 150

Miltonia candida, 152

" Clowesii, 152

, cuneata, 152

, flavescens, 152

, phalænopsis, 152

" stellata, 153

Names of orchids, 35

Nanodes Medusæ (figured, p. 154), 153

Odontoglossum Adrianæ, 162

Andersonianum

(figured), 163

apiatum, 164

, aspersum, 164

" baphicanthum, 164

" Bictoniense ( figured, p. 164), 165

",$\quad$ album, 165

" blandum, 165

" cariniferum, 165

, Cervantesii, 165
Odontoglossum Cervantesii decorum (figured, p. 166), 165

Chestertonii, 165

cirrhosum, 166

citrosmum (figured), 167

Coradinei, 168

cordatum, 168

coronarium, 168

crispum Alexandræ

(figured in plate), 169

,Amesianum, 169

"Annie, 169

"apiatum, 169 ; story of, 58

"Cooksoni, 169

"Duke of York, 169

"Franz Masereel, 169

"guttatum, 169

"Leliotropium, 170

, Lady Jane

(figured, p. 170), 171

"Mundyanum, 171

,Pittianum

(figured, p. 172), 171

,Sanderæ, 171

, The Earl, 171

cristatellum, 172

cristatum, 172

cuspidatum, 172

Edwardi (figured), 173

elegans, 174

excellens, 174 


\section{Index}

Odontoglossum facetum, 174

gloriosum, 174

grande (figured), 175

Hallii, 176

" Harryanum

(figured), 176

. hastilabium, 177

, Hebraicum, 177

" Huneanum, 177

"Hunnewellianum, 178

hystrix (figured), 178

Insleayi, 179

, leopardinum, 179

, splendeus, 179

Kegeljani, 179

læve, 179

, Lindenii, 179

, Lindleyanum, 179

"Londesboroughianum, 180

luteo-purpureum

(figured, p. 181), 180

" $\quad$, sceptrum, 180

maculatum, 180

Madrense, 180

membranaceum, 181

mulus, 181

nævium, 182

nebulosum, 182

Nevadense, 182

odoratum, 182

Oerstedii, 182

Pescatorei (figured, p. 183), 182

phalænopsis, 183

, polyxanthum, 183

, pulchellum, 184

, ramosissimum, 184
Odontoglossum Reichenheimi, 184

"roseum, 150

, Rossii (figured, p. I85), 184

Ruckerianum, 185

Sanderianum, 186

Sehlieperianum, 187

tripudians (figured, p. 186), 188

triumphans(figured, p. 187), 188

Uro-Skinneri

(figured, p. 188), 189

"vexillarium superbum, story of, 58

Wilckeanum

(figured), 189

Oncidium aurosum, 191

barbatum, 192

bifolium majus, 192

candidum, 192

cheirophorum, 193

concolor (figured, p. 193), 194

crispum ( figured), 194

Crossus, 195

cucullatum, 196

curtum (figured, p.

195), 196

dasytyle, 197

divaricatum, 197

excavatum, 197

flexuosum (figured, p. 196), 197

Forbesii (figured, p. 198), 197

Gardnerianum, 198

Gravesianum, 199

inourvum, 199

" album, 199 


\section{Index}

Oncidium leucochilum, 199

" Limminghei, 199

" Loxense, 199

"Lucasianum, 199

" macranthum (figured in plate), 200

" $\quad$ hastiferum, 200

, Marshallianum, 200

, micropogon, 200

" nubigenum, 201

", olivaceum, 201

", ornithorynchum, 20 I

" phalænopsis, 201

, pratextum, 201

.reflexum, 201

"Saint-legerianum, 201

" sarcodes, 202

. serratum, 202

, sessile, 202

" sphacelatur, 202

" spilopterum, 202

" Sprucei, 202

" sprucel, 202

" superbiens, 203

" tetracopis (figured, $\mathrm{p}$. 203), 204

, tigrinum(figured), 204

, undulatum, 205

, unguiculatum, 205

, varicosum, 205

" Rogersi (figured, $p$. 206), 205

Wentworthianum, 207

Orchids, food, 3

$$
\begin{array}{ll}
" & \text { manure, 12 } \\
" & \text { names, 35 } \\
" & \text { nature, 1 } \\
& \text { prices, 52 }
\end{array}
$$

Orchid-house, plan, 19

Palumbina candida, 207 Pilumna fragrans, 207
Pilumna laxa, 207

nobilis, 207

Pleione Hookeriana, 210

, bumilis (figured, p. 210), 211

lagenaria, 211

" maculata, 211

" præcox, 211

, Reichenbachiana, 211

, Wallichiana, 211

Pleurothallis insignis, 212 Roezlii, 212

Potting, 41

Potting, peat, 44 " leaf-mould, 47

Prices of orchids, 52

Promenæa citrina (figured), 213

" stapeloides, 213

Restrepia antennifera, 214

, elegans, 215

" pandurata, 215

Saccolabium Blumei album, story of, 56

Shading, 6

Sophronitis cernua, 215

$$
\begin{aligned}
& \Rightarrow \quad \text { coccinea, } 215 \\
& \text { grandiflora ( fiqured), } \\
& 216
\end{aligned}
$$

, violacea, 218

Struggle for existence, 8

Syringing, 24

'Temperature, 34

Terre de bruyère, 47

Travellers' reports, 7

Trichopilia coccinea, 218

crispa, 219 


\section{Index}

Trichopilia Galeottiana, 219

$$
\begin{gathered}
\text { Zygo-colax Amesianus, } 87 \\
, \quad \text { leopardinus, } 87 \\
\text { Veitchii, } 87 \\
\text { Zygopetalum crinitum ( figured, } \\
\text { p. 223), } 222
\end{gathered}
$$

$" \quad$ lepida, 219

, suavis, 219

" tortilis, 219

'Trichosma suavis, 220

Ventilation, 4, 20, 24

Water, 32

" Gautieri, 223

", intermedium, 22*3

" Mackayi, 224

THE END

I"RINTISD BT WILLAM CLOWFB AND SONS, IMMTEN, LUNDUN AND BLCCLES. 



\section{ORCHID HOUSES}

A SPECIALITY.

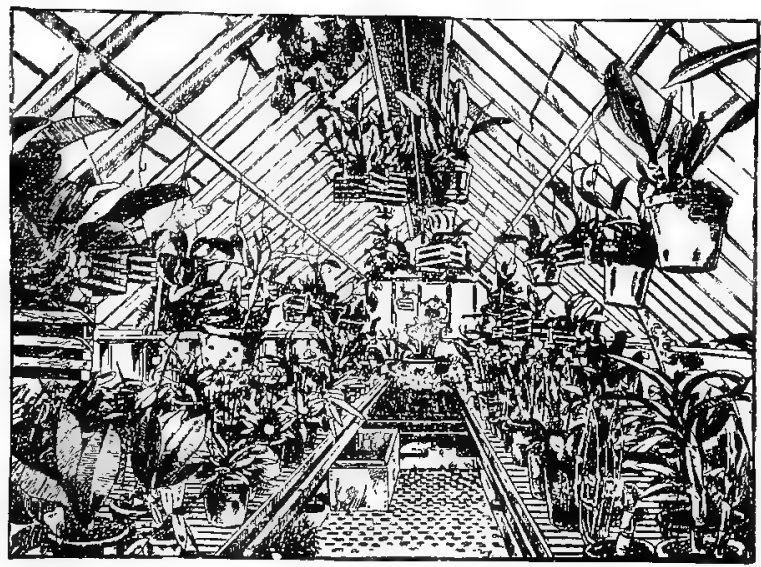

FOR ALL CLASSES OF

\section{Hot-Water Boilers . .} $A N D$

- Heating Apparatus

James Crispin \& Sons, Fr.H.S.S.

NELSON STREET,

BIEISTOI. 
. . TO SUCCEED IN . .

GROWING ORCHIDS TO PERFECTION USE RICHARDS' NOTED ORCHID PEAT

FOR POTTING THE PLANTS.

To Maintain the Foliage in Perfect Health and Free from all Insect Life,

USE RICHARDS' PATENT XL ALL

Vaporising Fumigator and Compound.

For Syringing, Spraying, and Dipping,

$X\llcorner$ ALL Liquid Insecticide Nicotine Wash IS THE THING.

ALL ARE USED BY THE LEADING ORCHID GROWERS.

To be obtained through my Agents, Nurserymen, Seedsmen, and Florists everywhere.

SEND FOR NAME OF NEAREST AGENT.

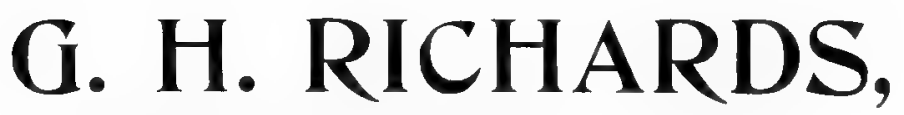

128, SOUTHWARK STREET, LONDON, S.E. 


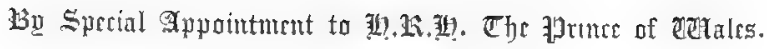

Telegrams-

"Ttreibhaus, Loxdon."

"Hothouse, EDINBURG."
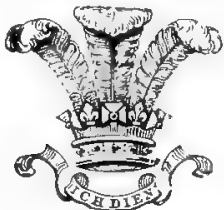

Telephone-

No. 74, MORNINGSIDE

EUINBURG.

\section{MACKENZIE \& MONCUR, Ltd. \\ Hothouse Builders \& Heating Engineers}

IONDON-8, Camden Road, N.W.

GIASGOW-43, Victoria Road.

EDINBURGH-Registered Office and Works, Balcarres Street.

\section{HORTICULTURAL BUILDINGS}

of every description erected, either in Wood or Iron, in any part of the Kingdom.

All Latest Improvements adopted. Teak Wood Houses a Speciality.

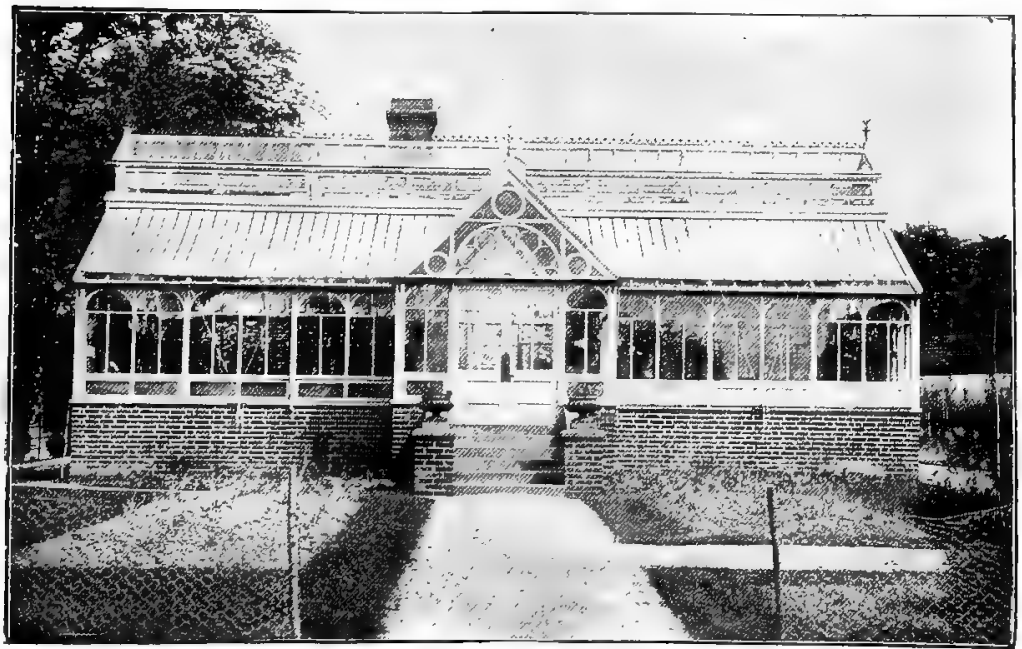

Conservatory Erected at Free Chase, Sussex.

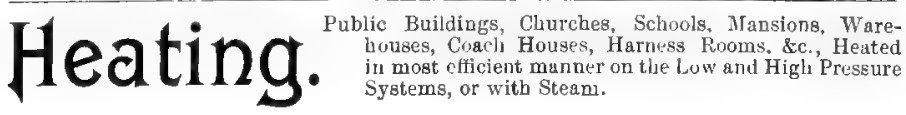




\section{HORTICULTURAL BUILDINGS. W. DUNCAN TUCKER, F.R.H.S. SOUTH TOTTENHAM}

(Three Mrinutes from Seven Sisters Railway Strion, G. E. Ruilway). SILVER MEDALLIST HORTICULTURAL EXHIBITION, 1892.

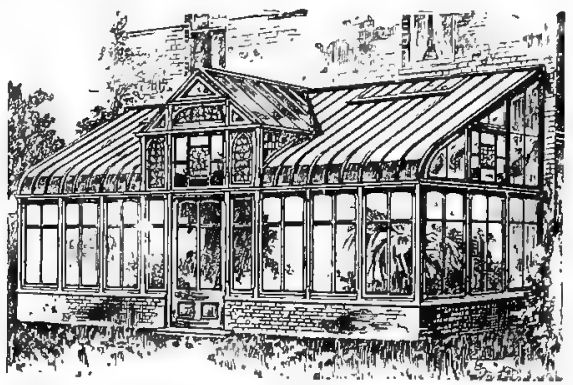

\section{CONSERVATORIES \& WINTER GARDENS}

DESIGNED AND BUILT TO SUIT ADJOLNING RESIDENCES.

VINERIES, STOVES, GREENHOUSES, PEACH HOUSES, FORCING AND ORCHID HOUSES

Constructed on my improved principles, are the perfection of Growing Houses, and for practical utility and durability are unequalled.

Patent Anti-Drip Bar for Orchid Houses MELON FRAMES, SASHES, etc., always in Stock.

arg PLANT PRESERVERS MADE IN ALL SIZES.
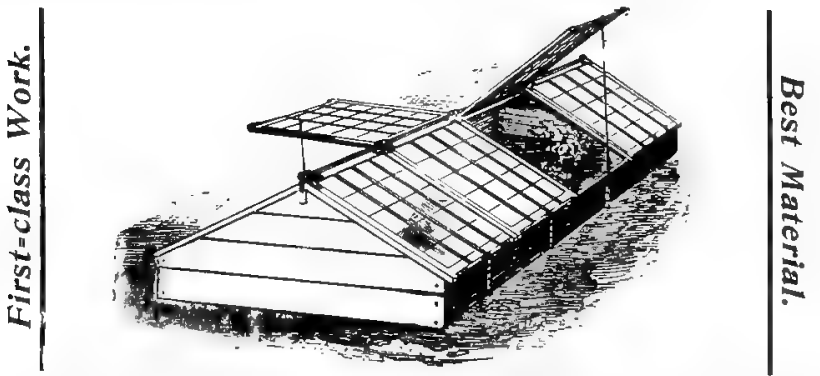

HOT WATER HEATING in all its Branches. Plans and Estimates Gratis.

Ladies and Gentlemen waited on in all parts of the Country.

TUCKER, TOTTENHAM.

Telegraphic Address: "Horticole, Lunvon." Telephone: Tottenham No. 2. 

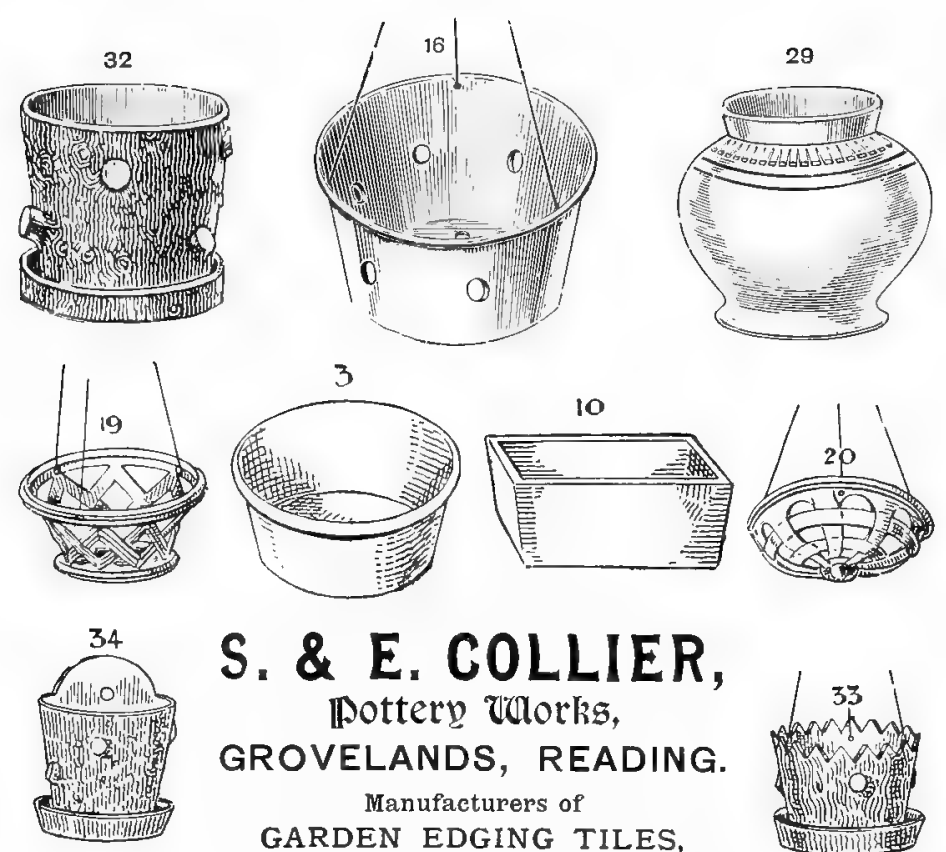

S. \& E. COLLIER,

Dottery volorks,

GROVELANDS, READING.

Manufacturers of

GARDEN EDGING TILES,

FLOWER POTS of ALL KINDS,

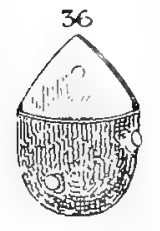

HYACINTH POTS,

WALL POTS, SEED PANS,

MIGNONETTE and

WINDOW BOXES,

SEAKALE and RHUBARB POTS,

PIGEON PANS,

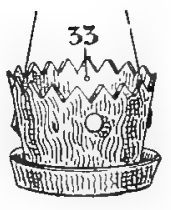

Plain and Ornamental

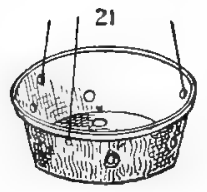

ORCHID PANS,

RED FLOWER VASES,

AND ALL REQUISITES FOR

Gardens, Greenhouses, Lawns, Etc.
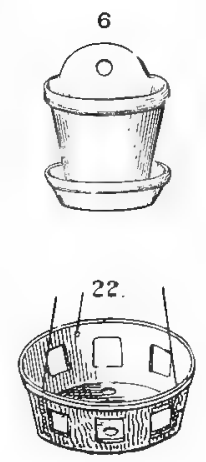

44

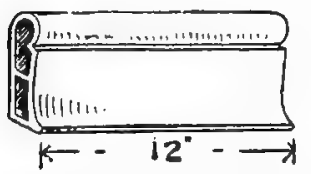

Complete List on Application. Post free.
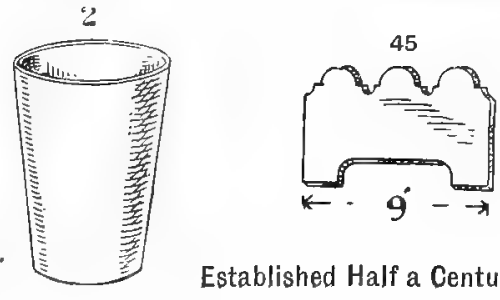

Established Half a Century. 


\section{F. SANDER \& CO., ST. AIBANS.}

Importers and Growers of Orchids.

THE LARGEST STOCK OF SPECIES, RARE VARIETIES, AND HYBRIDS.

Clean, Healthy, Well=grown Plants at the most Reasonable Prices.

SPECIAL QUOTATIONS FOR QUANTITIES.

Collections for the Cool, Intermediate, or Warm Houses supplied at Special Rates.

\section{INSPECTION CORDIALLY INVITED.}

Within easy reach of the Great Northern and Midland Railways.

Sander's Platform, G.N.Ry., adjoins entrance door of Nursery.

\section{SANDER'S ORCHID GUIDE.}

EAn Encyclopxoia of all the best=known

\section{ORCHIDS IN CULTIVATION,}

Their native Countries, descriptions of the Plants and Flowers,

Season of Flowering, Cultural Information, Temperature, Watering, Potting, Ventilation, etc.

CONCISE, RELIABLE, INSTRUCTIVE, \& USEFUL. Necessary alike to Expert and Amateur.

\section{ARRANGED ALPHABETILALLY,}

TOGETHER WITH

Names and Parentages of all the known Hybrids. 330 pages, strongly bound. Price 10s. 6d. 


\section{A SELECTION FROM}

\section{The New and Forthcoming Publications}

OF

\section{CHAPMAN \& HALL, LTD.}

\section{Anticipations}

OF THE REACTION OF MECHANICAL AND SCIENTIFIC PROGRESS UPON HUMAN LIFE AND THOUGHT.

\section{By H. G. WELLS,}

Author of "The Time Machine," "When the Sleeper Wakes," etc., etc.

Second Edition. Crown 8vo, 7s. 6d.

\section{Diaries of the Emperor Frederick}

DURING THE CAMPAIGNS OF I866 AND I870-71 AND HIS JOURNEYS TO THE EAST AND TO SPAIN.

\section{Edited by MARGARETHE VON POSCHINGER.}

Translated from the German by FRAnces A. WeLBy.

Demy svo, i2s. net.

"THE EIGHTEENTH CENTURY."

The Memoirs of Jacques Casanova de Seingalt.

A NEW EDITION WITH INTRODUCTIONS, NOTES, AND PORTRAITS.

Two Volumes. Large crown 8vo, 2 Is.

CHAPMAN \& HALL, LIMITED, LONDON. 


\section{Recollections of the Congress of Vienna (I8I4-I5).}

By COUNT DE LA GARDE $=$ CHAMBONAS.

Edited with Introduction and Notes by CoUNT Fi EURY. Translated by the Author of "An Englishman in Paris."

Demy Szo.

\section{The Norwich Road:}

AN EAST ANGLIAN HIGH WAY.

\section{By CHARLES G. HARPER,}

Illustrated by the Author, and by Prints and Pictures from the Grace Collection and after Constable and others.

Demy 8z0, I6s.

\section{Indian Dishes}

FOR ENGLISH TABLES.

\section{By KETAB.}

Crow' $8 v 0,2 s .6 d$.

\section{A NEW AND COMPLETE EDITION OF The Novels of Samuel Richardson.}

With 78 Illustrations, reproduced from Etchings, by THOMAS STOTHARD and E. F. BURNEY, and a Portrait of Richardson.

In Twenty Volumes. Small crown 8vo. Price 2s. 6d. net per Volume in cloth, and $3 s .6$. net per volume in leather, and half-calf.

LIST OF WORKS.

PAMELA. SIR CHARLES GRANDISON. CLARISSA HARLOWE.

Prospectus on application.

CHAPMAN \& HALL, LIMITED, LONDON. 


\section{CHARLES DICKENS'S WORKS.}

A NEW AND COMPLETE POCKET EDITION.

\section{The Oxford India Paper Dickens.}

In Seventeen Volumes. Foolscap 8vo, gilt top.

Price 2s. 6d. net per volume, cloth, and 3s. 6d. net per volume in leather.

This edition of Dickens's Works is issued jointly by Messrs. Chapman \& Hall, the owners of the copyrights, and Mr. Frowde, who has printed it on Oxford India Paper at the Oxford University Press. It includes all the additional stories and sketches which appear in the Gadshill and Authentic Editions, and the new illustrations especially drawn for those editions by Charles Green, Maurice Greiffenhagen, Harry Furniss, A. Jules Goodman, F. H. Townsend, and others, together with reproductions from the etchings and woodcuts of the famous pictures by Seymour, Phiz, George Cruikshank, F. Walker, Sir Edwin Landseer, R.A., D. Maclise, R.A., John Leech, Marcus Stone, George Cattermole, S. Luke Fildes, R.A., C. Stanfield, J. Tenniel, etc, and portraits of Charles Dickens.

At the beginning of each book a list of the principal characters therein is given, and on the covers will be embossed outline portraits of the chief character, taken from one of the original drawings by Phiz, Cruikshank, and others.

Full Prospectus on application.

\section{GEORGE GISSING'S BOOK ON SOUTHERN ITALY.}

\section{By the Ionian Sea.}

NOTES OF A RAMBLE IN SOUTHERN ITALY.

By GEORGE GISSING.

With Eight Illustrations in Colour by LEO DE LITTROW, and others in Black and White.

Small 4to. I6s.

\section{Some Adjectives used by the Press to describe it.}

ELOQUENT, DAINTY, CHARMING, DEILICATE, VIVID, FASCINATING, ATTRACTIVE, POETICAL, DELIGHTFUL, BEAUTIFUL, VALUABLE, ELEGANT, REFINED, LEARNED, SHREWD, ENTHUSIASTIC, DISTINCTIVE, POWERFUL, JOYOUS. 


\title{
Omnibuses and Cabs:
}

\author{
THEIR ORIGIN AND HISTORY.
}

\section{BY HENRY CHARLES MOORE.}

With Illustrations from rare old Engravings, Prints and Photographs.

Large crown 8vo, 75. 6d.

STEPHEN CRANE'S NEW BOOK.

Great Battles of the World. By STEPHEN CRANE,

Author of "The Red Badge of Courage."

With Eight Full-page Illustrations by JoHN SLOAN

Crown 8vo, 6s.

20,000 Miles of Road Travel in Central and Western Europe. By W. J. A. STAMER,

Author of "The Gentleman Emigrant," "Dolce Napoli," etc.

With Illustrations. Demy 8vo, I2s.

\section{Italian Wall Decorations}

OF THE I5TH AND 16TH CENTURIES.

A HANDBOOK TO THE MODELS ILLUSTRATING INTERIORS OF ITALIAN BUILDINGS IN THE VICTORIA AND ALBERT

MUSEUM, SOUTH KENSINGTON. WRITTEN BY VARIOUS AUTHORITIES, WITH AN INTRODUCTION BY T. ARMSTRONG.

With Fifty-two Illustrations. Large crown 8vo, 3 s.

CHATMAN \& HALL, LiMited, LONDON. 


\title{
THE WORKS OF THOMAS CARLYLE.
}

\author{
The Library Edition.
}

In 34 volumes, demy 8vo, red cloth, 7s. 6d. and 9s.

\section{The Centenary Edition.}

Edited, with Introductions, by H. D. TRAILL, D.C.L. In 30 volumes, square crown 8vo. Price 35.6 . per wolume.

\section{The People's Edition.}

In 37 volumes, small crown 8vo, red cloth. Separate volumes, Is.

\section{Cheap Issue.}

In II volumes, crown 8vo, bound in blue cloth, EI 4 s.

\section{The Chelsea Edition.}

In special red cloth binding, II volumes, with gilt tops,

$$
\text { EI 5s. net. }
$$

\section{The French Revolution:}

A HISTORY.

Complete in one volume. With Illustrations. Demy 8vo, 5 s.

This edition of "The French Revolution" is printed from large modern type on full demy paper, is complete in one volume of 8 zo pages, and contains many illustrations reproduced from pictures depicting the stirring times of the period. It is well bound, and forms a handsome book suitable for prize or library.

\author{
Uniform with above. \\ Sartor Resartus, \\ AND ON HEROES AND HERO WORSHIP.
}

With Portraits of Carlyle, Shakespeare, Knox, Johnson, and Napoleon.

Demy 8vo, 5 s.

CHAPMAN \& HALL, LIMITED, LONDON. 


\title{
THE WORKS OF CHARLES DICKENS.
}

\author{
The Authentic Edition.
}

In 2 f volumes, square crown $8 v 0$, with all Original Illustrations and a coloured Frontispiece.

Price 5s. per volume.

\section{The Oxford India Paper Dickens.}

In 17 volumes, foolscap 8vo, with all Original Illustrations. Price 2s. 6d. net per volume, cloth, and 3s. 6d. net per volume in leather.

\section{The Crown Edition.}

In 17 volumes, large crown 8vo, maroon cloth, containing all the Original Illustrations.

Separate volumes, 5 s.

\section{The Half-Crown Edition.}

In 2 r volumes, crown $8 \mathrm{vo}$, blue cloth, Original Illustrations.

Sepurate volumes, $2 s .6 d$.

\section{The "Charles Dickens" Edition.}

In 21 volumes, crown 8 vo, red cloth, with Illustrations by PHIz,

Cattermole, Cruikshank, Marcus Stone, etc. etc.

$$
3 s ., 3 s .6 d ., \text { and } 4 s \text {. }
$$

\section{The Shilling Edition.}

In 2 I volumes, each with Frontispicce. Separate z'olumes, Is.

Complete sets in special binding, 2 I volumes, gilt top, in sets only, EI I s. net. 






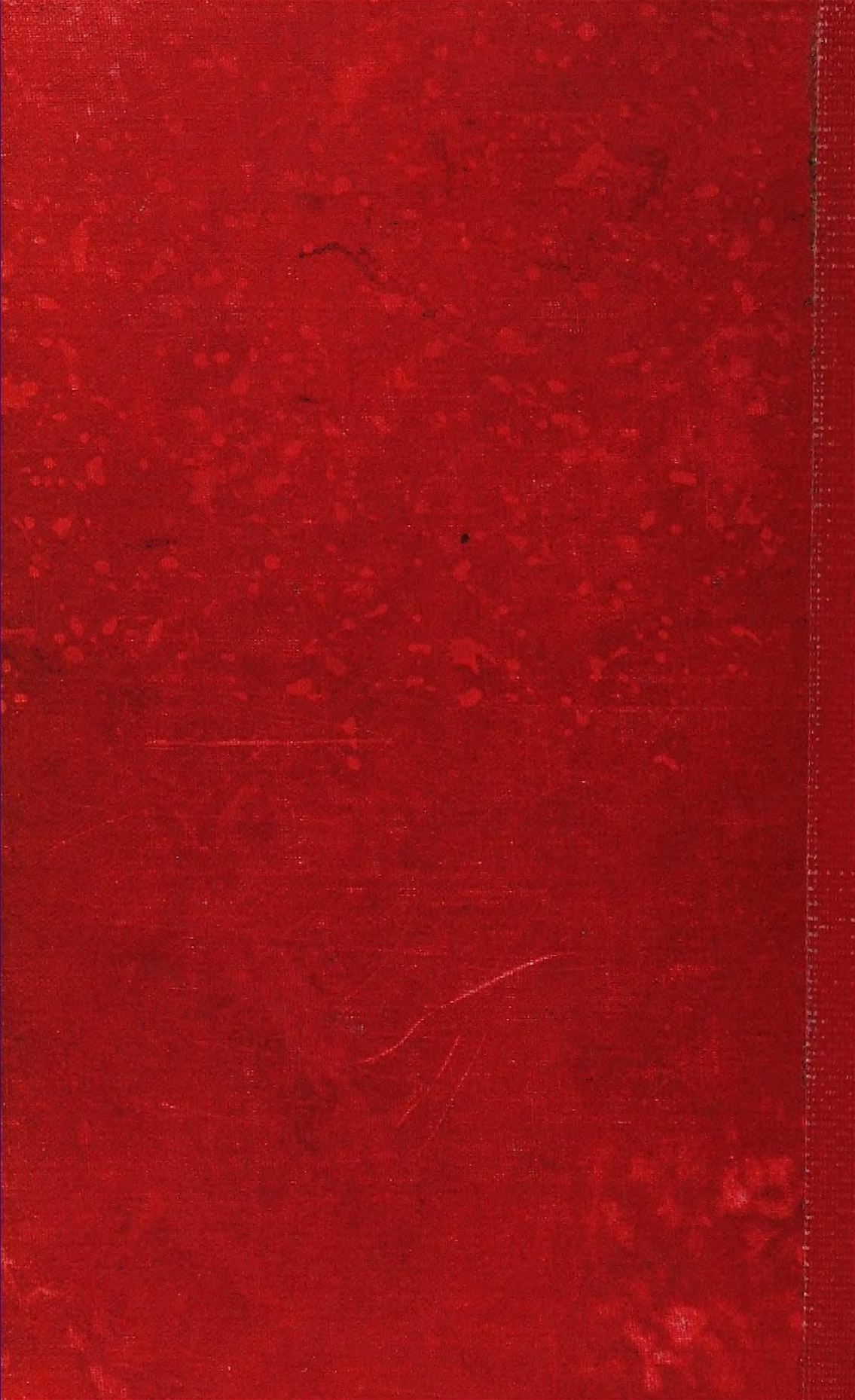

